\title{
Estudo das propriedades adjuvantes da vacina celular pertussis em combinação com o antígeno PspA de Streptococcus pneumoniae
}

Dissertação apresentada ao Programa de Pós-Graduação Interunidades em Biotecnologia USP/Instituto Butantan/IPT para obtenção do título de Mestre em Biotecnologia. 


\section{Estudo das propriedades adjuvantes da vacina celular pertussis em combinação com o antígeno PspA de Streptococcus pneumoniae}

Dissertação apresentada ao Programa de Pós-Graduação Interunidades em Biotecnologia USP/IPT/Instituto Butantan para o para obtenção do título de mestre em Biotecnologia.

Área de concentração: Biotecnologia

Orientadora: Maria Leonor Sarno Oliveira Versão original 
DADOS DE CATALOGAÇÃO NA PUBLICAÇÃO (CIP)

Serviço de Biblioteca e Informação Biomédica do

Instituto de Ciências Biomédicas da Universidade de São Paulo

(C) reprodução total

Lima, Fernanda Aparecida de.

Estudo das propriedades adjuvantes da vacina celular pertussis em combinação com o antígeno PspA de Streptococcus pneumoniae / Fernanda Aparecida de Lima. -- São Paulo, 2012.

Orientador: Profa. Dra. Maria Leonor Sarno de Oliveira.

Dissertação (Mestrado) - Universidade de São Paulo. Instituto de Ciências Biomédicas. Programa de Pós-Graduação Interunidades em Biotecnologia USP/IPT/Instituto Butantan. Área de concentração: Biotecnologia. Linha de pesquisa: Desenvolvimento de vacinas.

Versão do título para o inglês: Study of the adjuvant properties of the cell pertussis vaccine in combination with the antigen PspA of Streptococcus pneumoniae.

1. Vacina 2. Adjuvantes imunológicos 3. Pneumococo 4. Pertussis 5. Streptococcus pneumoniae 6. Proteínas recombinates I. Oliveira, Profa. Dra. Maria Leonor Sarno II. Universidade de São Paulo. Instituto de Ciências Biomédicas. Programa de Pós-Graduação Interunidades em Biotecnologia USP/IPT/Instituto Butantan III. Título. 
Candidato(a): $\quad$ Fernanda Aparecida de Lima.

Título da Dissertação: $\quad$ Estudo das propriedades adjuvantes da vacina celular pertussis em combinação com o antígeno PspA de Streptococcus pneumoniae.

Orientador(a): $\quad$ Profa. Dra. Maria Leonor Sarno de Oliveira.

A Comissão Julgadora dos trabalhos de Defesa da Dissertação de Mestrado, em sessão pública realizada a .../..................................
( ) Aprovado(a)
( ) Reprovado(a)

Examinador(a): Assinatura:

Nome:

Instituição:

Examinador(a): Assinatura:

Nome:

Instituição:

Presidente: Assinatura:

Nome:

Instituição: 


\section{COMISSÃO DE ÉTICA NO USO DE ANIMAIS INSTITUTO BUTANTAN \\ Av. Vital Brazil, 1500, CEP 05503-900, São Paulo, SP, Brazil \\ Telefone: (55) (011) 3726-7222 ramal 2106 - Fax: (55) (011) 3726-1505}

\section{CERTIFICADO}

Certificamos que o Projeto intitulado "Expressão de proteínas de difusão compostas por domínios dos antígenos PspC e PspA de Streptococcus pneumoniae e avaliação de seu potencial como vacinas de mucosas", protocolo $n^{\circ} 586 / 09$, sob a responsabilidade de Maria Leonor Sarno de Oliveira, está de acordo com os Princípios Éticos na Experimentação Animal adotado pela Sociedade Brasileira de Ciência de Animais de Laboratório (SBCAL/cobea) e foi aprovado pela COMISSÃO DE ÉTICA NO USO DE ANIMAIS DO INSTITUTO BUTANTAN (CEUAIB) em reunião de 04/03/2009.

\begin{tabular}{|c|c|}
\hline $\begin{array}{c}\text { Vigência do Projeto: } \\
\text { 01/03/2009 a 30/02/2011 }\end{array}$ & $\mathbf{N}^{\circ}$ de animais/espécie \\
\hline Laboratório de Biotecnologia Molecular I & Total 300/Camundongo C57Bl-6 - Fêmea \\
\cline { 2 - 2 }
\end{tabular}

São Paulo; 05 de Março de 2009.

De acordo:

Dr. Otávio Azevedo Mercadante

Diretor do Instituto Butantan 


\section{COMISSÃO DE ÉTICA NO USO DE ANIMAIS \\ INSTITUTO BUTANTAN}

Av. Vital Brazil, 1500, CEP 05503-900, São Paulo, SP, Brazil

\section{CERTIFICADO}

Certificamos que o Projeto intitulado "Estudo das propriedades adjuvantes das vacinas Celular Pertussis e BCG em combinação com o antígeno PspA de Streptococcus pneumoniae" protocolo $\mathrm{n}^{\circ}$ 825/11, sob a responsabilidade de Maria Leonor Sarno de Oliveira e Fernanda Aparecida de Lima, está de acordo com os Princípios Éticos na Experimentação Animal adotado pelo Colégio Brasileiro de Experimentação Animal (COBEA), e foi aprovado pela COMISSÃO DE ÉTICA NO USO DE ANIMAIS DO INSTITUTO BUTANTAN (CEUAIB) em reunião de 06/09/2011.

\begin{tabular}{|c|c|}
\hline Vigência do Projeto: & $\mathbf{N}^{\circ}$ de animais/espécie \\
$06 / 2011-042013$ & 336 camundongos Balb/c Fêmeas \\
Centro de Biotecnologia - \\
Laboratório de Biotecnologia \\
Molecular I
\end{tabular}

São Paulo, 13 de junho de 2011

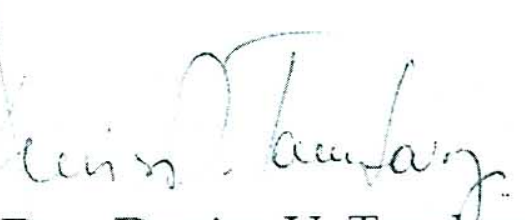

Dra. Denise V. Tambourgi

Presidente da CEUAIB 
Aos meus pais João e Maria, pelo amor incondicional. 


\section{AGRADECIMENTOS}

À Deus, por ter me dado força para a realização deste trabalho, passando por mais este estágio de minha vida.

Aos meus pais, por todo o apoio, por sempre estarem comigo e sempre me fazerem o possível para que a minha formação como profissional fosse a melhor possível, sempre superamos juntos todas as dificuldades e me compreenderam até nos momentos das piores crises. Vocês sempre foram para mim exemplo de honestidade e perseverança.

À minha irmã Fabiola, que se faz presente em todos os momentos com sua alegria de sempre, obrigada por todo o orgulho que tem de mim. Agradeço por todos os momentos felizes, pelos SMSs no meio do dia, pelos jantares no japonês, por rir das mesmas coisas, compartilhar os mesmos sentimentos e dúvidas, e por me fazer sentir melhor. Nossa amizade é algo muito precioso.

Minha irmã Flavia mostra-se sempre compreensiva, por nossas conversas longas realizadas nos intervalos das nossas correrias do dia a dia, por todo o carinho, com seu jeitinho meigo.

Ao Fabio meu irmãozão, por sempre me dar apoio, ser sempre exemplo de dedicação e concentração. Sempre demonstra que podemos ser fortes e conseguiremos alcançar nossos objetivos.

Ao amor da minha vida, meu namorado Wilson, por ter ser a pessoa mais virtuosa que já conheci. Por ser sempre meu refúgio nos momentos tristes, meu motivo de sorrir nos momentos felizes, por ser carinhoso, divertido, compreensivo. Com seu jeito educado e prestativo conquistou a amizade de todos ao nosso redor.

À minha sobrinha princesa Giovanna, minha talentosa bailarina, por ser tão bom todos os momentos que passamos juntas, por todo o amor que torna tudo que fazemos juntas tão especial, por ser tão meiga, inteligente, divertida e carinhosa. Obrigada por ser tão especial.

À minha orientadora, Dra. Maria Leonor, por ter me confiado este trabalho, me ensinando a realizar as mais diferentes atividades, por estar sempre presente me ajudando em todas as etapas da realização deste trabalho, mesmo perdendo noites de sono ou fins de semana. Sempre foi modelo de responsabilidade, dedicação e ética profissional.

Ao Dr. Paulo Lee Ho, por ser sempre tão inspirador, por fazer com que a ciência seja ainda mais encantadora, por querer sempre o nosso bem. À Dra. Eliane Miyaji, pelas discussões e críticas, por ajudar sempre neste trabalho e por ser sempre uma ótima colega, sempre disposta a ensinar, com seu jeito meigo e divertido.

Às minhas amigas Monica e Daiane, por estarem sempre presentes, mesmo que não fisicamente, por todos os bons momentos que passamos juntas em todos estes anos, pelas conversas divertidas ou construtivas.

À minha super amiga Renata, por conseguir me mostrar que as coisas são sempre mehores do que eu imagino, pelo carinho, por ouvir, torcer, ajudar sempre que pode e por estar sempre por perto, por ser tão irmã. 
Aos meus amigos cientistas natos Diogo e Toshi, pela amizade, pelos conselhos e pela ajuda nesta vida de Biólogos.

À minha amiga Pri, por dividir diversos momentos desta nossa vida de estudante, por ser sempre tão compreensiva e estar sempre tão parecida comigo que nos identificamos sem mesmo falar.

Às minhas amigas do laboratório, tão importantes e que me ajudaram tanto: A Patricia, pelas boas conversas, por ter sempre uma dica, por ajudar o tornar a vida mais leve e os problemas menores. A Adriana por estar sempre pronta pra ajudar. À Cintia, por dar exemplo de organização, à Marilia por ter me ensinado muito no laboratório e a Giovana por sempre ser tão leve e divertida. Obrigada meninas do grupo de pneumo pela ajuda com os desafios, ensaios longos e pela boa convivência no dia a dia.

À Swiany, por me ajudar com as células, os cálculos, os problemas da vida, a Luciane, por ajudar com o Prisma, e na minha batalha contra o computador. À Carol (devo escrever Dra. Caroline?), à Liliane por todos os momentos de descontração, por comer junto, beber junto, sorrir junto, me diverti bastante com todas vocês nestes anos. À Regiane e a Fernanda Gomes, à Aghta que foram tão boa companhia no laboratório. Todas vocês me ajudaram muito neste tempo no laboratório que com certeza lembrarei com saudades.

Ao pessoal do laboratório de Biotecnologia Molecular, que esteve sempre dando uma mão em diversas áreas.

Ao Dr. Wagner Quintilio pela ajuda com o ensaio de desafio de pertussis. À Dra. Flavia Kubrusly por ter fornecido o LPS de Bordetella pertussis. À Dra. Patricia Abreu por ter ajudado com o desafio de tétano. Ao Dr. Jorge Ferreira por ter ajudado com às análises de citometria. À Seção de Vacinas aeróbicas do Instituto Butantan por ter fornecido às vacinas pertussis e DTP, DT.

À FAPESP e à Fundação Butantan, pelo apoio financeiro que possibilitou a realização deste projeto. 


\section{RESUMO}

Lima, FA. Estudo das propriedades adjuvantes da vacina celular pertussis em combinação com o antígeno PspA de Streptococcus pneumoniae. Dissertação (Mestrado em Biotecnologia). São Paulo: Instituto de Ciências Biomédicas da Universidade de São Paulo; 2012.

Streptococcus pneumoniae (pneumococo) é um patógeno causador de infecções como pneumonia, meningite e otite média, responsável pela morte de aproximadamente 1 milhão de crianças no mundo todo anualmente. As vacinas atuais são compostas por polissacarídeos conjugados a proteínas e apresentam altos custos de produção e proteção específica contra sorotipos incluídos nas formulações. O antígeno PspA (do inglês "Pneumococcal Surface Proteín A") é um candidato vacinal bastante promissor, conferindo proteção contra pneumococo em diferentes modelos animais. Neste trabalho, avaliamos as propriedades adjuvantes da vacina celular pertussis (wP) em combinação com o antígeno PspA do clado 5 (PspA5) em modelos animais. Diferentes combinações vacinais do antígeno PspA5 com as vacinas $\mathrm{wP}, \mathrm{wP}_{\text {low }}$ (uma nova vacina celular pertussis, com baixa quantidade de LPS) ou com a vacina $\mathrm{DTP}_{\text {low }}$ (contra difteria, tétano e pertussis) foram testadas em imunizações de camundongos por via nasal ou subcutânea. As combinações PspA5-wP e PspA5-wP $\mathrm{P}_{\text {low }}$ inoculadas por via nasal, induziram elevadas concentrações de anticorpos anti-PspA5 sistêmicos e na mucosa respiratória, quando comparadas à administração de PspA5 sozinho ou de um dos adjuvantes. Estas formulações conferiram sobrevivência significativamente maior aos camundongos após um desafio respiratório letal com a linhagem de pneumococo ATCC6303 (sorotipo 3, PspA5), em relação aos grupos controle. A vacina PspA5-wP também conferiu proteção significativa contra um desafio de colonização em camundongos, com a linhagem de pneumococo 0603 (sorotipo 6B, PspA1). Níveis significativamente mais altos de linfócitos foram observados nos pulmões dos animais vacinados por via nasal com PspA5-wP ou PspA5-wP ${ }_{\text {low }}$, quando comparados aos grupos controle. Estes linfócitos foram caracterizados como $\mathrm{T} \mathrm{CD}^{+}, \mathrm{T} \mathrm{CD}^{+}$e B. Em ensaios de imunização passiva, anticorpos presentes no soro dos camundongos imunizados com PspA5-wP conferiram proteção a 75\% dos camundongos não imunizados. A imunização subcutânea da combinação PspA5-DTP low $_{\text {na }}$ também induziu altos níveis de IgG anti-PspA5 sistêmicos e na mucosa respiratória, conferindo proteção contra desafios respiratórios letais com as linhagens ATCC6303 e A66.1 (sorotipo 3, PspA2). Elevadas concentrações de IgG anti-PspA5 foram observados nos lavados bronqueoalveolares dos animais imunizados por esta via.Entretanto, não houve 
aumento no influxo de linfócitos nos pulmões dos camundongos imunizados após o desafio. Juntos, estes resultados indicam um papel fundamental dos anticorpos para a proteção neste modelo. A combinação de PspA5 com a vacina $\mathrm{DTP}_{\text {low }}$ não alterou a proteção induzida por esta vacina contra desafios com $B$. pertussis ou com a toxina tetânica em camundongos e nem a capacidade de neutralização da toxina diftérica in vitro pelo soro. Estes resultados sugerem que a combinação do antígeno PspA5 com a vacina $\mathrm{DTP}_{\text {low }}$ é uma estratégia promissora para a composição de uma vacina quádrupla. Nesta proposta, proteção adicional contra o pneumococo seria possível em uma mesma formulação, aproveitando o calendário nacional de imunizações vigente.

Palavras-chave: Vacinas proteicas. PspA. Streptococcus pneumoniae. Adjuvante. Vacina pertussis. 


\begin{abstract}
Lima, FA. Study of the adjuvant properties of the cell pertussis vaccine in combination with the antigen PspA of Streptococcus pneumoniae. Dissertation (M.Sc. Biotechnology). São Paulo (Brazil): Instituto de Ciências Biomédicas, Universidade de São Paulo; 2010.
\end{abstract}

Streptococcus pneumoniae (pneumococcus) is a pathogen that causes infections such as pneumonia, meningitis and otitis media, responsible for the death of approximately 1 million children per year worldwide. Current vaccines are composed of polysaccharides conjugated to proteins. These vaccines have high production costs and protect against the specific serotypes included in the formulations. The PspA (Pneumococcal Surface Protein A) antigen is a promising vaccine candidate that confers protection against pneumococci in different animal models. In this study, we evaluated the adjuvant properties of the whole cell pertussis (wP) vaccine in combination with the PspA antigen from clade 5 (PspA5) in animal models. Different combinations of the PspA5 antigen with $\mathrm{wP}$ or ${ }^{\mathrm{w}} \mathrm{P}_{\text {low }}$ (a new whole cell pertussis vaccine, with low amounts of LPS) or with the $\mathrm{DTP}_{\text {low }}$ (diphtheria-tetanus-pertussis) vaccine were tested in mice by nasal or subcutaneous immunization. The combinations PspA5-wP and PspA5-wP $\mathrm{P}_{\text {low }}$ inoculated through the nasal route induced high concentrations of systemic and mucosal anti-PspA5 antibodies, compared with the administration of PspA5 alone or one of the adjuvants. These formulations conferred significantly higher survival to mice after a lethal respiratory challenge with the ATCC6303 (serotype 3, PspA5) pneumococcal strain, when compared with the control groups. The PspA5-wP vaccine also conferred significant protection against a colonization challenge in mice with the 0603 pneumococcal strain (serotype 6B, PspA1). Significantly higher levels of lymphocytes were observed in the lungs of animals immunized with PspA5-wP or PspA5-w $\mathrm{P}_{\text {low }}$ when compared with the control groups. These lymphocytes were characterized as $\mathrm{T} \mathrm{CD} 4^{+}, \mathrm{T} \mathrm{CD}^{+}$, and $\mathrm{B}$. In passive immunization experiments, the antibodies present in sera of mice immunized with PspA5-wP conferred protection to $75 \%$ of non-immunized mice. Subcutaneous immunization with the combination PspA5-DTP ${ }_{\text {low }}$ also induced high levels of systemic and mucosal antiPspA5 IgG, providing protection against lethal respiratory challenges with the ATCC6303 and A66.1 (serotype 3, PspA2) pneumococcal strains. High concentrations of anti- PspA5 IgG in bronqueoalveolar lavage fluids were observed in animals immunized by this route. However, no influx of lymphocytes in the lungs of immunized mice was observed after 
challenge. Together, these results indicate an important role of antibodies for protection in this model. The combination of PspA5 with $\mathrm{DTP}_{\text {low }}$ did not alter protection induced by this vaccine against the challenges with $B$. pertussis or tetanus toxin in mice, neither the neutralization capacity of the sera against diphtheria toxin in vitro . These results suggest that the combination of the PspA5 antigen with the $\mathrm{DTP}_{\text {low }}$ vaccine is a promising strategy for the composition of a quadruple vaccine. In this proposal, additional protection against pneumococci would be possible in a single formulation, using the current national immunization schedule.

Keywords: Vaccines. PspA. Pneumococcus. Streptococcus pneumoniae. Adjuvant. Pertussis vaccine. Protein vaccines. 


\section{LISTA DE ABREVIATURAS}

BALF - do inglês: broncheoalveolar lavage fluid

BCG - Bacillus Calmette-Guérin

CDR - do inglês: clade-defining region

$\mathrm{CRM}_{197}$ - toxina diftérica mutada, sem atividade tóxica

DNA - do inglês: Deoxyribonucleic acid

DO - Densidade Óptica

DT - vacina contra difteria e tétano

$\mathrm{DTP}_{\text {low }}$ - vacina tríplice, contra difteria, tétano e pertussis, contendo a vacina $\mathrm{wP}_{\text {low }}$

ELISA - do inglês: Enzime-Linked Immunosorbent Assay

Flt3 - do inglês fms- receptor type tyrosine-protein kinase

FITC - isoticianato de fluoresceína

$\mathrm{h}-$ hora

IFN- $\gamma$ - interferon gama

Ig A - Imunoglobulina A

IgG - Imunoglobulina G

IL-17 - interleucina 17

kDa - kilodalton

Lf - limites de fluoculação

LPS - lipopolissacarídeo

$\mathrm{M}$ - molar

mg - miligrama

$\mathrm{mL}$ - microlitro

$\mathrm{mM}-$ milimolar

$\min -$ minutos

$\mu \mathrm{g}-$ micrograma

$\mu \mathrm{L}-$ microlitro

nm - nanômetro 
PCV7 - do inglês: 7-valent pneumococcal conjugate vaccine

PCV10 - do inglês: 10-valent pneumococcal conjugate vaccine

PCV13 - do inglês: 13-valent pneumococcal conjugate vaccine

PHiD-CV - do inglês: Pneumococcal Haemophillus influenzae protein D conjugate vaccine PS - polissacarídeo

PspA - do inglês: Pneumococcal surface protein A

PspC - do inglês: Pneumococcal surface protein C

S - segundos

SDS-PAGE - do inglês: sodium dodecyl sulfate polyacrylamide gel electrophoresis

TNF- $\alpha$ - do inglês: tumor necrosis factor alpha

TLR - do inglês: Toll Like receptor

UFC - unidade formadora de colônia

$\mathrm{v}-$ volume

wP - vacina celular pertussis

wDTP - vacina tríplice, contra difteria, tétano e pertussis, contendo a vacina celular pertussis ${ }_{w} \mathrm{P}_{\text {low }}$ - vacina celular pertussis com baixa quantidade de LPS 


\section{LISTA DE TABELAS}

Tabela 1 - Sobrevivência de animais imunizados por via nasal após o desafio letal com a linhagem ATCC6303 (sorotipo 3, PspA5), utilizando a vacina wP como adjuvante.

Tabela 2 - Sobrevivência de animais imunizados por via nasal após o desafio letal com a linhagem ATCC6303 (sorotipo 3, PspA5), utilizando a vacina $\mathrm{wP}_{\text {low }}$ como adjuvante.

Tabela 3 - Sobrevivência de animais $\mathrm{C} 3 \mathrm{H} / \mathrm{HePas}$ e $\mathrm{C} 3 \mathrm{H} / \mathrm{HeJ}$ imunizados por via nasal após o desafio letal com a linhagem ATCC6303(sorotipo 3, PspA5)

Tabela 4 - Sobrevivência de animais C3H/HeJ imunizados por via nasal após o desafio letal com a linhagem ATCC6303 (sorotipo 3, PspA5)

Tabela 5 - Sobrevivência de animais imunizados por via subcutânea após o desafio letal com a linhagem ATCC6303 (sorotipo 3, PspA5)....

Tabela 6 - Sobrevivência de animais imunizados por via subcutânea após o desafio letal com a linhagem A66.1 (sorotipo 3, PspA2) .76

Tabela 7 - Sobrevivência dos camundongos BALB/c imunizados por via subcutânea, após desafio com B. pertussis

Tabela 8 - Sobrevivência dos camundongos BALB/c imunizados por via subcutânea, após desafio com toxina tetânica 


\section{LISTA DE FIGURAS}

Figura 1 - Representação esquemática da bactéria $S$. pneumoniae, com seus fatores de virulência; entre eles, o antígeno PspA.

Figura 2 - Esquema representativo da estrutura da proteína PspA, indicando as diferentes regiões

Figura 3 - Purificação de PspA5

Figura 4 - Concentrações de anticorpos anti-PspA5 nos soros de camundongos BALB/c imunizados por via nasal com as diferentes formulações

Figura 5 - Concentrações de anticorpos anti-PspA5 nos soros de camundongos C3H/HePas e $\mathrm{C} 3 \mathrm{H} / \mathrm{HeJ}$ imunizados por via nasal.

Figura 6 - Concentrações de anticorpos anti-PspA5 nos soros de camundongos C3H/HeJ imunizados por via nasal

Figura 7 - Concentrações de anticorpos IgG anti-PspA5 nos BALFs de camundongos $\mathrm{BALB} / \mathrm{c}$ imunizados com as diferentes formulações.

Figura 8 - Concentrações de anticorpos IgG1 e IgG2a anti-PspA5 nos BALFs de camundongos $\mathrm{BALB} / \mathrm{c}$ imunizados com as diferentes formulações

Figura 9 - Concentrações de anticorpos IgA anti-PspA5 nos BALFs de camundongos $\mathrm{BALB} / \mathrm{c}$ imunizados com as diferentes formulações.

Figura 10 - Ligação de IgA presente nos BALFs à superfície do pneumococo. .52

Figura 11 - Ligação de IgG presente nos BALFs à superfície do pneumococo.

Figura 12 - Ligação de IgG1 e IgG2a presente nos BALFs à superfície do pneumococo

Figura 13 - Reatividade da IgA e IgGpresente nos BALFs contra o antígeno PspA na superfície de pneumonococo.

Figura 14 - Indução da deposição do componente C3 do complemento na superfície do pneumococo pelas amostras de BALF.

Figura 15 - Contagem de células totais e linfócitos nos BALFs de camundongos BALB/c imunizados por via nasal com as diferentes combinações

Figura 16 - Caracterização dos linfócitos nos BALFs dos camundongos BALB/c imunizados por via nasal antes do desafio.

Figura 17 - Concentrações de anticorpos IgG e IgA anti-PspA5 nos BALFs de camundongos BALB/c imunizados por via nasal, 12 h após o desafio com a linhagem de $S$. pneumoniae ATCC6303.

Figura 18 - Contagem de células nos BALFs dos camundongos BALB/c imunizados por via nasal, 12 h após o desafio com a linhagem de S. pneumoniae ATCC6303. 
Figura 19 - Caracterização de linfócitos nos BALFs de camundongos BALB/c imunizados por via nasal, 12 h após o desafio com a linhagem de S. pneumoniae ATCC6303.

Figura 20 - Concentrações de anticorpos IgG e IgA anti-PspA5 nos BALFs de camundongos BALB/c imunizados por via nasal, 10 dias após o desafio com a linhagem de $S$. pneumoniae ATCC6303.

Figura 21 - Contagem de células no BALF de camundongos BALB/c imunizados por via nasal, 10 dias após o desafio com a linhagem de S. pneumoniae ATCC6303

Figura 22 - Caracterização de linfócitos nos BALFs de camundongos BALB/c imunizados por via nasal, 10 dias após o desafio com a linhagem de S. pneumoniae ATCC6303. .68

Figura 23 - Reatividade dos soros dos camundongos BALB/c imunizados por via nasal com PspA5 ou com a combinação PspA5-wP contra lisados de S. pneumoniae.

Figura 24 - Contagem de unidades formadoras de colônia (CFU) presentes nos lavados nasais de camundongos não imunizados ou imunizados com wP, PspA5 ou PspA5-wP. .71

Figura 25 - Sobrevivência dos animais que receberam os soros de camundongos imunizados por via nasal. .72

Figura 26 - Concentrações de IgG anti-PspA5 nos soros de camundongos BALB/c imunizados por via subcutânea.

Figura 27 - Concentrações dos subtipos IgG1 e IgG2a anti-PspA5 nos soros de camundongos BALB/c imunizados por via subcutânea.

Figura 28 - Concentrações de anticorpos IgG anti-PspA5 nos BALFs de camundongos BALB/c imunizados por via subcutânea.

Figura 29 - Contagem de células nos BALFs dos camundongos BALB/c imunizados por via subcutânea.

Figura 30 - Caracterização dos linfócitos presentes nos BALFs de camundongos BALB/c imunizados por via subcutânea.

Figura 31 - Western blot utilizando extratos proteicos da linhagem de $S$. pneumoniae ATCC6303 e o sobrenadante do cultivo de B. pertussis...

Figura 32 - Concentrações de anticorpos IgG anti-pertussis nos soros de camundongos $\mathrm{BALB} / \mathrm{c}$ imunizados por via nasal.

Figura 33 - Concentrações de IgG anti-pertussis presente nos soros de camundongos imunizados por via subcutânea.

Figura 34 - Concentrações de IgG anti-toxoide tetânico nos soros de camundongos imunizados por via subcutânea.

Figura 35 - Concentrações de IgG anti-toxoide diftérico nos soros de camundongos imunizados por via subcutânea. .86

Figura 36 - Ensaio de neutralização da toxina diftérica com os diferentes soros experimentais..... 


\section{SUMÁRIO}

1 INTRODUÇÃ

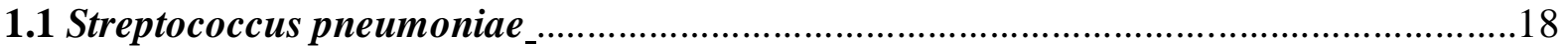

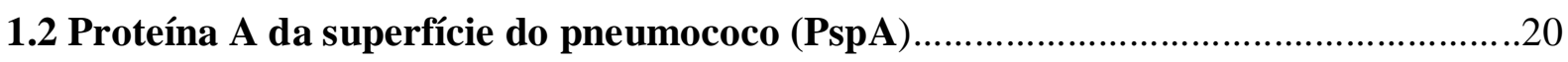

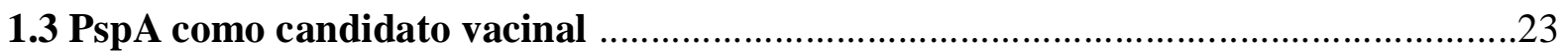

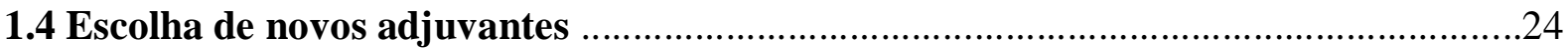

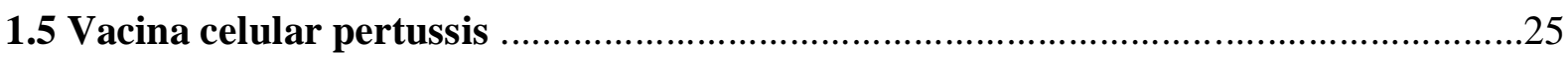

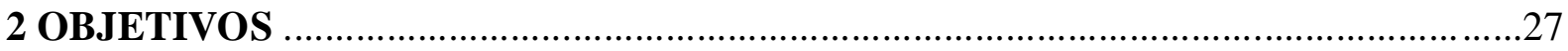

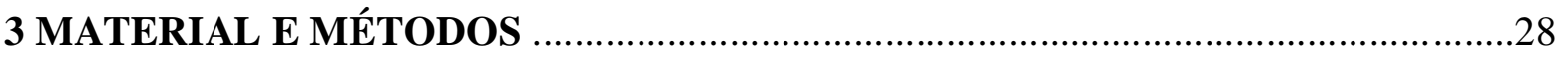

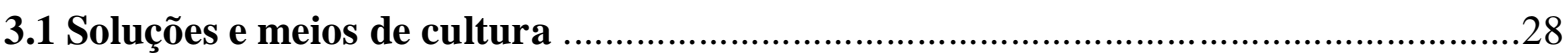

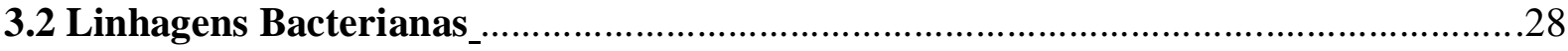

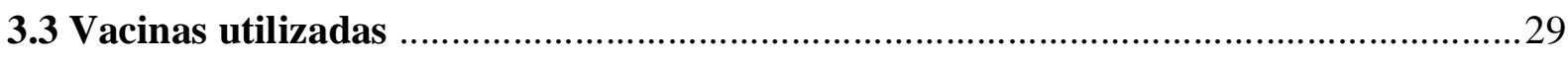

3.4 Expressão da proteína PspA5 em Escherichia coli e purificação por cromatografia de

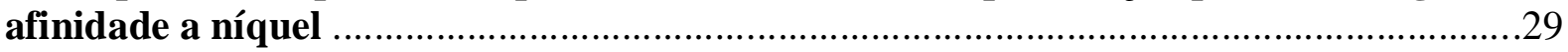

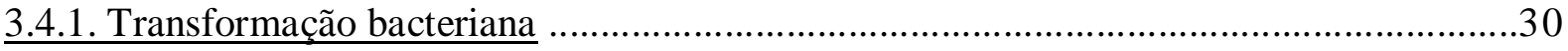

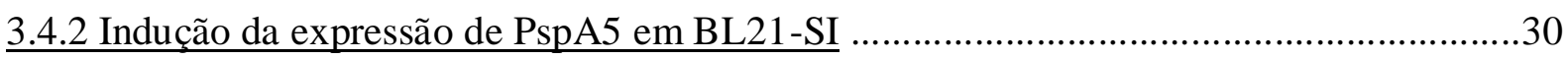

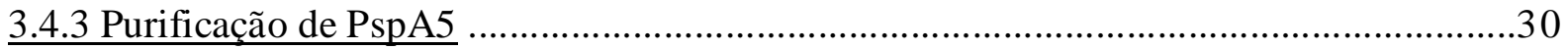

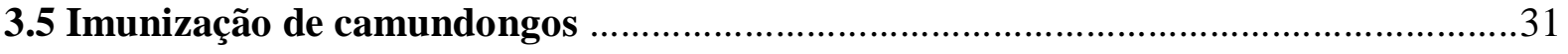

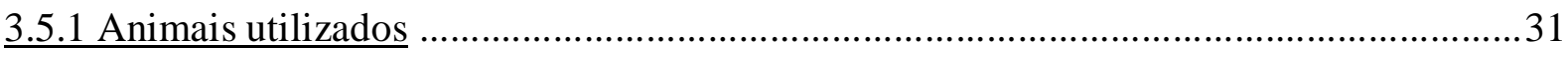

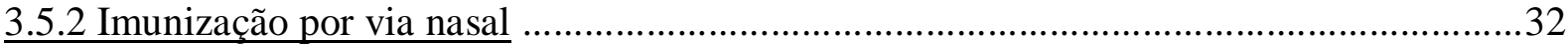

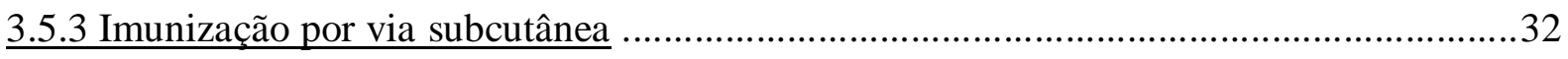

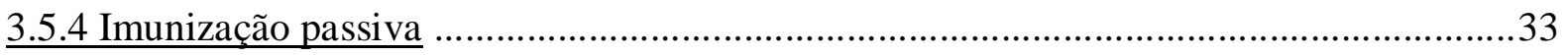

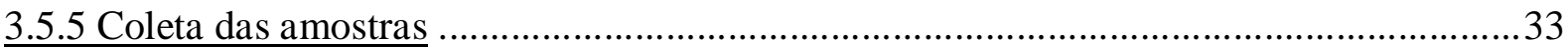

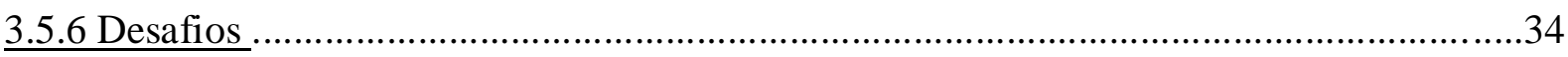

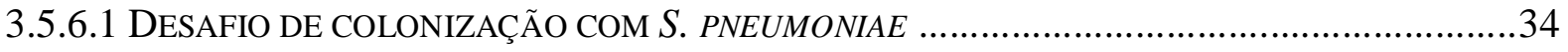

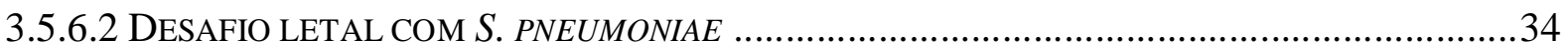

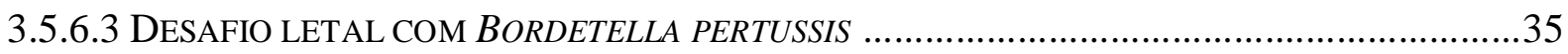

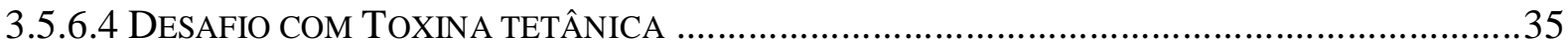

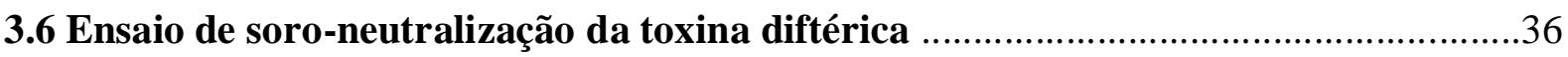


3.7 Análise da indução de anticorpos anti- PspA5, anti-antígenos de Bordetella pertussis, anti-toxóide tetânico e anti-toxóide diftérico

3.8 Análise da reatividade dos soros dos animais imunizados contra PspAs de diferentes clados e contra antígenos de $B$. pertussis

3.9 Análise de linfócitos em lavados broqueoalveolares (BALF) de camundongos BALB/c imunizados

3.10 Análise da ligação de anticorpos à superfície de $S$. pneumoniae 40

3.11 Análise da deposição do componente $\mathrm{C} 3$ do complemento à superfície de $S$. pneumoniae

3. 12 Análises estatísticas

4 RESULTADOS 42

4.1 Purificação da proteína PspA5 42

4.2 Avaliação das formulações vacinais inoculadas em camundongos por via nasal .43

4.2.1 Imunização de camundongos BALB/c e desafio letal com S. pneumoniae

4.2.2 Análise do papel do LPS de B. pertussis na proteção induzida pela combinação PspA5$\underline{\mathrm{wP}}$.....

4.2.3 Análise dos anticorpos anti-PspA5 presentes nos BALF dos camundongos BALB/c imunizados antes do desafio

4.2.4 Análise da capacidade de ligação dos anticorpos presentes nos BALFs à superficie do pneumococo

4.2.5 Avaliação da deposição do componente C3 do complemento à superfície de $S$. pneumoniae, induzida por amostras de BALF

4.2.6 Análise do influxo de linfócitos nos pulmões dos camundongos imunizados

4.2.6.1 ANÁLISE DOS LINFÓCITOS PRESENTES NOS B ALFS ANTES DO DESAFIO

4.2.6.2 ANÁLISE DOS ANTICORPOS ANTI-PSPA5 E DOS LINFÓCITOS PRESENTES NOS BALFS $12 \mathrm{~h}$ APÓS O DESAFIO

4.2.6.3 ANÁLISE DOS ANTICORPOS ANTI-PSPA5 E DOS LINFÓCITOS PRESENTES NOS BALFS DOS CAMUNDONGOS IMUNIZADOS, 10 DIAS APÓS O DESAFIO

4.2.7 Avaliação da reatividade dos soros anti-PspA5 provenientes das imunizações nasais contra PspAs expressos por diferentes linhagens de S. pneumoniae

4.2.8 Avaliação da proteção contra desafio de colonização em camundongos C57B1/6 …......70

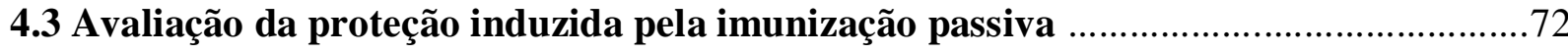

4.4 Avaliação das formulações vacinais inoculadas em camundongos por via subcutânea 
4.4.2 Análise dos anticorpos anti-PspA5 e do influxo de linfócitos presentes nos BALFs dos camundongos imunizados por via subcutânea .76

4.5. Análise da resposta imune contra os outros componentes das diferentes formulações vacinais

4.5.3 Análise da reatividade dos soros dos camundongos imunizados por via subcutânea contra o toxóide tetânico

4.5.5 Análise da soro-neutralização da toxina diftérica induzida pelo soro de camundongos imunizados por via nasal

4.5.5 Análise da reatividade dos soros dos camundongos imunizados por via subcutânea contra toxoide diftérico

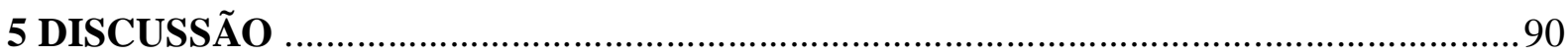

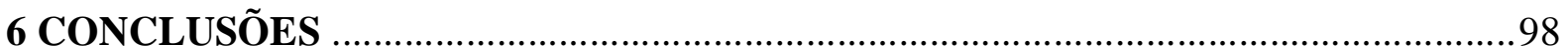

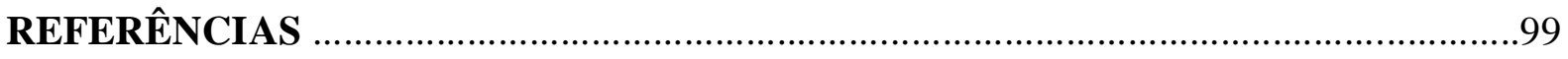

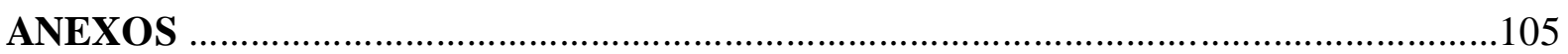

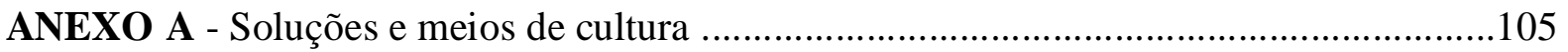

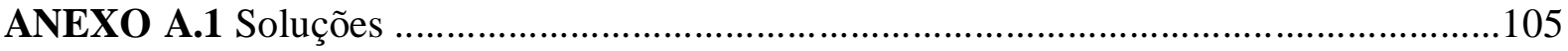

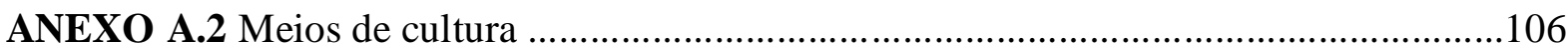

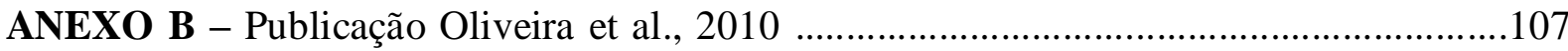




\section{INTRODUÇÃO}

\subsection{Streptococcus pneumoniae}

Streptococcus pneumoniae (pneumococo) é uma bactéria gram positiva que coloniza a nasofaringe de indivíduos saudáveis, podendo ser disseminada destes reservatórios para novos hospedeiros. A partir da colonização, o pneumococo pode invadir sítios normalmente estéreis, causando doenças pneumocócicas como pneumonia, septicemia e meningite (Klein, 1981). Aproximadamente de 14,5 milhões de episódios de doenças pneumocócicas graves ocorreram em 2000, resultando na morte de 826.000 crianças de 1 a 59 meses de idade no mundo (O'Brien et al., 2009). Este número de mortes se mantém estável a cada ano, variando de 700.000 a 1 milhão no mundo todo, sendo que a maioria ocorre em países em desenvolvimento. Na América Latina, o número de mortes registradas varia entre 20.000 a 33.000, por ano, dependendo do estudo (O'Brien et al., 2009). Estimativas baseadas em dados do Brasil no ano de 2005 indicam que ocorreram mais de 300 casos de septicemia, 370.000 casos de otite média e 150.000 casos de pneumonia (Constenla, 2008). O uso de agentes antimicrobianos está entre as estratégias para o combate a estas infecções, mas o aumento no surgimento de cepas com múltiplas resistências limitam o alcance de tais condutas médicas. Em países desenvolvidos, apesar de ocorrerem números menores de mortes, altos custos com internações hospitalares são registrados (O'Brien et al., 2009).

A cápsula polissacarídica do pneumococo é um importante fator de virulência que atua protegendo a bactéria contra a fagocitose por células do hospedeiro (Kadioglu et al., 2008). As vacinas licenciadas atualmente são baseadas nos polissacarídeos (PS) capsulares. Entretanto, estes PS apresentam variabilidade estrutural e antigênica e induzem pouca ou nenhuma imunidade cruzada. A grande quantidade de sorotipos diferentes (mais de 90 descritos até o momento) dificulta a produção de uma vacina polissacarídica de ampla cobertura (Calix e Nahm, 2010). A vacina 23-valente (Pneumovax, Merck, Whitehouse Station, NJ, Estados Unidos) foi a primeira vacina pneumocócica licenciada. Esta vacina é composta por PS de 23 sorotipos de pneumococo $(1,2,3,4,5,6 \mathrm{~B}, 7 \mathrm{~F}, 8,9 \mathrm{~N}, 9 \mathrm{~V}, 14,15 \mathrm{~B}$, 17F, 18C, 19A, 19F, 20, 22F, 23F, 33F) e apresenta uma boa eficácia em adultos. Entretanto, pela composição polissacarídica, esta vacina não induz a ativação de linfócitos T, não sendo, portanto, imunogênica em crianças menores de 2 anos. Além disso, também pela composição polissacarídica, esta vacina não induz resposta de memória, implicando na sua administração 
periódica. As vacinas de segunda geração desenvolvidas foram as vacinas conjugadas PSproteína. A proteína carreadora possibilita a indução de resposta imune dependente de linfócitos T, e, portanto, a resposta imune em crianças menores de 2 anos, além de resposta de memória. Em 2000 a vacina 7 valente (PCV7, Prevnar, Wyeth Madison, NJ, Estados Unidos) foi licenciada nos Estados Unidos. Esta vacina é composta por 7 polissacarídeos (4, 6B, 9V,14, 18C, 19F e 23F) conjugados ao carreador $\mathrm{CRM}_{197}$, um variante não tóxico da toxina diftérica. A PCV7 é eficaz também em crianças e protege contra a colonização e contra doenças pneumocócicas invasivas causadas pelos sorotipos presentes na sua formulação. A estimativa é de mais de $90 \%$ de proteção contra doenças invasivas causadas pelos sorotipos vacinais (WHO, 2007). Entretanto, estudos sobre o impacto da implementação da vacina PCV7 em alguns países, reportaram o aumento nos casos de infecções causadas por sorotipos não presentes na vacina após alguns anos, verificando-se, assim, a substituição dos sorotipos prevalentes devido à pressão seletiva promovida pela vacina (Weinberger et al., 2011). Um exemplo claro de substituição de sorotipos é o caso do aumento de doenças pneumocócicas causadas pelo sorotipo 19A, um sorotipo que não era muito frequente, em países que introduziram a vacina PCV7 (Bettinger et al., 2010; Hsu et al., 2010; Techasaensiri et al., 2010). Por este motivo, as indústrias farmacêuticas investiram no desenvolvimento de novas versões de vacinas conjugadas como a 10 valente e a 13 valente. A vacina 10 valente (PCV10, Glaxo Smithkline Biologicals Brantford, Midllesex, UK) foi licenciada em 2009 na Europa e em 2010 no Brasil. Esta vacina é composta pelos polissacarídeos dos sorotipos 1, 5, 6B, 7F, $9 \mathrm{~V}, 14,23 \mathrm{~F}$ e 4 conjugados a proteína D de Haemophillus influenzae, o polissacarídeo 18C conjugado ao toxoide tetânico e o 19F conjugado ao toxoide diftérico (Wysocki et al., 2009). Também em 2010 foi licenciada a vacina 13 valente nos Estados Unidos (PCV13, PrevnarPfizer), que é composta pelos 7 polissacarídeos presentes na PCV7 mais os polissacarídeos dos sorotipos 1, 3, 5, 6A, 7F e 19A, todos conjugados a CRM 197 (Nuorti e Whitney, 2010).

A PCV10 foi produzida com base nos principais sorotipos presentes no hemisfério norte, que variam em outras partes do mundo. Estudos realizados antes da introdução da PCV10 no Brasil estimaram que a proteção contra colonização em crianças de creches de Goiânia- GO por esta vacina seria de 59,3\%, enquanto que para a vacina 13 valente seria de 72\% (Franco et al. 2010). Em Salvador - BA, um estudo realizado com isolados de meningite pneumocócica em crianças abaixo de 5 anos, ocorridos no período de 2000 a 2007, projetou a cobertura para a vacina 10 valente em 75,7\% e para a vacina 13 valente em 83,1\%. (Menezes et al. 2011). Apesar da boa cobertura, estudos de vigilância epidemiológica são necessários 
para avaliar um possível aumento de doenças causadas por sorotipos não cobertos por esta vacina, assim como ocorreu após a introdução da vacina PCV7. Estes fatores são indicadores da necessidade de desenvolvimento de novas vacinas que ofereçam ampla cobertura.

\subsection{Proteína A da Superfície do pneumococo (PspA)}

Ao longo da última década, muito se descobriu sobre os fatores de virulência do pneumococo e o papel de cada um deles durante a evolução das doenças (Tai, 2006). Além da cápsula polissacarídica que cobre a superfície da bactéria e participa na evasão do sistema imune, diversas proteínas se projetam para o meio externo (Figura 1) e assim interagem com células epiteliais e endoteliais, promovendo adesão e invasão do patógeno, e com componentes do sistema imune. O antígeno PspA ( do inglês "Pneumococcal Surface Protein A”) está entre os mais promissores candidatos vacinais propostos até o momento já que uma quantidade grande de trabalhos mostra o potencial protetor deste antígeno utilizando diferentes modelos de apresentação e desafios em animais (Areas et al., 2005; Briles et al., 2000a; Briles et al., 2000b; Campos et al., 2008; Ferreira et al., 2009a; Fukuyama et al., 2010; Oma et al., 2009).

Figura 1 - Representação Esquemática da bactéria $S$. pneumoniae, com seus fatores de virulência; entre eles, o antígeno PspA.

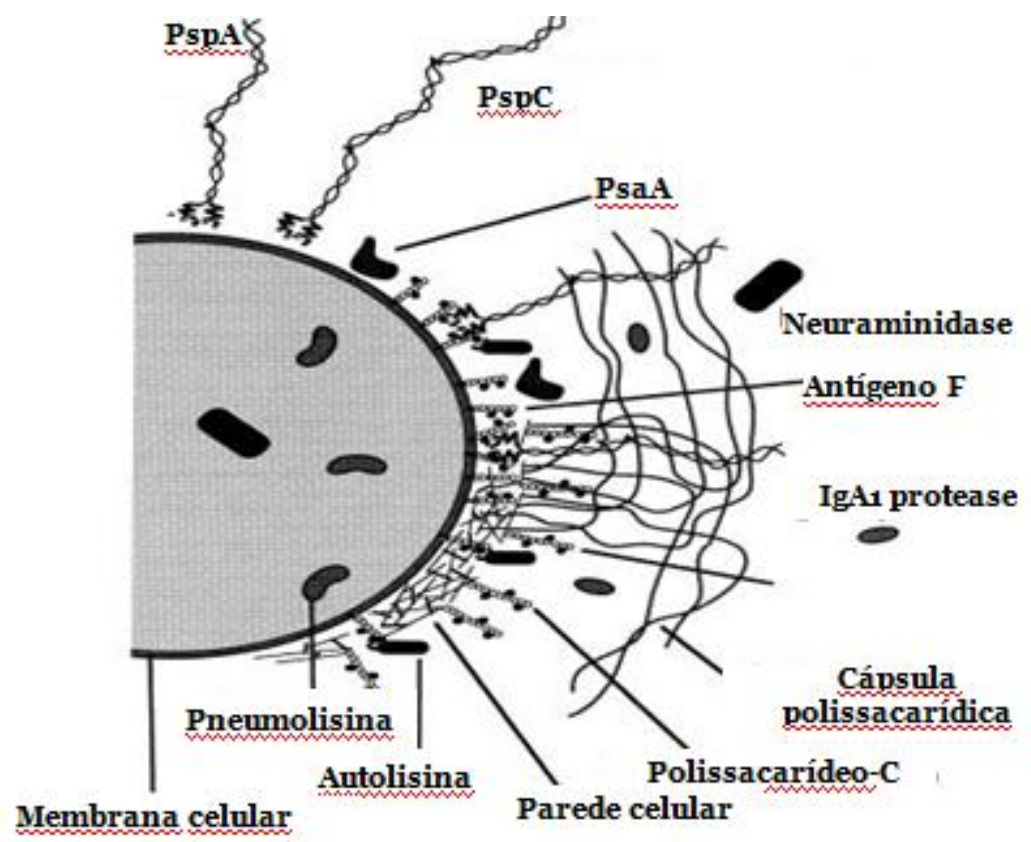

Fonte:Adaptado de Briles et al. (2000a). 
PspA tem papel fundamental na fase invasiva das doenças pneumocócicas. Algumas de suas funções estão relacionadas com a evasão do sistema imune por meio da inibição da fixação do componente C3 do sistema complemento na superfície da bactéria (Ren et al., 2004; Tu et al., 1999). Anticorpos produzidos contra a região N-terminal de PspA são capazes de reverter esta inibição e assim conferem proteção contra infecção sistêmica (Ren et al., 2004). Embora o papel de PspA durante a colonização por pneumococo não esteja bem determinado até o momento, algumas evidências indicam que ele pode também interferir nesta fase. A imunização nasal de camundongos com PspA na presença de adjuvantes (Arulanandam et al., 2001; Oma et al., 2009) ou em combinação com outros antígenos (Briles et al., 2000b) inibe a colonização nasal por pneumococo em modelos animais. Em estudos conduzidos em humanos, anticorpos anti-PspA pré-existentes parecem prevenir a colonização (McCool et al., 2002). Um estudo realizado recentemente demonstrou que uma vacina nasal composta por PspA e um plasmídeo expressando o ligante de Flt3 (do inglês "fms- receptor type tyrosine-protein kinase", cujo receptor é expresso por células do sistema imune, como as células dendríticas) confere proteção contra colonização por pneumococo através da indução de IgA em camundongos. Esta vacina não é eficaz quando administrada em camundongos deficientes em $\operatorname{IgA}\left(\operatorname{IgA}^{-/}\right)$. Além disso, a administração de $\operatorname{IgA}$ purificada proveniente dos camundongos imunizados em camundongos não imunizados promove a proteção contra colonização (Fukuyama et al., 2010). Uma possível explicação para o papel de PspA durante a colonização é a capacidade de se ligar à apolactoferrina presente nas secreções de mucosas, e assim, inibir sua atividade bactericida (Shaper et al., 2004). Apolactoferrina é uma proteína capaz de que sequestrar ferro restringindo o crescimento bacteriano. Além disso, também pode atuar como agente bactericida devido à interação hidrofóbica com a superfície bacteriana, desestabilizando a função normal da membrana.

Um dos problemas relacionados à escolha de PspA como componente vacinal é a relativa variabilidade que eles apresentam nos diversos isolados (Hollingshead et al., 2000). A proteína PspA apresenta massa molecular entre 67 e 99 kDa (Waltman et al., 1990) sendo dividida em 4 regiões: a região $\mathrm{N}$-terminal de $\alpha$-hélice altamente carregada com porções de carga negativa e outras de carga positiva, a região rica em resíduos de prolina, a região de ligação à colina e uma cauda C-terminal de 17 aminoácidos com caráter hidrofóbico (Figura 2). 
Figura 2 - Esquema representativo da estrutura da proteína PspA, indicando as diferentes regiões.

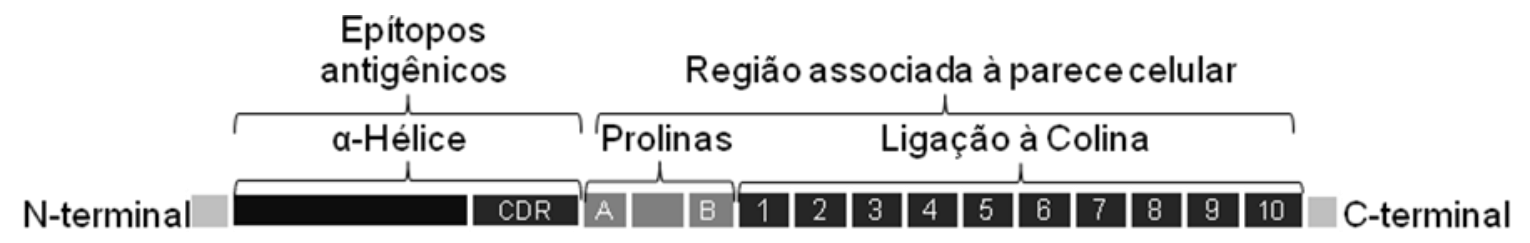

Fonte: Adaptado de Hollingshead et al.(2000)

Com base na sequência de aminoácidos da região imediatamente anterior à região rica em resíduos de prolina (CDR - do inglês “clade-defining region”) os estudos de Hollingshead e colaboradores agruparam os PspAs em 6 clados que, por sua vez, são agrupados em 3 famílias (Hollingshead et al., 2000). Dados obtidos em diversas partes do mundo mostram que 99\% dos isolados de pneumococo expressam PspAs pertencentes às famílias 1 (clados 1 e 2) e 2 (clados 3, 4 e 5) (Hollingshead et al., 2006). Na América do Sul, dois estudos feitos no Brasil (Brandileone et al., 2004; Pimenta et al., 2006) mostram resultados similares, com a prevalência de linhagens expressando PspAs pertencentes às famílias 1 e 2 em 94\% e 97,5\% dos isolados, respectivamente. Até recentemente, acreditava-se que uma vacina ideal composta por PspA deveria conter um representante da família 1 e um representante da família 2, devido à reatividade cruzada entre membros da mesma família. Assim, tal vacina apresentaria teoricamente uma cobertura ao redor de $90 \%$ dos isolados. Entretanto, novos dados apontam para moléculas de PspA que apresentam baixa reatividade cruzada contra outras da mesma família. Devido a isto, o grupo da Dra. Eliane Miyaji do Instituto Butantan, São Paulo, Brasil, passou a estudar a reatividade cruzada de anticorpos produzidos contra a região N-terminal de PspAs dos clados 1 a 5, contra extratos proteicos de diversos sorotipos isolados no Brasil. Este trabalho mostrou que moléculas de PspAs dos clados 4 e 5 induzem anticorpos que reconhecem diferentes PspAs, mesmo pertencentes a famílias diferentes (Darrieux et al., 2008). Além disso, imunização com estes PspAs é capaz de induzir proteção cruzada contra linhagens que expressam PspAs heterólogos em modelos animais (Moreno et al., 2010). Assim, vacinas compostas pelas moléculas de PspA4 ou PspA5 definidas pelo 
grupo da Dra. Miyaji parecem ser os antígenos de escolha para uma vacina que apresente ampla cobertura de isolados.

\subsection{PspA como candidato vacinal}

Diferentes abordagens já foram testadas como propostas de vacinas baseadas no antígeno PspA. Entre elas, a combinação de PspA com diferentes adjuvantes (Arulanandam et al., 2001; Oma et al., 2009), a apresentação deste antígeno por sistemas heterólogos de expressão como bactérias lácticas (Campos et al., 2008; Ferreira et al., 2009a; Oliveira et al., 2003) ou BCG (Langermann et al., 1994) e vacinas de DNA (Miyaji et al., 2003). Como o primeiro contato do pneumococo com o indivíduo é a mucosa nasal, nosso grupo vem estudando, ao longo dos anos, sistemas de imunização mucosa que possam conferir resposta imune local e sistêmica contra PspA. O trabalho de Arêas et al.(2005) demonstrou que uma proteína de fusão composta por PspA e a subunidade B da toxina colérica (CTB), conhecida por sua propriedade adjuvante, não é eficaz na proteção contra desafios sistêmicos com pneumococo, quando a vacina é inoculada por via nasal. Entretanto, a inoculação desta vacina por via intradérmica confere proteção neste modelo. Em uma estratégia parecida, um estudo recente demonstrou que a imunização de camundongos com uma proteína de fusão composta pela flagelina de Vibrio vulnificus (agonista do receptor TLR5) com PspA do clado 2 (FlaBPspA), por via nasal, induziu o aumento da concentração de $\operatorname{IgG}$ e $\operatorname{Ig} A$ anti-PspA na mucosa respiratória dos animais e promoveu proteção contra desafio letal utilizando as linhagens de $S$. pneumoniae D39 (sorotipo 2, PspA2) e WU2 (sorotipo 3, PspA2). No entanto, administração da mistura das proteínas PspA e flagelina purificadas induziu concentrações mais baixas de anticorpos e não foi eficiente em proteger os camundongos nestes desafios (Nguyen et al., 2011).

Utilizando o sistema de apresentação de antígenos baseados em bactérias lácticas, nosso grupo observou proteção parcial de camundongos vacinados por via nasal com Lactobacillus casei expressando o antígeno PspA do clado 1 contra um modelo de desafio sistêmico com pneumococo (Campos et al., 2008). Em um trabalho mais recente, uma vacina nasal composta por Lactobacillus casei expressando PspA do clado 5, conferiu proteção significativa contra um desafio respiratório letal com pneumococo em camundongos (Ferreira 
et al., 2009a). Ainda que significativa, esta proteção foi parcial e menor que a conferida pela própria proteína PspA5 recombinante inoculada por via nasal. Este mesmo trabalho definiu algumas características importantes da resposta protetora contra a infecção por pneumococo no modelo animal de desafio respiratório letal. Os dados demonstraram que a indução de anticorpos anti-PspA sistêmicos, preferencialmente do tipo IgG2a, aliada à indução das citocinas pró-inflamatórias IFN-y e IL-17 e um controle rápido da inflamação pela diminuição dos níveis de TNF- $\alpha$, tem papel importante neste sistema (Ferreira et al., 2009a). De fato, em publicações anteriores, o papel de anticorpos IgG2a anti-PspA foi associado à maior indução de deposição de complemento na superfície das bactérias, resultando em proteção (Arulanandam et al., 2001; Ferreira et al., 2008).

Entre as estratégias vacinais que não se baseiam no antígeno PspA, merece destaque uma vacina celular composta por uma linhagem de pneumococo não capsulada e inativada por tratamento com etanol. Esta vacina é eficaz contra colonização em modelos animais e apresenta como mecanismo protetor a indução células $\mathrm{T} \mathrm{CD}^{+}$circulantes, secretoras da citocina IL-17 (Lu et al., 2008; Malley et al., 2005). Após a determinação do mecanismo protetor induzido por esta vacina, vários grupos buscam em formulações vacinais a indução de tal tipo de resposta.

\subsection{Escolha de novos adjuvantes}

Apesar dos dados da literatura apontarem para o antígeno PspA como importante alvo no desenvolvimento de vacinas, todas as abordagens publicadas até o momento estão longe de ser ideais. Fatores como número de doses, vias de imunização e adequação das estratégias para uso em crianças recém nascidas ou com poucos meses de vida são fatores que devem ser considerados para uma proposta de vacina que apresente eficácia aliada a baixos custos, segurança e abrangência de toda a população. A combinação de antígenos com diferentes adjuvantes modula quantitativa e qualitativamente a resposta imune, influenciando decisivamente nos fatores mencionados acima para o sucesso de uma vacina (Reed et al., 2009). Em geral, vacinas compostas por patógenos atenuados ou inativados (como a vacina celular pertussis) apresentam propriedades imunomodulatórias inerentes, dispensando o uso de adjuvantes. Componentes bacterianos como lipopolissacarídeos, ácidos lipoteicóicos, 
proteínas e ácidos nucleicos são conhecidos ligantes de receptores de reconhecimento padrão, presentes nas superfícies das células de hospedeiros, através dos quais exercem seus efeitos estimulantes do sistema imune (Harandi et al., 2009; Reed et al., 2009).

\subsection{Vacina celular pertussis}

A vacina celular pertussis (wP), produzida pelo Instituto Butantan e distribuída pelo Ministério da Saúde, é composta pela bactéria Bordetella pertussis inativada por tratamento com formaldeído. Esta vacina é administrada a crianças em combinação com toxoide tetânico e toxoide diftérico, numa formulação conhecida como tríplice ou wDTP que protege contra tétano, difteria e coqueluche. Após a sua introdução no país, observou-se uma redução rápida e significativa na incidência de casos de coqueluche (Ministério da Saúde, 2012). Antigamente, wP era adotada por diversos países com sucesso; entretanto, alguns efeitos adversos provavelmente relacionados às impurezas derivadas dos métodos de inativação (que variam nas diferentes vacinas produzidas por países distintos) ou à quantidade de lipopolissacarídeos (LPS) presentes nas formulações, levaram à substituição por formulações acelulares em alguns países (Locht, 2008). No Brasil, não há relatos de efeitos adversos sérios relacionados à vacina $\mathrm{wP}$ produzida pelo Instituto Butantan, que vem sendo administrada em crianças a partir dos dois meses de vida há mais de 20 anos. Vacinas celulares também continuam a ser adotadas por outros países em desenvolvimento já que as vacinas acelulares apresentam, em geral, menor eficácia e, principalmente, altos custos de produção (Locht, 2008). Recentemente, o Instituto Butantan desenvolveu uma tecnologia para remoção da maior parte do LPS, produzindo a nova vacina celular pertussis "low" ( $\left.\mathrm{wP}_{\text {low }}\right)$. Esta nova vacina foi testada com sucesso em ensaios clínicos de fase 1 e apresentou resultados de imunogenicidade semelhantes ao da antiga vacina celular (Zorzeto et al., 2009).

Nos últimos anos, um aumento nos casos de coqueluche tem sido relatado em crianças e adolescentes, principalmente em países que adotaram a vacina acelular (De Carvalho e Pereira, 2006; Locht, 2008). Alguns grupos propõem como alternativa, estratégias de imunização com vacinas celulares inativadas ou atenuadas por via nasal, que já se mostraram eficazes em modelos animais (Berstad et al., 2000a; Locht, 2008; Mielcarek et al., 2006). Em 
combinação com outros antígenos, as vacinas celulares pertussis apresentam atividade adjuvante também por via nasal (Mielcarek et al., 1997).

Dados preliminares do nosso grupo mostram que quando combinadas com o antígeno PspA5 e administradas por via nasal em camundongos, as vacinas $\mathrm{wP}$ e $\mathrm{wP}_{\text {low }}$ apresentam atividade adjuvante, e as formulações PspA5-wP e PspA5-wP $\mathrm{P}_{\text {low }}$ conferem proteção contra um modelo de desafio respiratório letal por pneumococo. No presente trabalho, a resposta imune induzida por estas vacinas em camundongos foi caracterizada. 


\section{OBJETIVOS}

Os objetivos deste trabalho foram:

a) Caracterizar a resposta imune protetora contra pneumococo induzida por formulações compostas pelo antígeno PspA do clado 5 (PspA5) em combinação com as vacinas $\mathrm{wP}$ e $\mathrm{wP}_{\text {low }}$, administradas por via nasal em camundongos;

b) Avaliar o potencial protetor contra pneumococo de formulações compostas pelo antígeno PspA5 em combinação com a vacina $\mathrm{DTP}_{\text {low }}$, administradas em camundongos por via subcutânea;

c) Avaliar o efeito da combinação de $\mathrm{PspA5}$ com as vacinas $\mathrm{wP}, \mathrm{wP}_{\text {low }} \mathrm{e} / \mathrm{ou}$ $\mathrm{DTP}_{\text {low }}$ na resposta imune induzida em camundongos contra os antígenos de pertussis, toxoide tetânico ou toxoide diftérico. 


\section{MATERIAL E MÉTODOS}

\subsection{Soluções e meios de cultura}

As soluções e meios de cultura utilizados neste trabalho estão descritas no Anexo A.

\subsection{Linhagens bacterianas}

Neste trabalho foram utilizadas bactérias Escherichia coli BL21 SI que contêm o gene da T7 RNA polimerase sob o controle de promotor osmoticamente induzível proU, cultivadas em meio 2 YT/ON a $30{ }^{\circ} \mathrm{C}$ sob agitação.

As bactérias S. pneumoniae das linhagens ATCC6303 (sorotipo 3, PspA5), A66.1 (sorotipo 3, PspA2); 0603 (sorotipo 6B, PspA1), 2139 (sorotipo 6A, PspA2) TIGR4 (sorotipo 4, PspA3) D39 (sorotipo 2, PspA2) e 2139 (sorotipo 6A, PspA2) foram cultivadas em meio THY sem agitação a $37^{\circ} \mathrm{C}$. Os estoques foram mantidos em meio THY contendo $15 \%$ (V/V) de glicerol a $-80{ }^{\circ} \mathrm{C}$. As bactérias sempre foram descongeladas e cultivadas em meio ágar sangue antes do cultivo em meio THY.

As bactérias mutantes ATCC6303 ${ }^{\text {PspA- }}$, ATCC6303 ${ }^{\text {PspC- }}$, ATCC6303 ${ }^{\text {PspA-/PspC- }}$ foram obtidas em outro trabalho realizado em nosso laboratório (dados não publicados) e foram cultivadas nas condições descritas acima em meio contendo $1 \mu \mathrm{g} / \mathrm{ml}$ de eritromicina ou $300 \mu \mathrm{g} / \mathrm{mL}$ de spectinomicina, ou ambos.

A linhagem 18323 de B. pertussis foi utilizada para desafio em animais e foi cultivada pelo Dr. Wagner Quintilio da Seção de Controle Biológico, Divisão de Desenvolvimento Tecnológico do Intituto Butantan, de acordo com os protocolos estabelecidos por este laboratório. 


\subsection{Vacinas utilizadas}

As vacinas utilizadas neste trabalho foram as seguintes:

wP: vacina celular pertussis, produzida pelo Instituto Butantan, composta pela Bordetella pertussis inativada por formaldeído;

${ }_{w} \mathrm{P}_{\text {low }}$ : vacina celular pertussis de nova geração, produzida pelo Instituto Butantan, após a remoção do excesso de LPS da vacina wP. Esta vacina já foi testada em ensaio clínico de fase 1 (Zorzeto et al., 2009).

DT: vacina dupla produzida pelo Instituto Butantan, composta pelo toxoide tetânico e diftérico, contendo hidróxido de alumínio na formulação.

$\mathrm{DTP}_{\text {low: }}$ vacina tríplice produzida pelo Instituto Butantan, composta pelo toxoide tetânico, toxoide diftérico e a vacina $\mathrm{wP}_{\text {low }}$, contendo hidróxido de alumínio na formulação.

\subsection{Expressão da proteína PspA5 em Escherichia coli e purificação por cromatografia de afinidade a níquel}

Neste trabalho foi utilizado como antígeno o fragmento $\mathrm{N}$ - terminal da proteína PspA do clado 5 (PspA5), que induz anticorpos com reatividade cruzada contra PspAs de diferentes clados (Darrieux et al., 2008). O fragmento que codifica a região N-terminal de PspA5 foi amplificado por PCR a partir do DNA genômico da linhagem de pneumococo 122/02 (da coleção do Instituto Adolpho Lutz, São Paulo, Brasil) e clonado no vetor plasmidial pAE, em trabalhos anteriores realizados no nosso laboratório (Ferreira et al., 2009b). Este vetor permite a expressão da proteína heteróloga com uma cauda adicional de 6 resíduos de histidina (6XHis) na extremidade N-terminal, a fim de facilitar a sua purificação por cromatografia em resina quelante, previamente carregada com $\mathrm{Ni}^{2+}$ (Ramos et al., 2004). O vetor pAE possui marca resistência a ampicilina e o promotor do fago T7 para o controle de expressão da proteína heteróloga. 


\section{$\underline{\text { 3.4.1. Transformação bacteriana }}$}

Bactérias E. coli BL21 SI foram transformadas com o vetor pAE-PspA5 por choque térmico. Para isto bactérias competentes foram incubadas com $100 \mathrm{ng}$ do vetor plasmidial por 20 min no gelo, incubadas por 2 min a $42{ }^{\circ} \mathrm{C}$ e incubadas novamente no gelo por $5 \mathrm{~min}$. Em seguida, foram adicionados $350 \mu \mathrm{L}$ de meio $2 \mathrm{YT} / \mathrm{ON}$ e as amostras foram colocadas em estufa a $30{ }^{\circ} \mathrm{C}$, por $1 \mathrm{~h}$. As bactérias foram plaqueadas em meio sólido $2 \mathrm{YT} / \mathrm{ON}$-amp e as placas foram incubadas em estufa a $30{ }^{\circ} \mathrm{C}$ por $18 \mathrm{~h}$ para a seleção dos clones transformantes.

\section{$\underline{\text { 3.4.2 Indução da expressão de PspA5 em BL21-SI }}$}

As bactérias transformadas foram cultivadas em meio liquido 2YT/ON-amp até a $\mathrm{DO}_{600}=0,6$ e a expressão de PspA5 foi induzida pela adição de $300 \mathrm{mM}$ de $\mathrm{NaCl}$ ao cultivo e incubação por $2 \mathrm{~h}$ a $30{ }^{\circ} \mathrm{C}$ sob agitação. Após a indução, frações dos extratos proteicos foram analisadas quanto à presença da proteína de interesse por eletroforese em gel de SDS-

poliacrilamida (SDS-PAGE) 10\%. Um clone positivo foi escolhido para cultivo em $1 \mathrm{~L}$ de meio 2YT/ON-amp até a $\mathrm{DO}_{600}=0,6$. A expressão de PspA5 foi induzida pela adição de $\mathrm{NaCl}$ como descrito anteriormente e, após o tempo de indução, as bactérias foram centrifugadas e suspensas em $100 \mathrm{~mL}$ de tampão de equilíbrio. As bactérias foram lisadas em aparelho French Pressure $^{\circledR}$ (Therno Cientific, Waltham, MA, Estados Unidos ) a 1500 psi, para obtenção do extrato proteico.

\section{$\underline{\text { 3.4.3 Purificação de PspA5 }}$}

Para a purificação foi utilizada uma coluna de $5 \mathrm{~mL}$ (GE healthcare, Uppsala, Suécia) acoplada a uma bomba peristáltica (GE Healthcare) com fluxo estabelecido a $1 \mathrm{~mL}$ por min. Inicialmente a coluna foi empacotada com resina quelante (Chelating Sepharose Fast Flow GE Healthcare). A resina foi lavada com $50 \mathrm{~mL}$ água destilada, e carregada com $50 \mathrm{~mL}$ de solução $300 \mathrm{mM}$ de $\mathrm{NiSO}_{4}$. Após um período de incubação de $30 \mathrm{~min}$, a resina foi novamente 
lavada com $50 \mathrm{~mL}$ de água destilada e equilibrada com $50 \mathrm{~mL}$ de tampão de equilíbrio. $\mathrm{O}$ extrato bacteriano foi centrifugado a $12900 \mathrm{~g}$ por $20 \mathrm{~min}$ e, em seguida, o sobrenadante foi adsorvido à resina. A purificação consistiu em lavagens sucessivas em tampão de lavagem, iniciando com $5 \mathrm{mM}$ de imidazol, aumentando para $20 \mathrm{mM}, 40 \mathrm{mM}, 60 \mathrm{mM}$ e $100 \mathrm{mM}$. A eluição foi realizada em tampão de lavagem contendo $500 \mathrm{mM}$ de imidazol. A purificação da proteína recombinante foi avaliada por SDS-PAGE 10\% e as frações contendo proteína foram dialisadas contra tampão de diálise. A proteína purificada foi quantificada por leitura em espectrofotômetro, utilizando o método de coloração de Bradford (Protein Assay Kit Bio-Rad, Hercules, CA, Estados Unidos).

A proteína recombinante purificada foi submetida a um protocolo de extração com Triton X-114 para retirada do excesso de LPS, provenientes da E. coli. Para tanto, foram adicionados $10 \mu \mathrm{l}$ de Triton X-114 para cada $\mathrm{mL}$ de proteína purificada. As amostras foram agitadas em vortex e incubadas por 5 min no gelo. As amostras foram novamente agitadas em vortex, incubadas por $5 \mathrm{~min}$ a $37^{\circ} \mathrm{C}$, e centrifugadas por $30 \mathrm{~s}$ a $16000 \mathrm{~g}$. O sobrenadante foi coletado e o procedimento repetido por três vezes (Aida e Pabst, 1990).

\subsection{Imunização de camundongos}

\section{$\underline{\text { 3.5.1 Animais utilizados }}$}

Foram utilizadas fêmeas de camundongos BALB/c, de 5 a 7 semanas, provenientes do Centro de Bioterismo da Faculdade de Medicina, Universidade de São Paulo. Os camundongos C57Bl/6 fêmeas, de 5 a 7 semanas, foram adquiridos do Biotério Central do Instituto Butantan. Camundongos $\mathrm{C} 3 \mathrm{H} / \mathrm{HeJ}$ (que apresentam mutação pontual no receptor de ligação a LPS, TLR4) e a linhagem parental C3H/HePas (machos e fêmeas), de 5 a 7 semanas, foram adquiridos da Faculdade de Medicina Veterinária e Zootecnia da Universidade de São Paulo. Os protocolos experimentais foram aprovados pela Comissão de Ética no Uso de Animais do Instituto Butantan (nº dos processos 586/09 e 825/11).

Os camundongos da linhagem C57B1/6 fêmeas foram utilizados nos experimentos de avaliação da colonização por pneumococo, nos quais este modelo foi estabelecido (Oliveira et al., 2006), conforme descrito no item 3.5.6.1. Camundongos BALB/c, C3H/HeJ e C3H/HePas 
foram avaliados quanto à sobrevivência em desafio respiratório letal com Streptococcus pneumoniae, conforme descrito no item 3.5.6.2

\section{$\underline{\text { 3.5.2 Imunização por via nasal }}$}

Para a imunização nasal grupos de 6 camundongos BALB/c, C57Bl/6, C3H/HeJ ou $\mathrm{C} 3 \mathrm{H} / \mathrm{HePas}$ foram anestesiados com $200 \mu \mathrm{L}$ de anestésico $(0,4 \mathrm{mg}$ de xilazina e $1 \mathrm{mg}$ de quetamina) (Syntec do Brasil Ltda, Cotia, SP, Brasil) por via intraperitonial. Depois de anestesiados os grupos de camundongos receberam PspA5, wP, wP $\mathrm{P}_{\text {low }}, \mathrm{PspA5-wP}$ ou PspA5${ }_{w} \mathrm{P}_{\text {low }}$ por via nasal. Em cada imunização foram administradas $5 \mu \mathrm{g}$ de PspA5, 1/8 da dose humana de $\mathrm{wP}$ ou de $\mathrm{wP}_{\text {low }}$ ou as diferentes combinações, de acordo com cada grupo de animais. Esta dose foi escolhida por ser a dose utilizada nos ensaios biológicos de controle de qualidade das vacinas. As formulações foram ajustadas para o volume de $10 \mu \mathrm{L}$ com salina estéril. Os camundongos receberam 2 doses por semana em 3 semanas não consecutivas, totalizando 6 doses, inoculadas com o auxílio de uma micropipeta. Animais não imunizados foram utilizados como controle. Para o teste da ação adjuvante do LPS de B. pertussis, camundongos $\mathrm{C} 3 \mathrm{H} / \mathrm{HeJ}$ e $\mathrm{C} 3 \mathrm{H} / \mathrm{HePas}$ foram imunizados com PspA5, LPS de B. pertussis (produzido pelo grupo da Dra. Flávia S. Kubrusly do Instituto Butantan) ou PspA5-LPS. Em cada imunização foram administrados $5 \mu \mathrm{g}$ de PspA5, $10 \mu \mathrm{g}$ de LPS de B. pertussis ou a mistura dos dois, de acordo com cada grupo de animais. A quantidade de LPS utilizada foi equivalente à quantidade presente em uma dose de wP.

\subsubsection{Imunização por via subcutânea}

Para a imunização por via subcutânea foram utilizados camundongos BALB/c. Os grupos de animais receberam PspA5, DT, DTP ${ }_{\text {low }}$, PspA5-DT ou PspA5-DTP low $_{\text {Em cada }}$ imunização foram administradas $5 \mu \mathrm{g}$ de PspA5, 1/8 da dose humana de DT ou de DTP $_{\text {low }}$, ou as diferentes combinações, de acordo com cada grupo de animais. Os grupos controle não foram imunizados. A vacina dupla DT, foi utilizada como controle da vacina $\mathrm{DTP}_{\text {low }}$ permitindo determinar se a $\mathrm{wP}_{\text {low }}$ funciona como um componente adjuvante determinante 
neste sistema. Os animais foram imunizados com uma dose das diferentes formulações suspensas em 100 uL de solução salina, administrada na região dos flancos.

\subsubsection{Imunização passiva}

Para o ensaio de imunização passiva os soros dos camundongos BALB/c imunizados por via nasal (conforme descrito no item 3.5.2) foram reunidos em pools de cada grupo e incubados a $56{ }^{\circ} \mathrm{C}$ por 30 minutos, para a inativação das proteínas do sistema complemento. Fêmeas de camundongos BALB/c foram inoculadas por via intraperitoneal com $500 \mu \mathrm{L}$ de uma diluição 1:100 de cada soro. Duas horas após a inoculação os camundongos foram desafiados conforme descrito no item 3.5.6.2

\section{$\underline{3.5 .5 \text { Coleta das amostras }}$}

O sangue e/ou lavados bronqueoalveolares (de acordo com cada experimento) foram coletados 20 dias após a imunização dos animais. Estas amostras foram utilizadas para avaliação da presença de anticorpos IgG e IgA específicos contra PspA5 ou contra os antígenos presentes na vacina tríplice $\mathrm{DTP}_{\text {low }}$ (antígenos de $B$. pertussis, toxoide tetânico e toxoide diftérico). $\mathrm{O}$ sangue foi coletado pelo plexo retro-orbital, mantido a $37{ }^{\circ} \mathrm{C}$ por $30 \mathrm{~min}$ e centrifugado a $350 \mathrm{~g}$ por $10 \mathrm{~min}$. O soro obtido foi mantido a $-20{ }^{\circ} \mathrm{C}$ até o uso. Para a coleta dos lavados bronqueoalveolares (BALF), os animais foram sacrificados com uma dose letal de uretano (15mg por 10g de peso) (Sigma Aldrich, St. Louis, MO, Estados Unidos) por via intraperitonial. Através de uma incisão na traquéia dos camundongos, foram injetados $500 \mu 1$ de PBS nos alvéolos pulmonares e o volume foi coletado com o auxilio de uma seringa. Este procedimento foi repetido injetando-se mais $1,0 \mathrm{~mL}$ de $\mathrm{PBS}$ e os dois volumes foram misturados, compondo o BALF. Para a coleta dos lavados nasais os animais foram sacrificados em câmara de $\mathrm{CO}_{2}$. Através de uma incisão na traqueia dos camundongos foram inoculados $200 \mu \mathrm{l}$ de solução salina e o volume passado pelas narinas foi coletado em micro tubos. Este procedimento foi repetido com mais $200 \mu \mathrm{l}$ e as duas coletas foram agrupadas. 


\section{$\underline{\text { 3.5.6 Desafios }}$}

\subsubsection{DESAFIO DE COLONIZAÇÃO COM S. PNEUMONIAE}

Vinte e um dias após a última imunização foi realizado um desafio de colonização nos camundongos C57B1/6 utilizando a linhagem de $S$. pneumoniae 0603, (sorotipo 6B, PspA1). Para tanto, as bactérias foram cultivadas em meio THY líquido até atingir a fase exponencial $\left(\mathrm{DO}_{600}=0.4\right)$. As bactérias foram centrifugadas a $1500 \mathrm{~g}$ por $20 \mathrm{~min}$ e suspensas em 1:10 do volume inicial, em meio THY contendo $15 \%$ de glicerol. Alíquotas de $100 \mu \mathrm{L}$ foram mantidas $\mathrm{a}-80{ }^{\circ} \mathrm{C}$. Após o congelamento, um dos tubos foi descongelado e diluições foram plaqueadas em ágar-sangue, para a análise da viabilidade das bactérias. Os animais foram anestesiados com $200 \mu \mathrm{L}$ de anestésico (0,4 mg de xilazina e $1 \mathrm{mg}$ de quetamina) (Syntec do Brasil Ltda), por via intraperitoneal e então foram inoculadas $5 \times 10^{6}$ bactérias suspensas em $10 \mu \mathrm{L}$ de salina em ambas as narinas dos camundongos. Após 5 dias (tempo determinado em testes prévios), os animais foram sacrificados e coletou-se lavados nasais conforme descrito no item anterior. Diluições seriadas dos lavados nasais foram plaqueadas em ágar sangue contendo $40 \mu \mathrm{g}$ gentamicina/mL e as placas foram incubadas a $37{ }^{\circ} \mathrm{C}$ por $24 \mathrm{~h}$ para a contagem de UFCs (Unidades Formadoras de Colônias).

\subsubsection{DESAFIO LETAL COM S. PNEUMONIAE}

Os camundongos foram desafiados, 21 dias após a última imunização, com a linhagem de S. pneumoniae ATCC6303 (sorotipo 3, PspA5) ou A66.1 (sorotipo 3, PspA2). Para tanto, as bactérias foram preparadas como descrito para a linhagem 0603 (descrito no item 3.5.6.1). Os animais foram anestesiados por via intraperitoneal com $200 \mu \mathrm{L}$ de anestésico $(0,4 \mathrm{mg}$ de xilazina e $2 \mathrm{mg}$ de quetamina) (Syntec do Brasil) e receberam por via nasal $50 \mu \mathrm{L}$ de uma suspensão contendo $3 \times 10^{5}$ bactérias (para a linhagem ATCC6303) ou 1 X10 6 bactérias (para a linhagem A66.1). A sobrevivência dos animais foi acompanhada por 10 dias. Neste desafio, os animais adoecem em aproximadamente 30 h e morrem entre 72 h e 5 dias. Após 5 dias, os animais em geral não adoecem mais e sobrevivem (Ferreira et al., 2010). 
A linhagem 18323 de B. pertussis foi cultivada pelo Dr. Wagner Quintilio, de acordo com os protocolos desenvolvidos na Seção de Controle Biológico da Divisão de Desenvolvimento Tecnológico e Produção do Instituto Butantan.

Camundongos BALB/c foram desafiados com a linhagem 18323 de B. pertussis, 15 dias após a última imunização, para avaliação do efeito da combinação de PspA5 com a vacina $\mathrm{DTP}_{\text {low }}$ na proteção contra este patógeno. Grupos de 12 camundongos foram vacinados por via subcutânea conforme descrito no item 3.5.3. Para o desafio, os animais receberam injeção intracerebral de $30 \mu \mathrm{L}$ de uma suspensão contendo $5 \times 10^{4}$ bactérias (Nascimento et al., 2008). Os camundongos que morreram até 3 dias após o desafio foram descartados e, após este período, foi feita a contagem dos sobreviventes até o $10^{\circ}$ dia. Este é o ensaio padrão de controle biológico da vacina pertussis realizado no Instituto Butantan.

\subsubsection{DESAFIO LETAL COM TOXINA TETÂNICA}

Para avaliação do efeito da combinação de PspA5 com a vacina $\mathrm{DTP}_{\text {low }}$ na proteção contra tétano, foi realizado um ensaio de desafio com toxina tetânica (produzida no Instituto Butantan). Os animais foram imunizados com 2 doses de PspA5, DTP por via subcutânea. Os camundongos foram desafiados 21 dias após a última imunização. Para determinar a dose de desafio foi feita uma curva de sobrevivência em camundongos não imunizados, em que foram administrados por via intraperitoneal $500 \mu \mathrm{L}$ de diluições da toxina tetânica (estoque a 100 limites de floculação/mL $-\mathrm{Lf} / \mathrm{mL}$ ) iniciando com $10^{-4}$ até $10^{-8}$. A diluição $10^{-4}$ foi escolhida porque matou $100 \%$ dos camundongos em $24 \mathrm{~h}$ (Abreu et al., 2004). Após a inoculação por via intraperitoneal, os camundongos foram observados por 10 dias. 


\subsection{Ensaio de soro-neutralização da toxina diftérica}

Para avaliação do efeito da combinação de PspA5 com a vacina DTP $_{\text {low }}$ na resposta contra difteria, foi realizado um ensaio de soro-neutralização da toxina diftérica em células Vero (células epiteliais de rim de macaco verde africano, Cercopithecus aethiops). As células foram mantidas em meio DMEM - "Dulbecco Modified Eagle Medium" (Sigma, USA) suplementado com 10\% de soro fetal bovino (Gibco, Invitrogen Corporation, Grand Island, NY, Estados Unidos), $5 \mathrm{mM}$ de L-glutamina (Gibco) e $100 \mu \mathrm{g} / \mathrm{mL}$ antibiótico e antimicótico (Antibiotic-Antimycotic $100 \mathrm{X}$ - Gibco) a $37{ }^{\circ} \mathrm{C}$, em atmosfera contendo $5 \%$ de $\mathrm{CO}_{2}$. Repiques das culturas foram realizados sempre que as células atingiam $80 \%$ da confluência, através do tratamento com $10 \%$ de tripsina em PBS. No ensaio de soro neutralização (Mazzantini et al., 2004), foram analisados os soros dos camundongos imunizados com DT, DTP $_{\text {low }}$, PspA5, PspA5-DT e PspA5-DTP low $_{\text {Os }}$ Soros foram adicionados em placas de cultura de células de 96 poços (Costar, Corning Incorporated, Corning, NY, Estados Unidos) em diluição seriada de 1:2, a partir de 1:8. Além dos soros experimentais, foi utilizado o soro anti-diftérico padrão produzido pela Divisão de Desenvolvimento Científico e Tecnológico do Instituto Butantan. Os soros foram incubados com $0,006 \mathrm{LF} / \mathrm{mL}$ de toxina diftérica (concentração que corresponde a duas vezes a DL50, determinada pela toxicidade em células Vero, por meio de curva de titulação) por $1 \mathrm{~h}$. Em seguida, foram adicionadas $1,5 \times 10^{4}$ células Vero por poço e a placa foi mantida por $96 \mathrm{~h}$ em estufa a $37{ }^{\circ} \mathrm{C}$, em atmosfera de $5 \% \mathrm{CO}_{2}$. As placas foram lavadas com PBS, fixadas e coradas com solução de $20 \%$ (v/v) de formaldeído e $1 \%(\mathrm{v} / \mathrm{v})$ de cristal violeta e novamente lavadas com PBS. As placas foram secas e fotografadas. O corante fixado foi coletado pela adição de $200 \mu \mathrm{L}$ de etanol $100 \%$ (v/v) aos poços, para leitura em leitor de ELISA (Uniscience do Brasil, São Paulo, SP, Brasil) a 595 nm. 


\subsection{Análise da indução de anticorpos anti- PspA5, anti-antígenos de Bordetella pertussis, anti-toxoide tetânico e anti-toxoide diftérico.}

Para verificar os níveis de anticorpos em amostras de BALF e nos soros dos animais utilizou-se o método de ELISA. Placas de poliestireno de 96 poços (Maxisorp-Nunc, Rochester, NY, Estados Unidos) foram sensibilizadas por 18 h a $4{ }^{\circ} \mathrm{C}$ com $10 \mu \mathrm{g} / \mathrm{mL}$ da proteína recombinante PspA5 ou a mesma concentração da vacina acelular pertussis (cedida pela Divisão de Desenvolvimento Tecnológico e Produção do Instituto Butantan, que contém proteínas da bactéria secretados para o meio durante o cultivo), da anatoxina diftérica ou do toxoide tetânico provenientes do Instituto Butantan, diluídas em tampão carbonato bicarbonato. Como referência, foram utilizadas curvas padrão de $\operatorname{IgG}, \operatorname{IgG} 1$, IgG2a ou $\operatorname{IgA}$ (Southern Biotech, Birmingham, AL, Estados Unidos), de acordo com cada experimento e com a amostra a ser analisada. As placas foram lavadas por 3 vezes com PBS-T e bloqueadas com uma solução de $10 \%$ de leite desnatado em PBS-T. Após incubação por $1 \mathrm{~h}$, as placas foram novamente lavadas e as amostras de soro, lavados nasais ou BALF foram diluídas seriadamente em PBS-T contendo 1\% de BSA. As placas foram incubadas por $1 \mathrm{~h}$ e $30 \mathrm{~min}$ em estufa a $37{ }^{\circ} \mathrm{C}$. Posteriormente as placas foram novamente lavadas e incubadas com anticorpos anti-IgG, anti-IgG1, anti-IgG2a ou anti $\operatorname{IgA}$ de camundongo produzido em cabras (Southern Biotech), por $1 \mathrm{~h}$ a $37{ }^{\circ} \mathrm{C}$. Após lavagens, adicionou-se um anticorpo anti-IgG de cabras conjugado a peroxidase (Southern Biotech) e a reação foi revelada pela adição de solução de 10 mg de o-phenilenediamina (OPD, Sigma Aldrich) em $20 \mathrm{~mL}$ de tampão citrato fosfato, contendo $10 \mu \mathrm{L}$ de água oxigenada. A reação foi parada pela adição de $50 \mu \mathrm{L}$ de $\mathrm{H}_{2} \mathrm{SO}_{4} 4 \mathrm{M}$ por poço. As placas foram lidas em leitor de ELISA (Uniscience) a $492 \mathrm{~nm}$. A determinação da concentração dos anticorpos foi realizada com base nas curvas de concentração aplicadas nas placas. 


\subsection{Análise da reatividade dos soros dos animais imunizados contra PspAs de diferentes clados e contra antígenos de $B$. pertussis}

Foram realizados ensaios de Western Blot para verificar a reatividade do soro dos animais imunizados com PspA5 ou PspA5-wP por via nasal com extratos obtidos de diferentes sorotipos de S. pneumoniae. Para isso, os isolados ATCC6303 (sorotipo 3, PspA5), 0603 (sorotipo 6B, PspA1), 2139 (sorotipo 6A, PspA2) e TIGR4 (sorotipo 4, PspA3) foram crescidos em meio THY até chegar a $\mathrm{DO}_{600}=0,5$. A seguir, o cultivo foi centrifugado a $1500 \mathrm{~g}$ por $10 \mathrm{~min}$, as bactérias foram lavadas com $1 \mathrm{~mL}$ de PBS e novamente centrifugadas a $1500 \mathrm{~g}$ por $10 \mathrm{~min}$. As bactérias foram lisadas em tampão de lise para S. pneumoniae por $10 \mathrm{~min}$ a 37 ${ }^{\circ} \mathrm{C}$ e as amostras foram centrifugadas a $16000 \mathrm{~g}$ por $10 \mathrm{~min}$. Os sobrenadantes contendo os extratos proteicos foram mantidos a $-20^{\circ} \mathrm{C}$ até o uso. Para reatividade contra antígenos de $B$. pertussis, foi utilizada a vacina acelular pertussis (descrita no item 3.6). Neste caso, foram testados os soros dos animais imunizados com wP, wP $\mathrm{P}_{\text {low }}, \mathrm{PspA5}$, PspA5-wP, PspA5-wP $\mathrm{P}_{\text {low }} \mathrm{e}$ não imunizados como controle. Os extratos dos pneumococos ou a vacina acelular pertussis foram submetidos à eletroforese em gel de SDS-PAGE 10\%. Foram utilizados $15 \mu \mathrm{g}$ de extratos dos pneumococos e $4 \mu \mathrm{g}$ da vacina acelular pertussis. Após separação, as proteínas foram transferidas para uma membrana de nitrocelulose. A membrana foi incubada com solução de bloqueio (10\% de leite desnatado em PBS-T) por $1 \mathrm{~h}$ e, em seguida, foram adicionadas soluções de $2 \%$ leite em PBS-T contendo os soros dos animais imunizados, nas diluições 1:500. Após 3 lavagens de 10 min com PBS-T, adicionou-se anticorpo anti- IgG de camundongo conjugado a peroxidase (Southern Biotech). A reação foi revelada por quemiluminescência utilizando o kit ECL Plus (GE Healthcare), de acordo com as instruções do fabricante. 


\subsection{Análise de linfócitos em lavados broqueoalveolares (BALFs) de camundongos BALB/c imunizados}

Para a análise de linfócitos infiltrados no pulmão dos camundongos coletou-se os BALFs dos camundongos imunizados com as diferentes formulações, administradas pela via nasal ou pela via subcutânea. As coletas dos BALFs foram feitas 20 dias após a última imunização ou em diferentes períodos após o desafio respiratório com a linhagem ATCC6303, de acordo com cada experimento. As amostras foram centrifugadas por $10 \mathrm{~min}$ a $100 \mathrm{~g}$ e os sobrenadantes foram armazenados a $-80{ }^{\circ} \mathrm{C}$ para posterior dosagem de anticorpos. As células contidas no sedimento foram suspensas em $300 \mu \mathrm{L}$ de tampão de lise de eritrócitos e incubadas por 3 min a temperatura ambiente. A lise foi parada pela adição de $700 \mu \mathrm{L}$ de PBS e as células foram coletadas por centrifugação (100 g por $10 \mathrm{~min}$ ). As células totais presentes no BALF foram contadas em câmara de Newbauer, com o auxílio de um microscópio. Suspensões de $10^{6}$ células em $100 \mu \mathrm{L}$ de PBS-1\% BSA foram incubadas por 30 min, no gelo e no escuro, com os anticorpos monoclonais anti-CD4 conjugado a APC (clone RM4-5), anti-CD8 conjugado a PerCP (clone CD8a 53-67) e anti-B220, conjugado a PE (clone RA3-6B2) (BD Biosciences, San Jose, CA Estados Unidos ) na diluição 1:100 (v/v). As células foram lavadas por 2 vezes com $1 \mathrm{~mL}$ de PBS e fixadas em $200 \mu \mathrm{L}$ da solução BD Citofix $^{\mathrm{TM}}$ (BD Biosciences). As análises de citometria de fluxo foram feitas em aparelho FACS Canto II (BD Biosciences), com contagem de 10000 linfócitos e os dados foram analisados utilizando o programa Flow Jo 7.6.1 (Tree Star, Ashland, OR, Estados Unidos). 


\subsection{Análise da ligação de anticorpos à superfície de $S$. pneumoniae}

A capacidade da ligação dos anticorpos, presentes no BALF de camundongos BALB/c imunizados por via nasal, à superfície do pneumococo foi analisada in vitro. As bactérias da linhagem ATCC6303 ou os mutantes ATCC6303 ${ }^{\text {PspA- }}$, ATCC6303 ${ }^{\text {PspC- }}$ ou ATCC6303 ${ }^{\text {PspA- }}$ /PspC- foram cultivadas em meio THY a $37{ }^{\circ} \mathrm{C}$ até a $\mathrm{DO}_{600}=0,5$, centrifugadas a $3200 \mathrm{~g}$ por 10 min e lavadas com o mesmo volume de PBS. As bactérias foram suspensas no mesmo volume de PBS e $90 \mu \mathrm{L}$ desta suspensão foram incubados com $10 \mu \mathrm{L}$ (para avaliação da ligação de IgG ou $\operatorname{IgA}$ ) ou $50 \mu \mathrm{L}$ (para avaliação da ligação de IgG1 ou IgG2a) dos BALFs dos camundongos imunizados (reunidos em pools de cada grupo), por $30 \mathrm{~min}$ a $37{ }^{\circ} \mathrm{C}$. Em seguida, as bactérias foram lavadas com PBS e suspensas em $100 \mu \mathrm{L}$ de PBS contendo antiIgG, anti-IgA, anti-IgG1 ou anti-IgG2a de camundongos conjugados a FITC (MP Biochemicals, Irvine, CA, Estados Unidos), todos na diluição de 1:100 (v/v). As amostras foram incubadas no gelo e no escuro por $30 \mathrm{~min}$, lavadas com PBS e as bactérias foram fixadas com $200 \mu \mathrm{l}$ da solução BD Cytofix ${ }^{\mathrm{TM}}$ (BD Biosciences). As análises de citometria de fluxo foram feitas em aparelho FACS Canto II (BD Biosciences), com a contagem de 10000 bactérias os dados foram analisados utilizando o programa Flow Jo 7.6.1 (Tree Star).

\subsection{Análise da deposição do componente $\mathrm{C3}$ do complemento à superfície de $S$. pneumoniae}

Para a análise da ligação do componente C3 do sistema complemento à superfície de S. pneumoniae, bactérias da linhagem ATCC6303 foram cultivadas, lavadas e suspensas em PBS conforme descrito para o ensaio de ligação. As amostras de BALF foram aquecidas a 56 ${ }^{\circ} \mathrm{C}$ por 30 min, para a inativação das proteínas do sistema complemento. As bactérias foram incubadas com $50 \mu \mathrm{L}$ dos BALFs (reunidos em pools de cada grupo) a $37{ }^{\circ} \mathrm{C}$ por $30 \mathrm{~min}$ e lavadas com PBS conforme descrito anteriormente. As bactérias foram suspensas em $90 \mu \mathrm{L}$ tampão gelatina veronal (Sigma) contendo $10 \mu \mathrm{L}$ de soro normal de camundongo (utilizado como fonte de complemento) e incubadas a $37{ }^{\circ} \mathrm{C}$ por $30 \mathrm{~min}$. Em seguida, foi realizada uma lavagem com PBS e as bactérias foram incubadas por $30 \mathrm{~min}$ com uma diluição de 1:100 de anti-C3 FITC (MP Biochemicals) em PBS em gelo e no escuro. As bactérias foram lavadas e 
fixadas conforme descrito para o ensaio de ligação. A leitura e as análises foram feitas conforme descrito no item anterior.

\section{12 Análises estatísticas}

Para a avaliação da diferença de infiltrados celulares nos pulmões dos animais foi utilizado o teste estatístico One-way Anova, seguido pelo teste de Tukey para comparação entre os grupos. As diferenças em concentrações de anticorpos e em contagem de bactérias recuperadas da nasofaringe foram analisadas pelo teste estatístico de Mann-Whitney. As diferenças em sobrevivência foram analisadas pelo teste estatístico de Fisher. Em todos os casos foram considerados significativos valores de $\mathrm{P} \leq 0,05$. 


\section{RESULTADOS}

\subsection{Purificação da proteína PspA5}

A região N-terminal da proteína PspA5 foi expressa em fusão com a cauda de histidina proveniente do vetor pAE e purificada por cromatografia de afinidade em coluna carregada com níquel. Após a purificação, as lavagens e as eluições obtidas foram analisadas por SDS PAGE (10\%).

Figura 3- Purificação de PspA5.

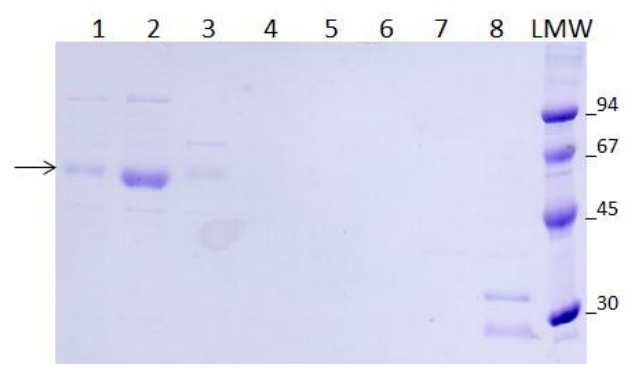

SDS-PAGE das amostras obtidas após a purificação Canaletas 1, 2, 3 e 4 lavagens com 5, 20, 40,e $60 \mathrm{mM}$ de imidazol respectivamente; canaletas 5, 6, 7 e 8 frações obtidas após eluição com $500 \mathrm{mM}$ de imidazol. Padrão de peso molecular LMW em kDa (GE Healthcare). A seta indica a banda de PspA5.

Fonte: Lima (2012)

Observa-se no gel (Figura 3) que a proteína PspA5 foi obtida apenas nas lavagens de 5, 20 e 40 mM (canaletas 1, 2 e 3) com maior concentração em 20 mM. Como o PspA5 obtido apresentou poucas impurezas, estas amostras foram reunidas e dialisadas em solução de diálise, e posteriormente quantificadas por método de coloração de BradFord, que permitiu verificar o rendimento de $40 \mathrm{mg}$ por litro de cultivo. A massa molecular predita para o fragmento N-terminal de PspA5 é de aproximadamente $45 \mathrm{kDa}$. Entretanto, a banda correspondente à proteína é observada entre as bandas de 45 e $67 \mathrm{kDa}$ do padrão de massa molecular. A migração anômala de PspA em gel de SDS-PAGE, já foi descrita na literatura para diferentes variantes da proteína (Yother e Briles, 1992). 


\subsection{Avaliação das formulações vacinais inoculadas em camundongos por via nasal}

\section{$\underline{\text { 4.2.1 Imunização de camundongos BALB/c e desafio letal com S. pneumoniae }}$}

Camundongos $\mathrm{BALB} / \mathrm{c}$ foram imunizados por via nasal, conforme descrito em materiais e métodos, para a avaliação do potencial adjuvante da vacina ${ }_{w} \mathrm{P}$ e ${ } \mathrm{wP}_{\text {low }}$ em combinação com PspA5. A Figura 4 mostra o resultado do ELISA das amostras de soros, testadas contra o antígeno PspA5.

Figura 4 - Concentrações de anticorpos anti-PspA5 nos soros de camundongos BALB/c imunizados por via nasal com as diferentes formulações.

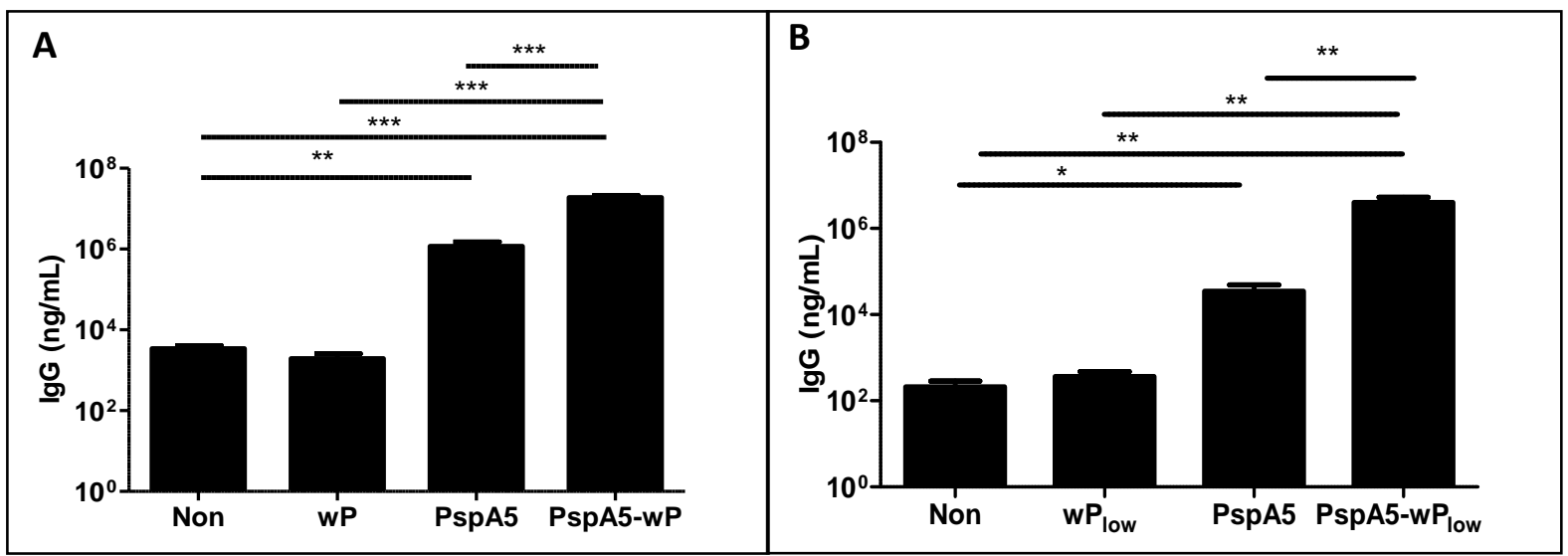

(A) vacina $\mathrm{wP}$ como adjuvante $\mathrm{e}(\mathbf{B})$ vacina $\mathrm{wP}_{\text {low }}$ como adjuvante. As barras representam as médias de 6 animais por grupo com os desvios padrão. Non $=$ soros provenientes de camundongos não imunizados. Os asteriscos apontam para os valores estatisticamente diferentes (em A ** $\mathrm{P}=0,002$; *** $\mathrm{P}<0,001$ e em $\mathrm{B} * \mathrm{P}=0,01 ; * * \mathrm{P}<0,01$; teste de Mann Whitney).

Fonte: Lima (2012)

É possível verificar que os camundongos que receberam PspA5, PspA5-wP ou PspA5${ }_{w} \mathrm{P}_{\text {low }}$ apresentaram maior concentração de anticorpos, sendo os dados estatisticamente diferentes das concentrações observadas nos demais grupos. Os valores de $\mathrm{P}$ estão apresentados na legenda da Figura 4. Além disso, quando são comparados os animais que receberam PspA5 com os animais que receberam PspA5-wP (Figura 4A) ou PspA5-wP $P_{\text {low }}$ (Figura 4B) observa-se indução significativamente maior de anticorpos anti-PspA5, nos animais imunizados com as combinações. 
O potencial protetor das formulações vacinais contra o desafio respiratório letal com a linhagem ATCC6303 foi avaliado nos camundongos BALB/c e o resultado está representado nas tabelas 1 e 2.

Tabela 1 - Sobrevivência de animais imunizados por via nasal após o desafio letal com a linhagem ATCC6303 (sorotipo 3, PspA5), utilizando a vacina wP como adjuvante.

\begin{tabular}{lccc}
\hline & Vivos/total & Sobrevivência & $\boldsymbol{P}^{*}$ \\
\hline Non & $0 / 6$ & -- & -- \\
wP & $1 / 6$ & $16,6 \%$ & 1 \\
PspA5 & $3 / 6$ & $50 \%$ & 0,09 \\
PspA5-wP & $6 / 6$ & $100 \%$ & 0,001 \\
\hline
\end{tabular}

* Valores em relação ao grupo não imunizado (Non), pelo teste exato de Fisher. Resultados representativos de 2 experimentos independentes.

Fonte: Lima (2012)

Tabela 2 - Sobrevivência de animais imunizados por via nasal após o desafio letal com a linhagem ATCC6303 (sorotipo 3, PspA5), utilizando a vacina $\mathrm{wP}_{\text {low }}$ como adjuvante.

\begin{tabular}{lccc}
\hline & Vivos/total & Sobrevivência & $\boldsymbol{P}^{*}$ \\
\hline Non & $0 / 6$ & -- & -- \\
$\mathrm{wP}_{\text {low }}$ & $0 / 5$ & -- & -- \\
PspA5 & $3 / 6$ & $50 \%$ & 0,09 \\
PspA5-wP & $5 / 6$ & $83 \%$ & 0,01 \\
\hline
\end{tabular}

* Valores em relação ao grupo não imunizado (Non), pelo teste exato de Fisher. Resultados representativos de 2 experimentos independentes

Fonte: Lima (2012)

As tabelas 1 e 2 mostram que todos os animais não imunizados (Non) morreram após o desafio e que a inoculação dos adjuvantes $\mathrm{wP}$ ou $\mathrm{wP}_{\text {low }}$ não produziu nenhum efeito 
significativo na sobrevivência. Por outro lado, 50\% dos animais imunizados apenas com PspA5 sobreviveram ao desafio. As imunizações com ambas as combinações PspA5-wP e PspA5-wP $\mathrm{P}_{\text {low }}$ protegeram significativamente os animais, conferindo sobrevivência a $100 \%$ (no caso da vacina PspA5-wP, Tabela 1), e a 83\% (no caso da vacina PspA5-wP $\mathrm{P}_{\text {low, }}$ Tabela 2) dos camundongos.

4.2.2 Análise do papel do LPS de B. pertussis na proteção induzida pela combinação PspA5$\underline{w P}$

Nos ensaios anteriores foi possível observar que tanto a combinação PspA5-wP quanto PspA5- $\mathrm{wP}_{\text {low }}$ protegeram os animais contra o desafio respiratório letal. Para a análise do papel do LPS de $B$. pertussis na atividade adjuvante e na proteção induzida pela combinação PspA5-wP, decidiu-se avaliar o efeito da vacinação em camundongos C3H/HeJ. Essa linhagem possui uma mutação no gene tlr4 que codifica o receptor de LPS. Como controle, foi utilizada a linhagem parental $\mathrm{C} 3 \mathrm{H} / \mathrm{HePas}$. Os animais foram imunizados conforme descrito para os camundongos BALB/c.

Figura 5 - Concentrações de anticorpos anti-PspA5 nos soros de camundongos C3H/HePas e $\mathrm{C} 3 \mathrm{H} / \mathrm{HeJ}$ imunizados por via nasal

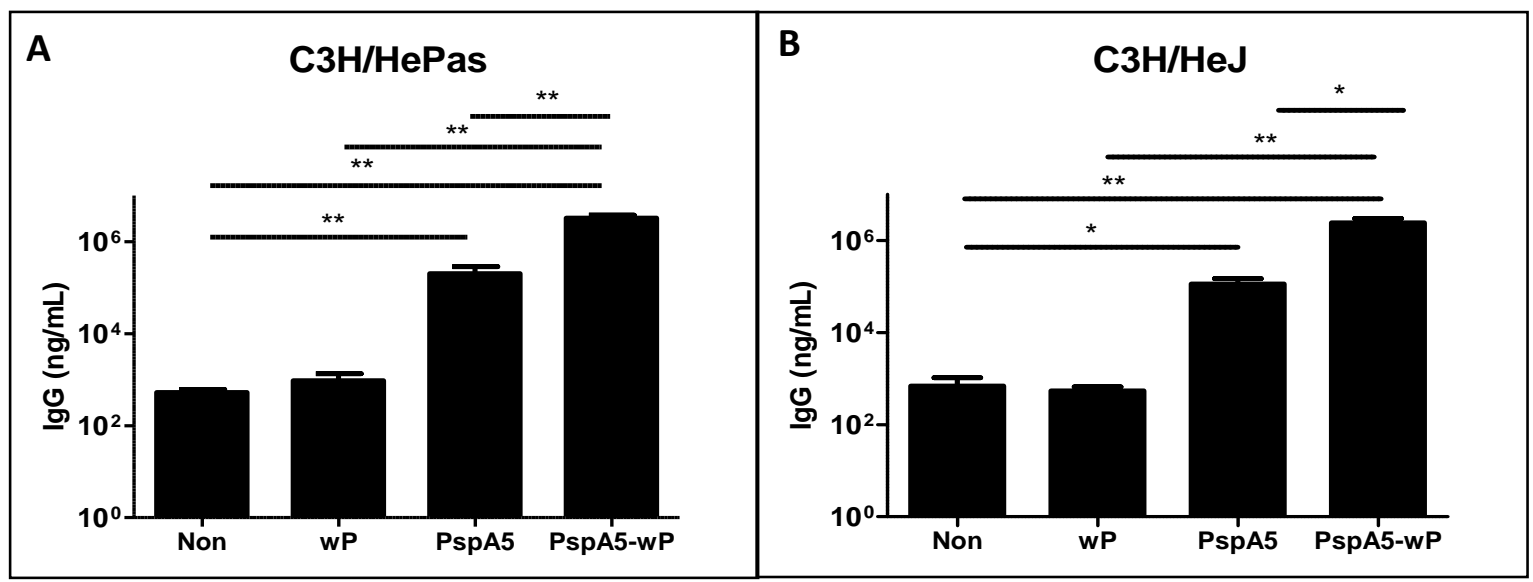

Camundongos $\mathrm{C} 3 \mathrm{H} / \mathrm{HePas}$ (A) e $\mathrm{C} 3 \mathrm{H} / \mathrm{HeJ}$ (B) imunizados por via nasal. As barras representam as médias de 5 animais por grupo com os desvios padrão. Non $=$ soros provenientes dos camundongos não imunizados. Os asteriscos apontam para os valores estatisticamente diferentes (Em A **P $=0,007$ e em B *P=0,01 e **P=0,007; teste de Mann Whitney).

Fonte: Lima (2012) 
A análise da indução de anticorpos, apresentada na Figura 5, demonstrou que camundongos $\mathrm{C} 3 \mathrm{H} / \mathrm{HePas}$ imunizados com PspA5-wP apresentaram elevadas concentrações de anticorpos anti-PspA5, que foram significativamente maiores quando comparadas ao observado para todos os outros grupos (valores de $\mathrm{P}$ anotados na legenda da Figura 5A). Da mesma forma, camundongos $\mathrm{C} 3 \mathrm{H} / \mathrm{HeJ}$ imunizados com PspA5-wP apresentaram concentrações de anticorpos significativamente maiores que as observadas nos outros grupos (Figura 5B, valores de $\mathrm{P}$ anotados na legenda da Figura). Os camundongos $\mathrm{C} 3 \mathrm{H} / \mathrm{HeJ}$ e $\mathrm{C} 3 \mathrm{H} / \mathrm{HePas}$ foram submetidos ao desafio letal com a linhagem ATCC6303 e os resultados estão apresentados na tabela 3.

Tabela 3 - Tabela 3: Sobrevivência de animais C3H/HePas e C3H/HeJ imunizados por via nasal após o desafio letal com a linhagem ATCC6303 (sorotipo 3, PspA5).

\begin{tabular}{lccc}
\hline C3H/HePas & Vivos/total & Sobrevivência & $\boldsymbol{P}^{*}$ \\
\hline Non & $1 / 9$ & $11,1 \%$ & -- \\
wP & $2 / 10$ & $20 \%$ & 0,54 \\
PspA5 & $4 / 10$ & $40 \%$ & 0,18 \\
PspA5-wP & $10 / 10$ & $100 \%$ & 0,0001 \\
C3H/HeJ & & & -- \\
Non & $0 / 9$ & -- & -- \\
wP & $0 / 10$ & -- & 0,054 \\
PspA5 & $4 / 10$ & $40 \%$ & 0,0001 \\
PspA5-wP & $9 / 10$ & $90 \%$ & \\
\hline
\end{tabular}

* Valores em relação ao grupo não imunizado (Non), pelo teste exato de Fisher.

Fonte: Lima (2012)

Os camundongos de ambas as linhagens, $\mathrm{C} 3 \mathrm{H} / \mathrm{HePas}$ e $\mathrm{C} 3 \mathrm{H} / \mathrm{HeJ}$, imunizados com PspA5-wP apresentaram um aumento significativo na sobrevivência em relação aos camundongos não imunizados (100\% e $90 \%$ de sobreviventes, respectivamente), conforme 
dados apresentados na Tabela 3. No geral, todos os grupos apresentaram sobrevivência semelhante ao observado para os camundongos BALB/c (Tabelas 1 e 2).

Para verificar se o LPS de $B$. pertussis apresenta atividade adjuvante na linhagem de camundongos $\mathrm{C} 3 \mathrm{H} / \mathrm{HeJ}$, foi realizado um ensaio de imunização com PspA5 em combinação com uma preparação de LPS derivada da linhagem vacinal wP.

Figura 6 - Concentrações de anticorpos anti-PspA5 nos soros de camundongos C3H/HeJ imunizados por via nasal.

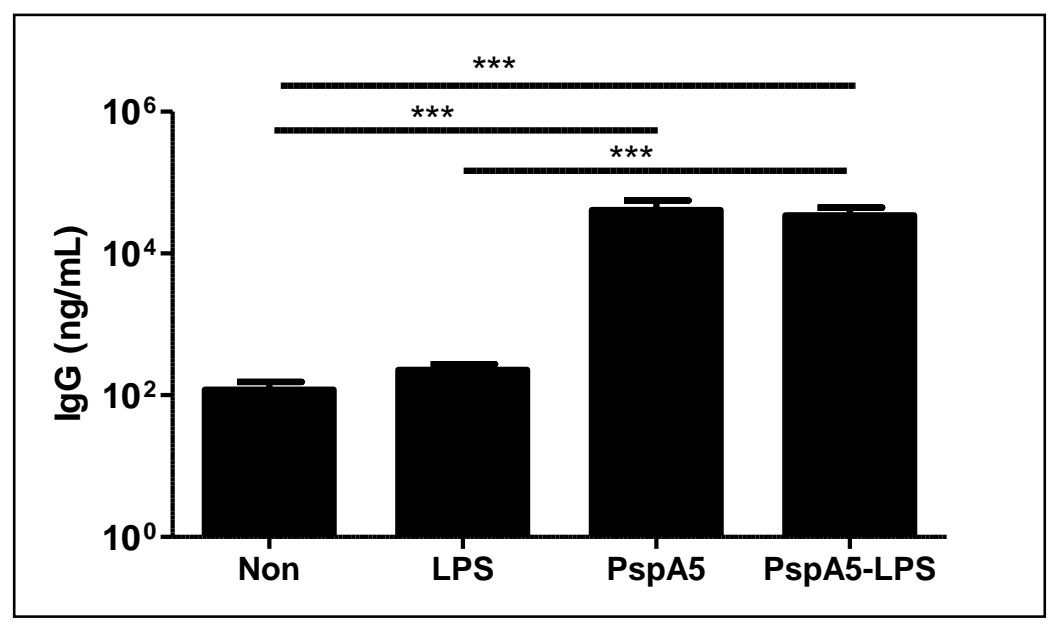

As barras representam as médias de 7 animais por grupo com os desvios padrão. Non $=$ soros provenientes de camundongos não imunizados. Os asteriscos apontam para os valores estatisticamente diferentes $(* * * \mathrm{P}=0,0006$; teste de Mann Whitney).

Fonte: Lima (2012)

A imunização com a combinação PspA5-LPS induziu concentrações semelhantes de IgG anti-PspA5 nos soros dos animais quando comparada à imunização com a proteína PspA5 sozinha (Figura 6). Em ambos os casos, foram observadas diferenças significativas em relação aos animais não imunizados (Non) e em relação aos animais inoculados com LPS. Os camundongos foram então desafiados com linhagem ATCC6303 e os resultados estão apresentados na tabela 4 . 
Tabela 4 - Sobrevivência de animais $\mathrm{C} 3 \mathrm{H} / \mathrm{HeJ}$ imunizados por via nasal após o desafio letal com a linhagem ATCC6303 (sorotipo 3, PspA5).

\begin{tabular}{lccc}
\hline & Vivos/total & Sobrevivência & $\boldsymbol{P}^{*}$ \\
\hline Non & $0 / 7$ & -- & -- \\
LPS & $0 / 7$ & -- & -- \\
PspA5 & $4 / 7$ & $57 \%$ & 0,03 \\
PspA5-LPS & $2 / 7$ & $28,5 \%$ & 0,23 \\
& & & \\
\hline & * Valores em relação ao grupo não imunizado (Non), pelo teste exato de Fisher.
\end{tabular}

A administração de PspA5 com LPS de B. pertussis não conferiu proteção significativa aos camundongos $\mathrm{C} 3 \mathrm{H} / \mathrm{HeJ}$, quando comparados aos camundongos não imunizados ou inoculados com LPS. Os animais imunizados com PspA5 apresentaram 57\% de sobrevivência, sendo este o único grupo significativamente diferente dos grupos controle (Tabela 4).

4.2.3 Análise dos anticorpos anti-PspA5 presentes nos BALF dos camundongos BALB/c $\underline{\text { imunizados antes do desafio }}$

A resposta imune na mucosa respiratória também foi avaliada nos camundongos

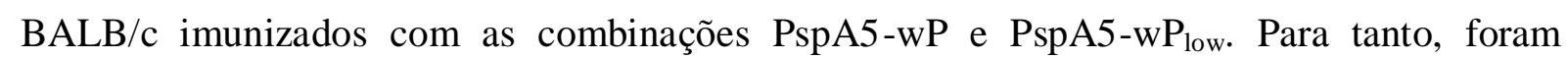
coletadas amostras de camundongos imunizados e não desafiados ou em diferentes períodos após o desafio. A Figura 7 apresenta a concentrações de IgG anti-PspA5 no BALF em animais imunizados. 
Figura 7 - Concentrações de anticorpos IgG anti-PspA5 nos BALFs de camundongos $\mathrm{BALB} / \mathrm{c}$ imunizados com as diferentes formulações.

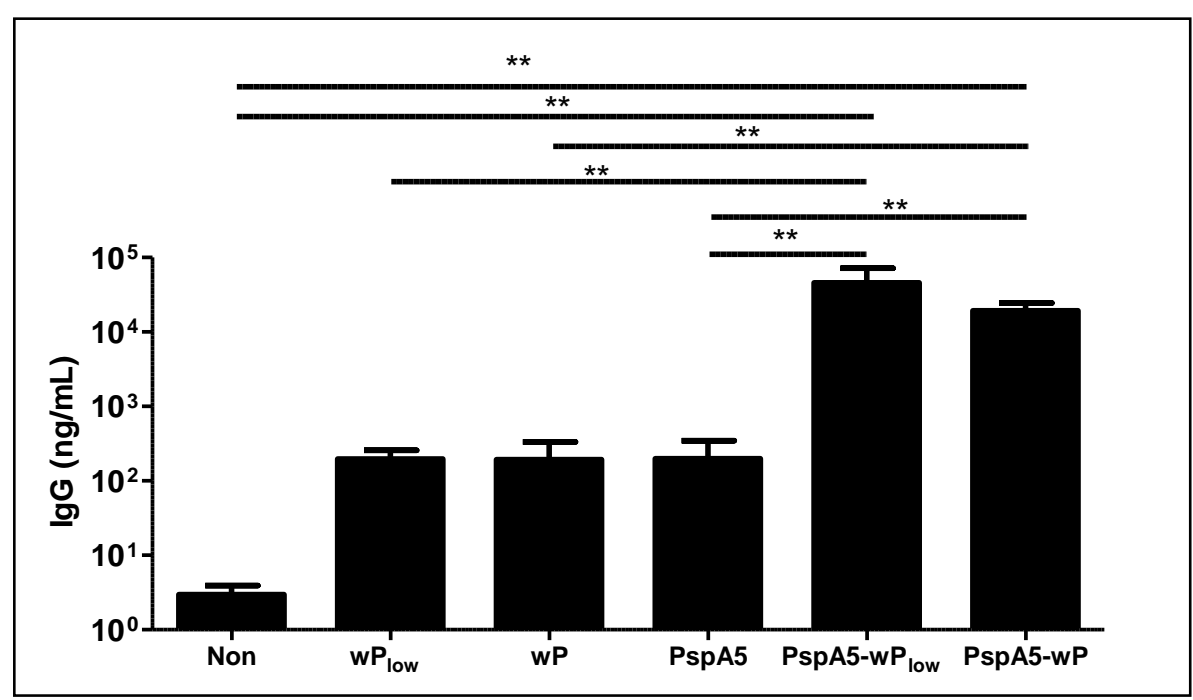

As barras representam as médias de 6 animais por grupo com os desvios padrão. Non $=$ BALFs provenientes de camundongos não imunizados. Os asteriscos apontam para os valores estatisticamente diferentes (** $\mathrm{P}=0,002$ para $\mathrm{PspA5}-\mathrm{wP}$ e $\mathrm{PspA5}-\mathrm{wP}_{\text {low }}$ em relação ao Non, e em relação à PspA5; **P=0,005 para PspA5-wP em comparação a wP ou para PspA5-wP $\mathrm{P}_{\text {low }}$ em comparação a $\mathrm{wP}_{\text {low }}$, teste de Mann Whitney).

Fonte: Lima (2012)

A análise demonstrou que houve aumento significativo nas concentrações de IgG antiPspA5 nos BALFs dos camundongos que receberam as combinações PspA5-wP e PspA5${ }_{w} \mathrm{P}_{\text {low }}$, em relação ao grupo não imunizado (Non), ao grupo que recebeu PspA5e em relação aos respectivos adjuvantes (valores de $\mathrm{P}$ anotados na legenda da Figura 7). A proteína sozinha não induziu concentrações mais elevadas de IgG anti-PspA5 em comparação aos controles. Para determinar as concentrações dos subtipos de IgG, IgG1 e IgG2a anti-PspA5 no BALF dos animais, foi realizado um ELISA com as amostras dos grupos vacinados com as combinações. 
Figura 8 - Concentrações de anticorpos IgG1 e IgG2a anti-PspA5 nos BALFs de camundongos $\mathrm{BALB} / \mathrm{c}$ imunizados com as diferentes formulações.

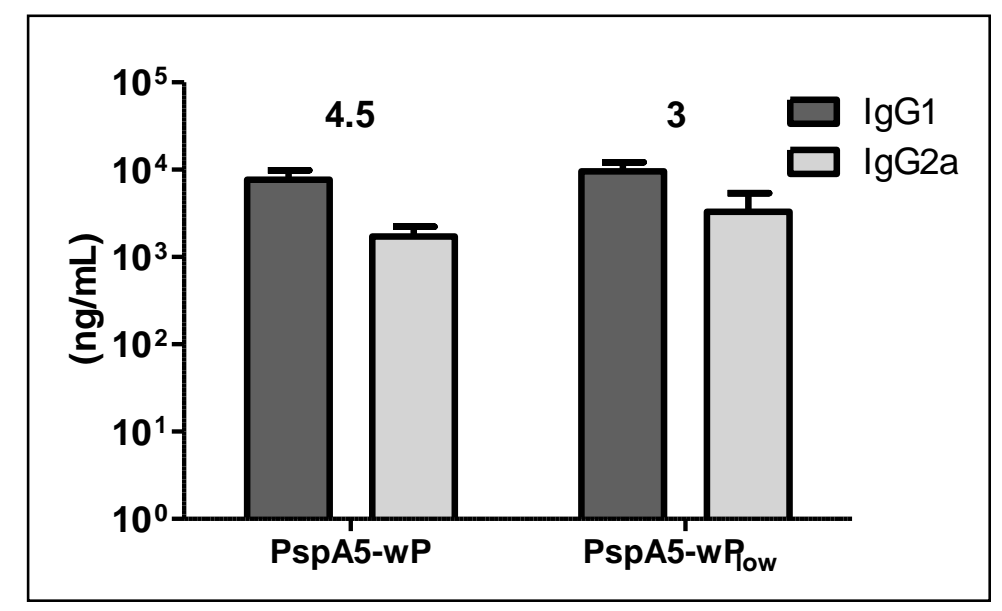

As barras representam as médias de 6 animais por grupocom os desvios padrão. $\mathrm{O}$ número acima das barras é o valor da razão $\operatorname{IgG} 1 / \operatorname{IgG} 2 \mathrm{a}$.

Fonte: Lima (2012)

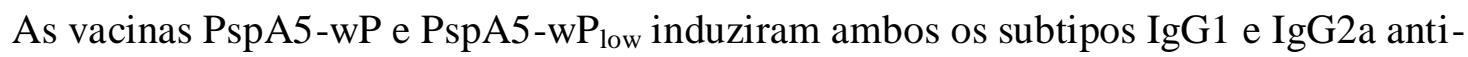
PspA5 nos BALFs dos camundongos (Figura 8), em concentrações semelhantes, resultando em um equilibrio nas respostas Th1 e Th 2. Não foi observada diferença significativa entre as duas combinações administradas. Além da detecção de IgG e dos subtipos IgG1 e IgG2a nos BALFs dos camundongos imunizados, foi realizado ELISA para determinar a concentração de IgA anti-PspA5, conforme mostrado na Figura 9. 
Figura 9 - Concentrações de anticorpos IgA anti-PspA5 nos BALFs de camundongos $\mathrm{BALB} / \mathrm{c}$ imunizados com as diferentes formulações.

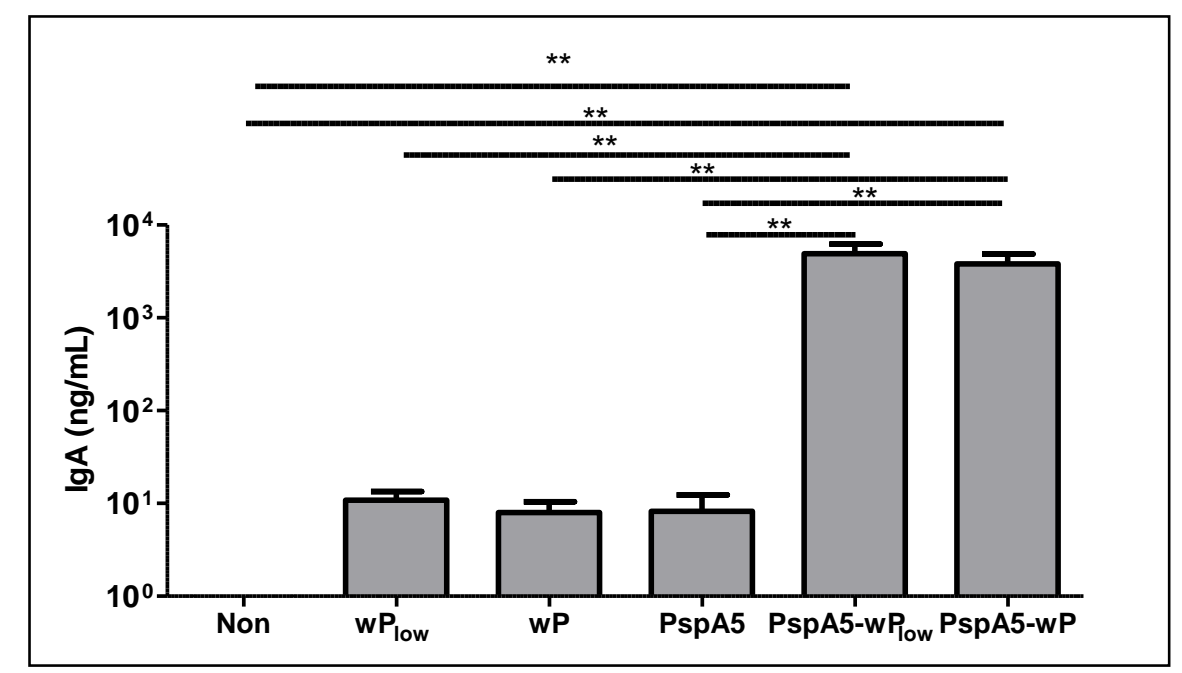

As barras representam as médias de 6 animais por grupo com os desvios padrão. Non = BALFs provenientes de camundongos não imunizados. Os asteriscos apontam para os valores estatisticamente diferentes $\left(* * \mathrm{P}=0,002\right.$ para $\mathrm{PspA} 5-\mathrm{wP}$ e $\mathrm{PspA5}-\mathrm{wP}_{\text {low }}$ em relação à Non e em relação à $\mathrm{PspA5}$; ** $\mathrm{P}=0,005$ para $\mathrm{PspA5}$-wP em relação à wP e ** $\mathrm{P}=0,004$ para $\mathrm{PspA} 5-\mathrm{wP}_{\text {low }}$ em relação à $\mathrm{wP}_{\text {low }}$, teste de Mann Whitney).

Fonte: Lima (2012)

As concentrações de IgA anti-PspA5 foram maiores nos BALFs de camundongos que receberam as combinações PspA5-wP ou PspA5-wP $\mathrm{P}_{\text {low }}$, sendo os valores significativamente maiores que os observados no grupo não imunizado, imunizado com PspA5 ou com os respectivos adjuvantes sozinhos (valores de $\mathrm{P}$ anotados na legenda da Figura 9). 
4.2.4 Análise da capacidade de ligação dos anticorpos presentes nos BALFs à superficie do pneumococo

Para verificar a funcionalidade dos anticorpos anti-PspA5 presentes nos BALFs, foram realizados ensaios de ligação à superfície de S. pneumoniae (linhagem ATCC6303 sorotipo 3, PspA5) in vitro.

Figura 10 - Ligação de IgA presente nos BALFs à superfície do pneumococo.

A
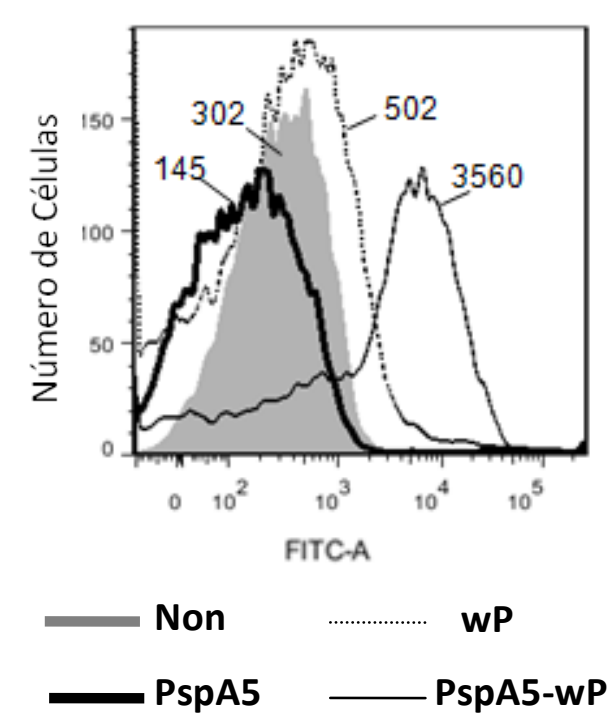

B

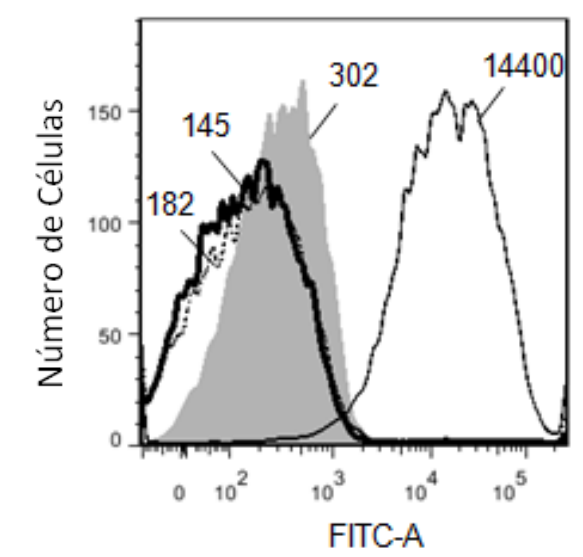

Non

$$
\text { WP } P_{\text {low }}
$$

PspA5-wPlow

A linhagem de S. pneumoniae ATCC6303 foi incubada com os BALFs dos camundongos imunizados com as diferentes formulações. As amostras foram posteriormente incubadas com anti-IgA de camundongo conjugado a FITC. Os resultados, analisados por citometria de fluxo estão representados em histogramas de intensidade de fluorescência. Non $=$ BALFs provenientes de camundongos não imunizados. As medianas das fluorescências obtidas estão indicadas em cada curva. Fonte: Lima (2012)

Foi possível observar maior capacidade de ligação do IgA presente no BALF de animais imunizados com PspA5-wP ou com PspA5-wP $\mathrm{P}_{\text {low }}$ à superfície do pneumococo, em relação ao IgA presente nos BALFs dos camundongos dos demais grupos (Figuras 10A e 10B). 
O mesmo ensaio foi realizado para avaliação da capacidade de ligação de IgG presente nos BALFs dos camundongos imunizados com as diferentes formulações (Figuras 11A e 11B).

Figura 11 - Ligação de IgG presente nos BALFs à superfície do pneumococo.

A
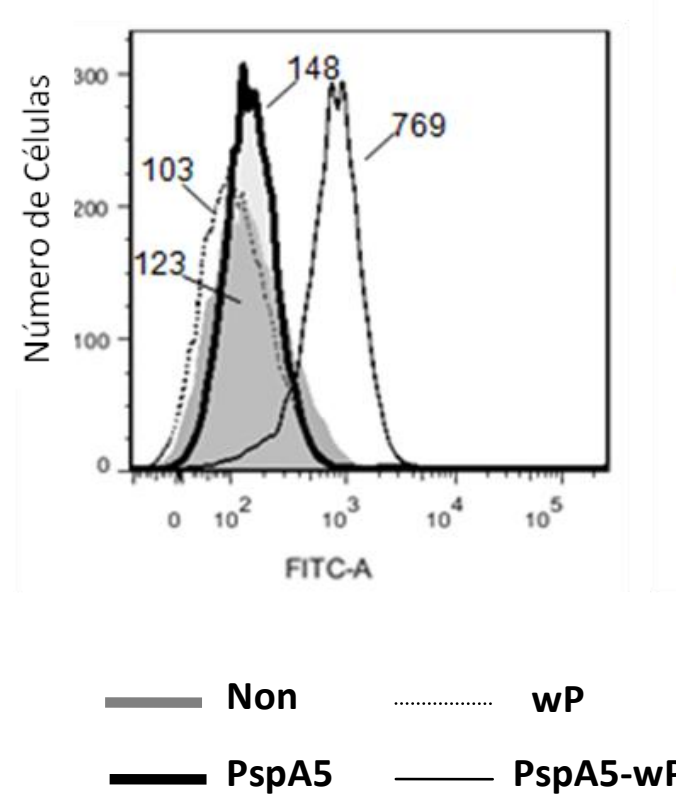

B
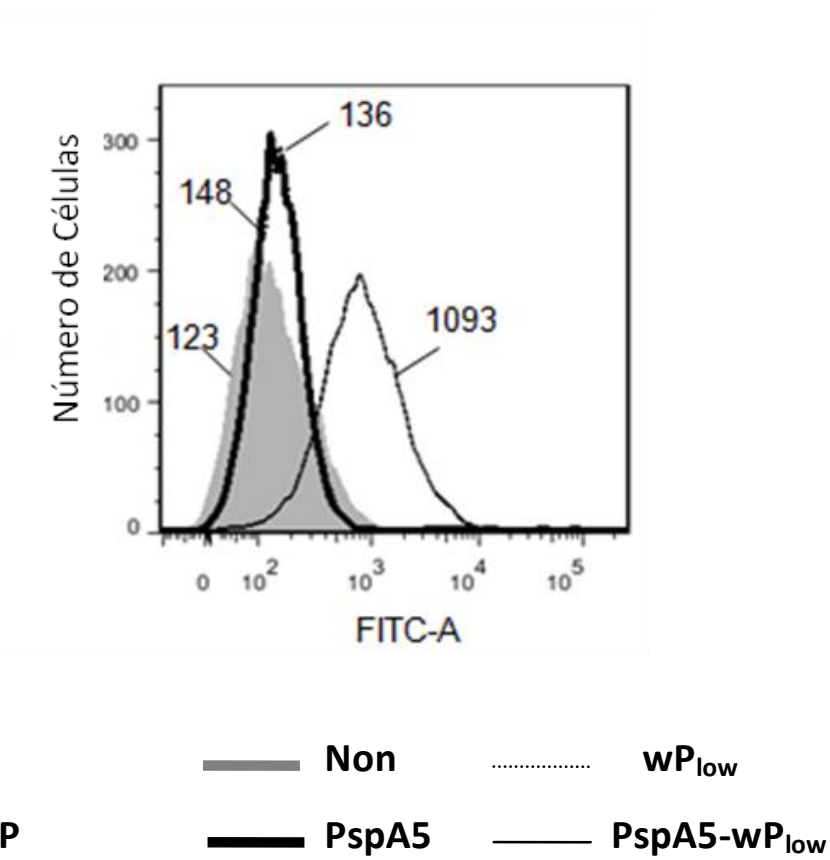

A linhagem de $S$. pneumoniae ATCC6303 foi incubada com os BALFs dos camundongos imunizados com as diferentes formulações. As amostras foram posteriormente incubadas com anti-IgG de camundongo conjugado a FITC. Os resultados, analisados por citometria de fluxo, estão representados em histogramas de intensidade de fluorescência. Non $=$ BALFs provenientes de camundongos não imunizados. As medianas das fluorescências obtidas estão indicadas em cada curva Fonte: Lima (2012).

A análise demonstrou maior capacidade de ligação da IgG presente nos BALFs coletados dos camundongos imunizados com PspA5-wP ou com PspA5-wP $\mathrm{P}_{\text {low }}$ à superfície do pneumococo (Figuras 11A e 11B). A seguir, foi avaliada a capacidade dos subtipos de IgG, IgG1 e IgG2a, presentes no B ALF, ligarem à bactéria in vitro. (Figuras 12 A-D). 
Figura 12 - Ligação de IgG1 e IgG2a presente nos BALFs à superfície do pneumococo.

A
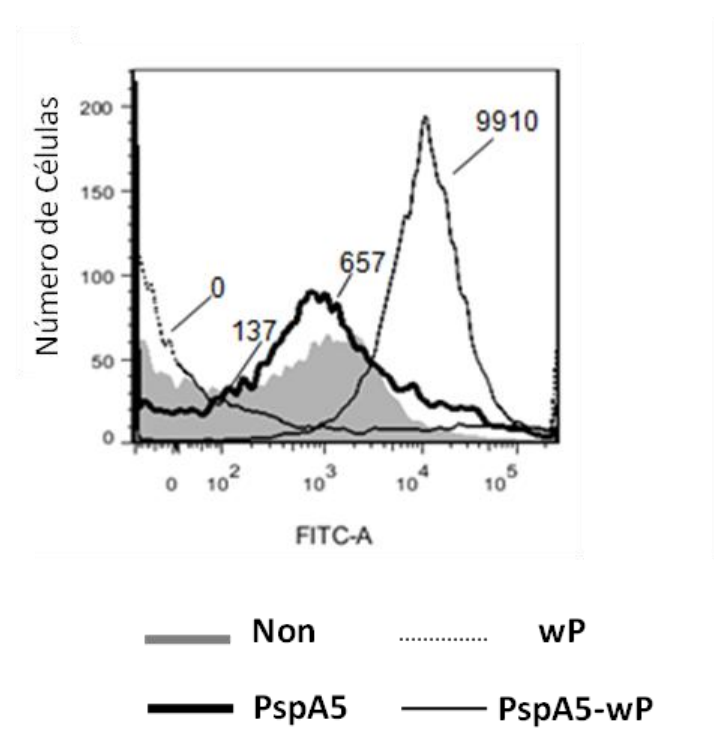

IgG1

B
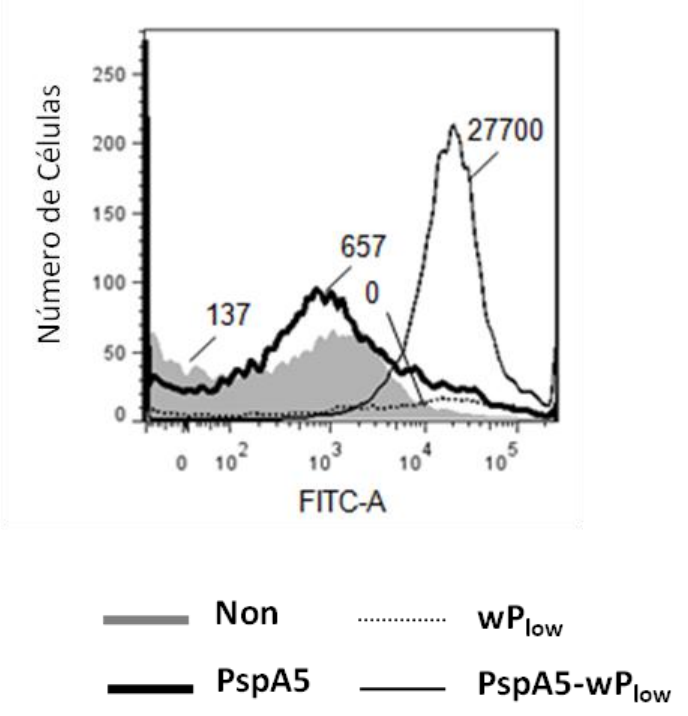

IgG2a

C

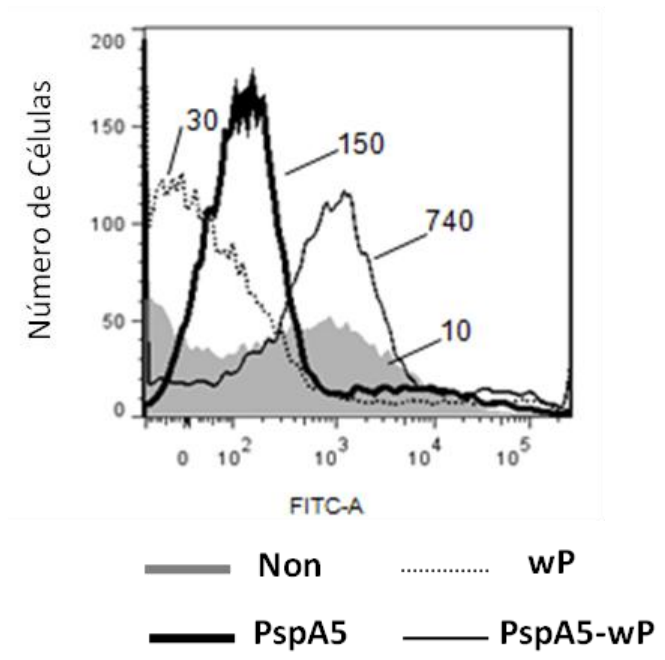

D

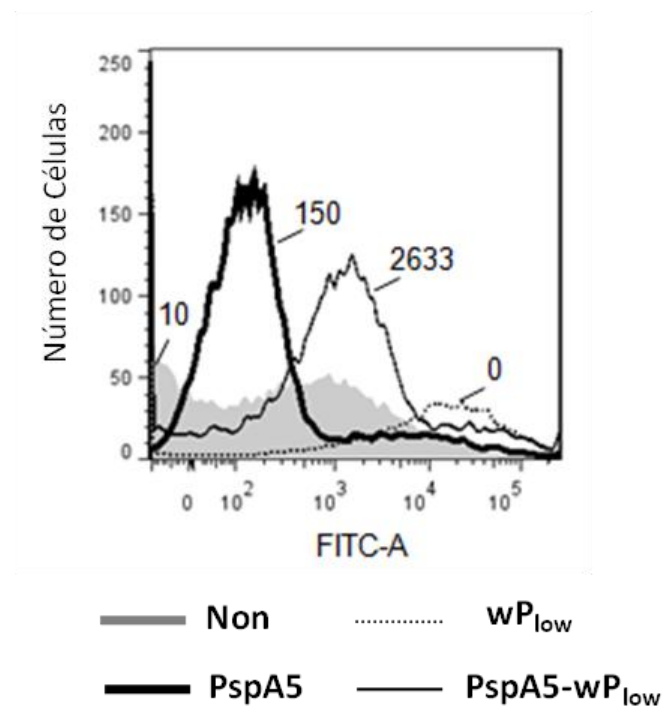

IgG1 (A e B) e IgG2a(C e D). A linhagem de S. pneumoniae ATCC6303 foi incubada com os BALFs dos camundongos imunizados com as diferentes formulações. As amostras foram posteriormente incubadas com anti-IgG1 ou anti-IgG2a de camundongo conjugado a FITC. Os resultados, analisados por citometria de fluxo, estão representados em histogramas de intensidade de fluorescência. Non = BALFs provenientes de camundongos não imunizados. As medianas das fluorescências obtidas estão indicadas em cada curva

Fonte: Lima (2012) 
Anticorpos IgG1 e IgG2a provenientes dos BALFs dos camundongos imunizados com PspA5-wP ou com PspA5-wP $\mathrm{P}_{\text {low }}$ apresentaram maior capacidade de ligação ao pneumococo comparados aos anticorpos provenientes dos camundongos não imunizados ou que receberam wP, $\mathrm{wP}_{\text {low }}$ ou PspA5 (Figura 12).

Para verificar a especificidade da ligação dos anticorpos presentes nos BALFs dos camundongos imunizados com PspA5-wP ou PspA5-wP $\mathrm{P}_{\text {low }}$ ao antígeno PspA presente na superfície do pneumococo, foram realizados ensaios de ligação utilizando mutantes da linhagem ATCC6303 com deleção nos genes que codificam as proteínas PspA e/ou PspC (Figuras 13). 
Figura 13 - Reatividade da IgA e IgG presente nos BALFs contra o antígeno PspA na superfície de pneumococo.

IgA

A

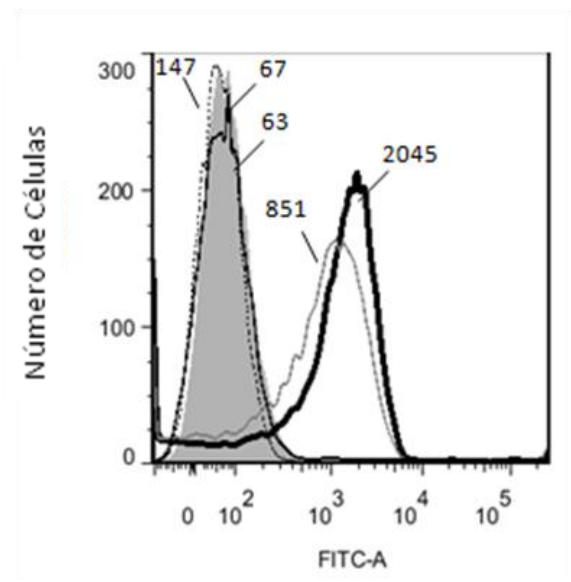

B

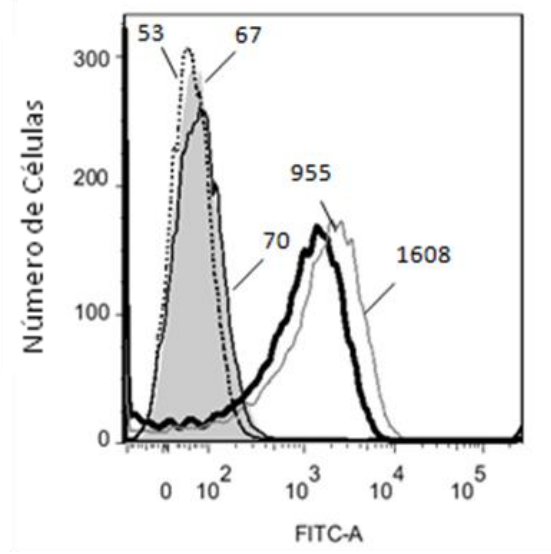

$\lg G$

\section{C}
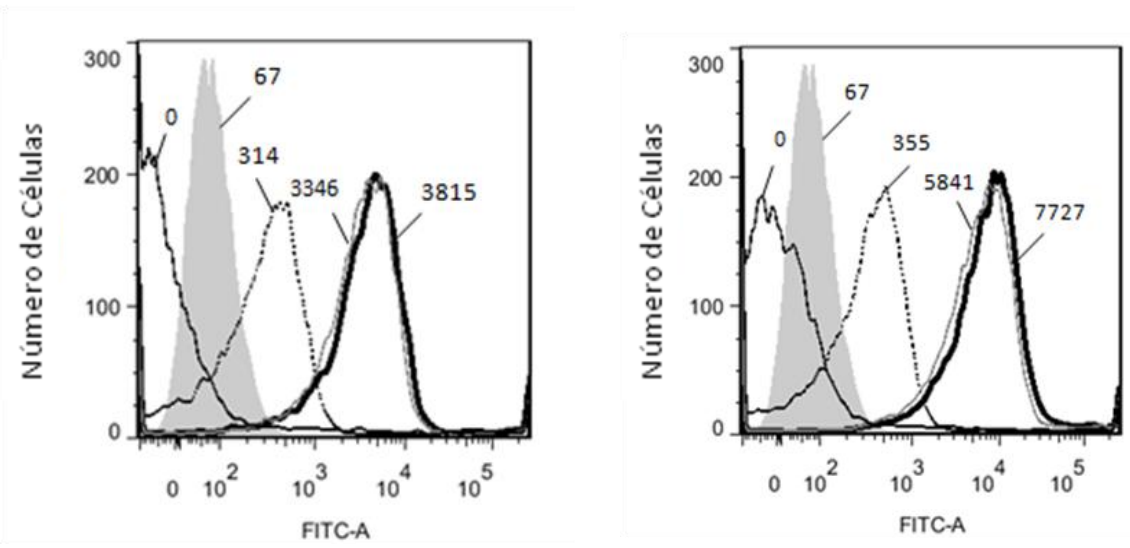

D

\begin{tabular}{|c|c|c|}
\hline & Bactéria & BALF \\
\hline- & 6303 & Non \\
\hline & 6303 & PspA5-wP ${ }_{\text {low }}$ \\
\hline ........ & $6303^{\text {PspA- }}$ & PspA5-wP $P_{\text {low }}$ \\
\hline & $6303^{\text {PspC- }}$ & PspA5-wP $P_{\text {low }}$ \\
\hline - & $6303^{\text {PspA-PspC- }}$ & PspA5-wP $P_{\text {low }}$ \\
\hline
\end{tabular}

IgA ( A e B) e $\operatorname{IgG}(\mathbf{C}$ e D). Os diferentes mutantes de pneumococo ou a linhagem selvagem ATCC6303 foram incubados com os BALFs de camundongos não imunizados ou imunizados com PspA5-wP (A e C) ou com PspA5-wP $P_{\text {low }}$ (B e D). As amostras foram incubadas posteriormente com anti-IgG de camundongo conjugado a FITC. Os resultados, analisados por citometria de fluxo, estão representados em histogramas de intensidade de fluorescência. As medianas das fluorescências obtidas estão indicadas em cada curva. Fonte: Lima (2012) 
O resultado mostra que a ausência de PspA nas bactérias $6303^{\text {PspA- }}$ e $6303^{\text {PspA-/PspC- }}$ abole completamente a ligação de IgA na superfície destas linhagens e as curvas apresentadas por estas bactérias são similares ao controle da linhagem ATCC6303 incubada com BALFs de animais não imunizados (controle negativo). Por outro lado, a ligação de IgA na superfície da bactéria $6303^{\text {PspC- }}$ foi mantida, sendo que esta bactéria apresentou curvas semelhantes às da linhagem ATCC6303 incubada com os BALFs dos animais imunizados com PspA5-wP ou PspA5-wP $\mathrm{P}_{\text {low }}$ (Figura 13 A e B). De forma similar ao observado para a ligação de $\operatorname{IgA}$, a ausência de PspA abole (no caso do mutante $6303^{\text {PspA-/PspC-}}$ ) ou diminui significativamente

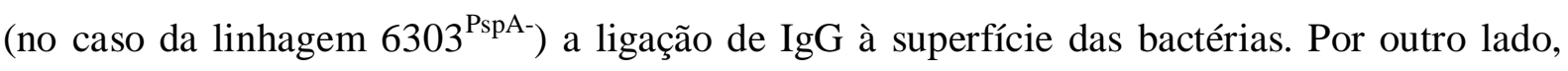
curvas similares ao controle positivo (linhagem selvagem ATCC6303 incubada com os BALFs dos animais imunizados com PspA5-wP ou PspA5-wP $\mathrm{P}_{\text {low }}$ ) foram observadas para a linhagem que não expressa PspC, $6303^{\text {PspC- }}$ (Figura 13 C e D).

\subsubsection{Avaliação da deposição do componente C3 do complemento à superfície de $S$.} pneumoniae, induzida por amostras de BALF

Anticorpos anti-PspA5 são capazes de induzir a deposição de complemento na superfície do pneumococo in vitro (Ren et al., 2004). As amostras dos BALFs foram também testadas quanto a esta propriedade, através da avaliação da deposição do componente C3 do sistema complemento na superfície da linhagem ATCC6303 (Figura 14). 
Figura 14 - Indução da deposição do componente C3 do complemento na superfície do pneumococo pelas amostras de BALF.

A
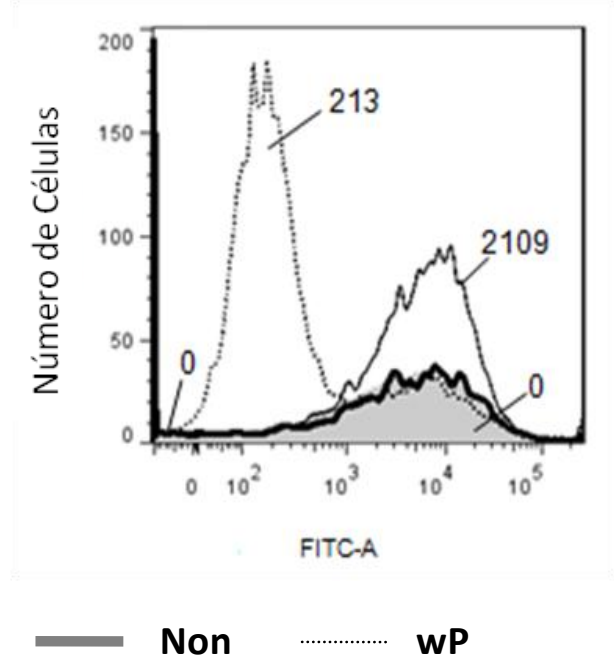

PspA5
B
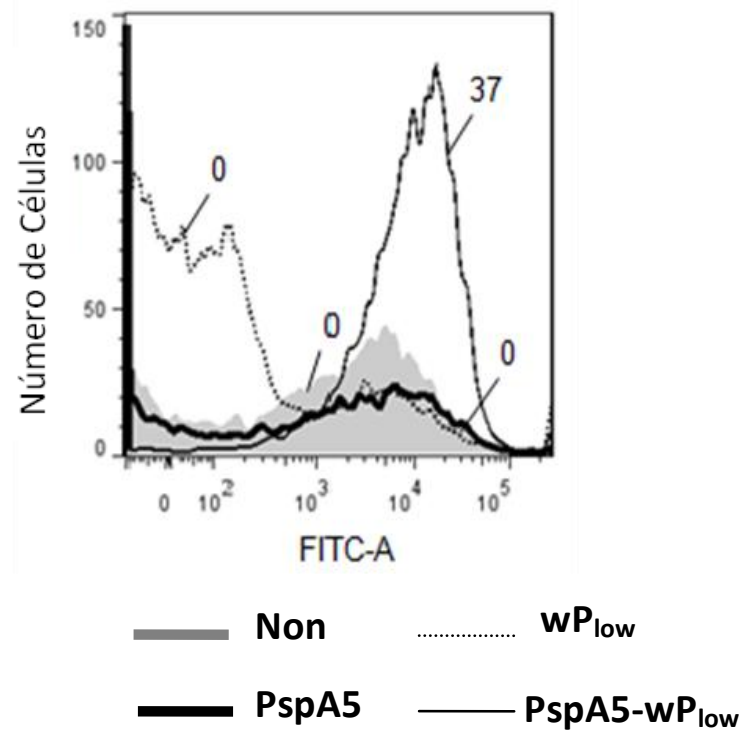

A linhagem ATCC6303 foi incubada com os BALFs dos camundongos imunizados com as diferentes formulações. Após incubação com fonte de complemento, as reações foram reveladas com anti-C3 de camundongo conjugado a FITC. Os resultados são representados em histogramas de intensidade de fluorescência. Non $=$ BALFs provenientes de camundongos não imunizados. As medianas das fluorescências obtidas estão indicadas em cada curva.

Fonte: Lima (2012)

As amostras de BALFs dos camundongos imunizados com PspA5-wP ou com PspA5${ } \mathrm{P}_{\text {low }}$ foram capazes de induzir maior deposição de complemento na superfície do pneumococo, in vitro, que as amostras de BALFs de camundongos não imunizados ou imunizados com wP, $\mathrm{wP}_{\text {low }}$ ou PspA5 (Figura 14A e 14B). 


\subsubsection{Análise dos linfócitos presentes nos BALFs antes do Desafio}

\subsubsection{ANÁLISE DOS LINFÓCITOS PRESENTES NOS B ALFS ANTES DO DESAFIO}

Os camundongos foram imunizados e 21 dias após a última dose, BALFs foram coletados para a quantificação do número total de células e de linfócitos, além da determinação de tipos linfócitos presentes, através de incubação com anticorpos específicos (Figuras 15 e 16).

Figura 15 - Contagem de células totais e linfócitos nos BALFs de camundongos BALB/c imunizados por via nasal com as diferentes combinações.

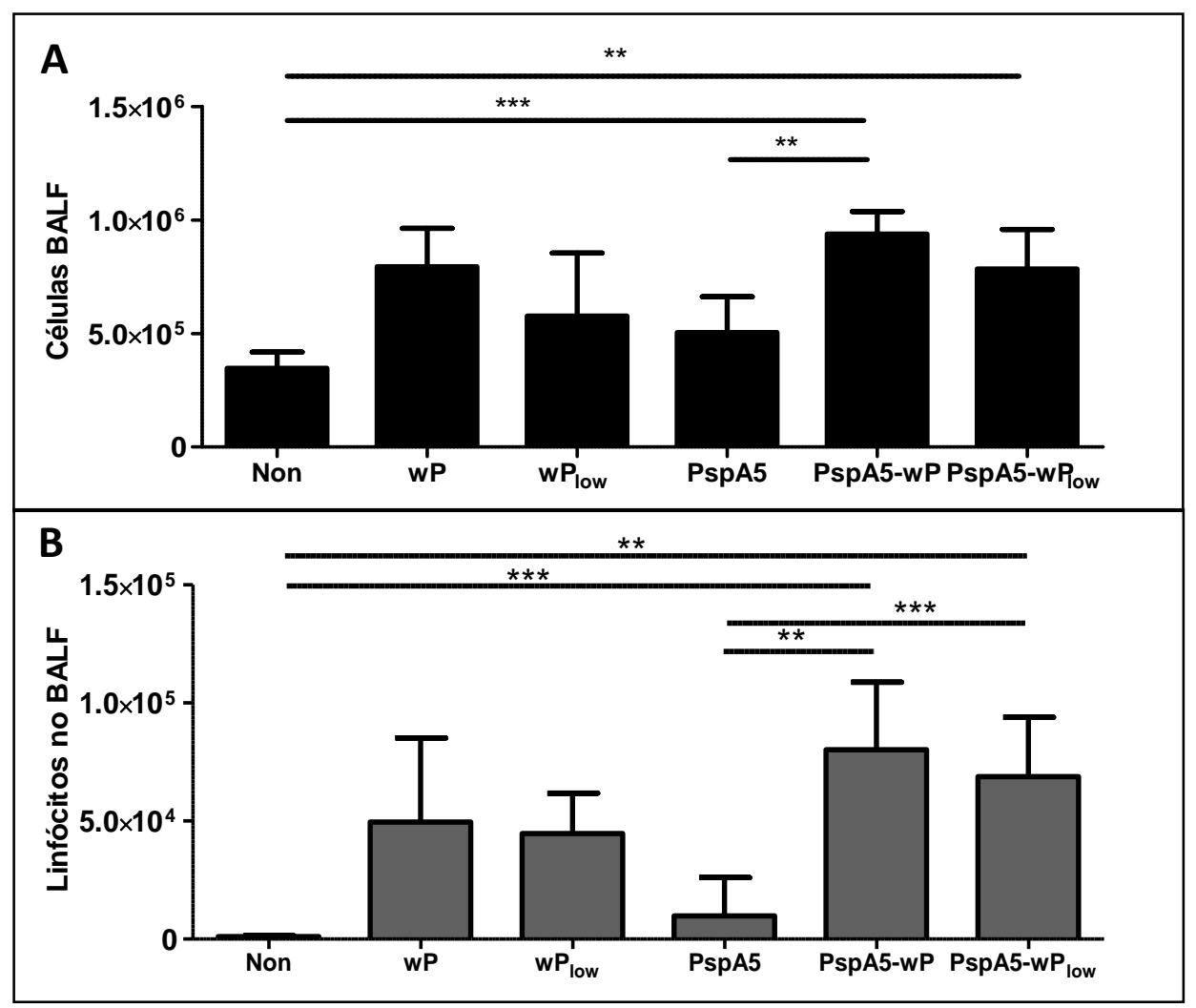

As barras representam as médias de 5 animais por grupo com os desvios padrão. Os asteriscos apontam para os valores estatisticamente diferentes $(* * \mathrm{P}<0,01, * * * \mathrm{P}<0,001$ teste de Tukey). Non = BALFs provenientes de camundongos não imunizados. (A) total de células e (B) total de linfócitos.

Fonte: Lima (2012) 
Camundongos imunizados com PspA5-wP ou PspA5-wP $\mathrm{P}_{\text {low }}$ apresentaram quantidades significativamente maiores de células totais e de linfócitos no BALF (Figura 15) com valores estatisticamente diferentes em relação ao grupo não imunizado e em relação ao grupo imunizado com PspA5, respectivamente (valores de P anotados na legenda da Figura 15). A seguir, foi feita a caracterização destes linfócitos, utilizando anticorpos específicos (Figura 16). 
Figura 16 - Caracterização dos linfócitos nos BALFs dos camundongos BALB/c imunizados por via nasal antes do desafio.

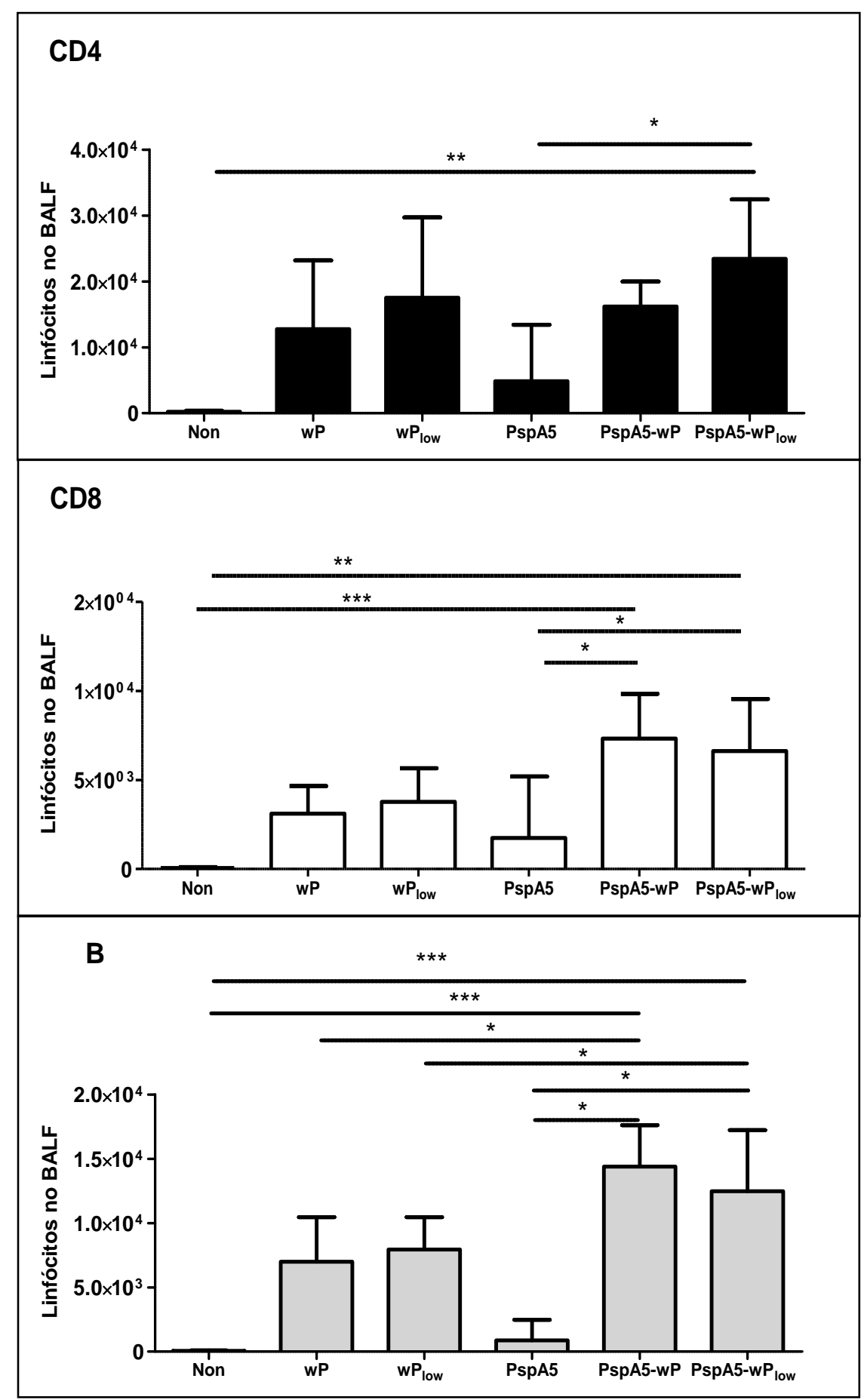

As barras representam as médias de 5 animais por grupo com os desvios padrão. Os asteriscos apontam para os valores estatisticamente diferentes $(* \mathrm{P}<0,05, * * \mathrm{P}<0,01$, $* * * \mathrm{P}<0,001$, teste de Tukey). Non $=\mathrm{BALFs}$ provenientes de camundongos não imunizados. Linfócitos T $\mathrm{CD}^{+}$(painel superior), linfócitos $\mathrm{T} \mathrm{CD}^{+}$(painel do meio) e linfócitos B (painel inferior).

Fonte: Lima (2012) 
Foi possível verificar aumento de linfócitos $\mathrm{T} \mathrm{CD}^{+}, \mathrm{T} \mathrm{CD}^{+}$e $\mathrm{B}$ em todos os grupos de animais que receberam $w \mathrm{P}$ ou $\mathrm{wP}_{\text {low }}$ (Figura 16), mas apenas as combinações com PspA5 produziram resultados que foram significativamente diferentes dos controles (valores de $\mathrm{P}$ anotados na legenda da Figura 16). Mais especificamente, os linfócitos $\mathrm{T} \mathrm{CD}^{+}$se apresentaram significativamente aumentados nos BALFs dos camundongos imunizados com PspA5-wP $\mathrm{l}_{\text {low }}$, em relação aos níveis observados nos BALFs dos animais não imunizados ou imunizados com PspA5 (Figura 16A). Os linfócitos $\mathrm{T} \mathrm{CD}^{+}$se apresentaram significativamente aumentados nos BALFs dos camundongos imunizados com PspA5-wP ou PspA5-wP $\mathrm{P}_{\text {low }}$, também em comparação aos níveis observados nos BALFs dos animais não imunizados ou imunizados com PspA5 (Figura 16B). O mesmo foi observado para os linfócitos B, sendo que neste caso, os dados foram também significativamente maiores que os observados nos grupos inoculados com wP ou $\mathrm{wP}_{\text {low }}$ (Figura 16C).

\subsubsection{ANÁLISE DOS ANTICORPOS ANTI-PSPA5 E DOS LINFÓCITOS PRESENTES NOS BALFS 12H APÓS O DESAFIO}

Foi realizada análise do BALF de camundongos imunizados, 12 h após o desafio com a linhagem de S. pneumoniae ATCC6303. Este tempo foi previamente determinado como o pico da inflamação em animais não imunizados (Ferreira et al., 2009b) e dados não publicados. As concentrações de $\operatorname{IgG}$ e $\operatorname{Ig} \mathrm{A}$ anti-PspA5 nos BALFs está representada na Figura 17. 
Figura 17 - Concentrações de anticorpos IgG e IgA anti-PspA5 nos BALFs de camundongos BALB/c imunizados por via nasal, $12 \mathrm{~h}$ após o desafio com a linhagem de $S$. pneumoniae ATCC6303.

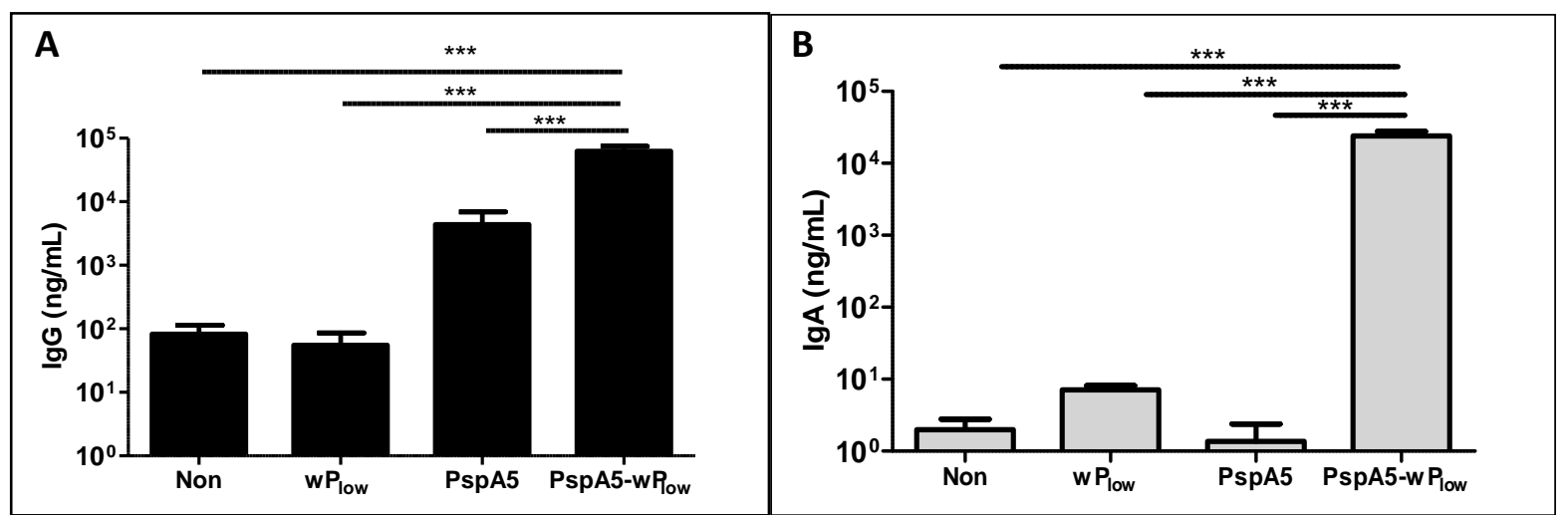

$\operatorname{IgG}(\mathbf{A})$ e $\operatorname{IgA}(\mathbf{B})$ As barras representam as médias de 3 animais por grupo com os desvios padrão. Os asteriscos apontam para os valores estatisticamente diferentes $(* * * \mathrm{P}<0,001$, teste de Tukey).

Fonte: Lima (2012)

Camundongos imunizados com PspA5-wP e PspA5-wP low $_{\text {apresentaram concentrações }}$ significativamente maiores de IgG e IgA anti PspA5 nos BALFs que os demais grupos avaliados (Figura 17, valores de P na legenda da Figura). Este experimento foi realizado com um número reduzido de animais e, devido a isto, foi aplicado o teste de Tukey para a análise estatística.

O influxo de células totais e de linfócitos nos pulmões dos camundongos imunizados foi também avaliado $12 \mathrm{~h}$ após o desafio com a linhagem ATCC6303 (Figura 18). 
Figura 18 - Contagem de células nos BALFs dos camundongos BALB/c imunizados por via nasal, 12 h após o desafio com a linhagem de S. pneumoniae ATCC6303.

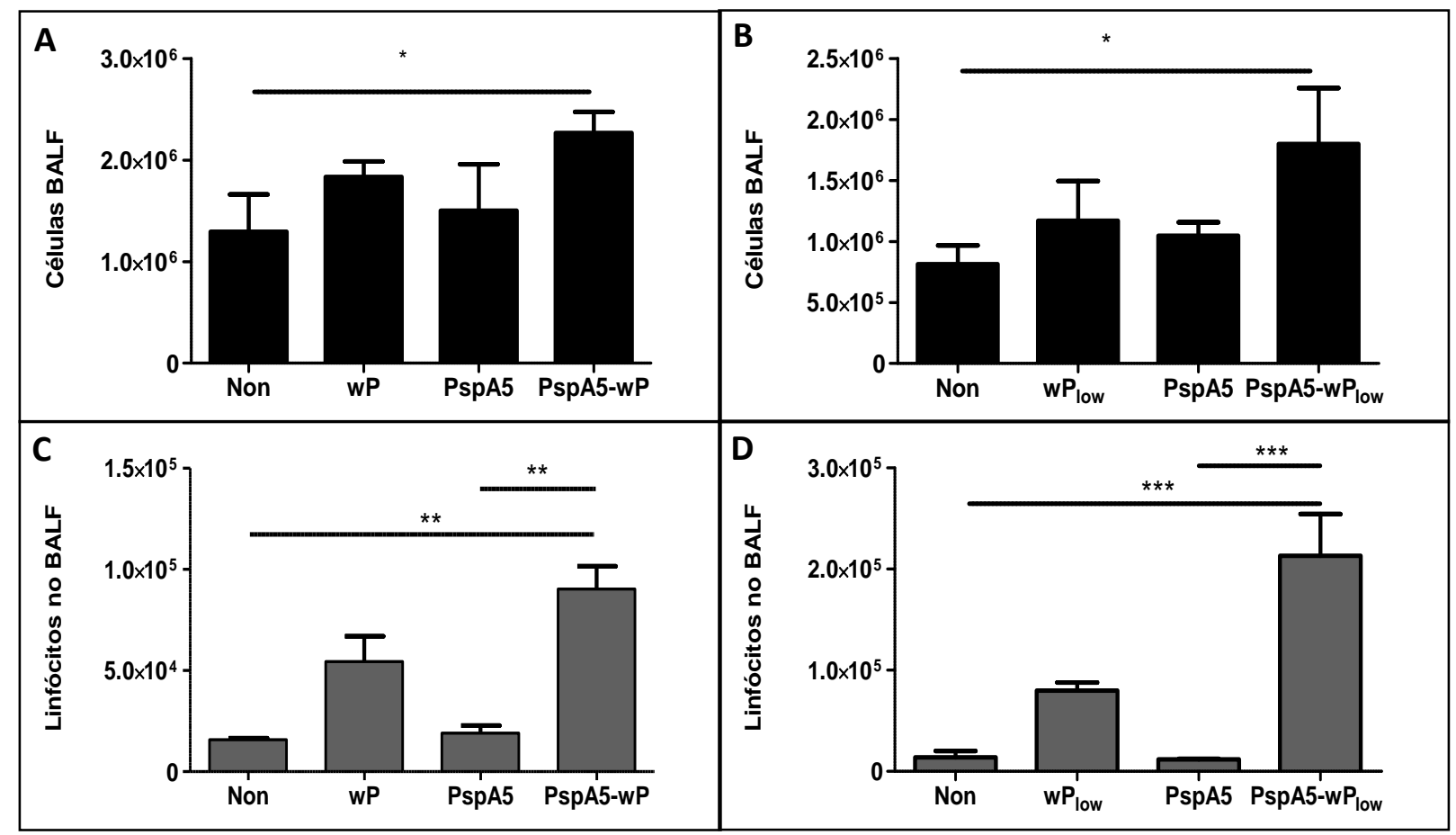

As barras representam as médias de 3 animais por grupo com os desvios padrão. Os asteriscos apontam para os valores estatisticamente diferentes $(* \mathrm{P}<0,05, * * \mathrm{P}<0,01$ e $* * * \mathrm{P}<0,001$, teste de Tukey). Non $=$ BALFs provenientes de camundongos não imunizados. (A) e (B) total de células; $(\mathbf{C})$ e (D) total de linfócitos. Em $(\mathbf{A})$ e $(\mathbf{C})$ a vacina $w P$ foi utilizada como adjuvante e em $(\mathbf{B})$ e $($ D $)$, foi utilizada a vacina $\mathrm{wP}_{\text {low }}$.

Fonte: Lima (2012)

Os camundongos imunizados com PspA5-wP ou PspA5-wP $\mathrm{P}_{\text {low }}$ apresentaram um influxo aumentado de células totais nos BALFs, 12 h após o desafio, sendo estatisticamente diferente do influxo de células totais nos camundongos não imunizados, submetidos às mesmas condições (Figura 18A e B). Com relação aos linfócitos, observou-se um aumento em todos os grupos inoculados com $\mathrm{wP}$ ou $\mathrm{wP}_{\text {low }}, 12 \mathrm{~h}$ após o desafio. Entretanto, o influxo foi significativamente maior apenas nos grupos imunizados com as combinações PspA5-wP ou PspA5-wP $\mathrm{P}_{\text {low }}$, em relação aos níveis observados nos camundongos não imunizados ou imunizados com PspA5 (Figura 18C e D). A análise dos tipos de linfócitos presentes nos BALFs 12 h após o desafio foi realizada, conforme demonstrado na figura seguinte. 
Figura 19 - Caracterização de linfócitos nos BALFs de camundongos BALB/c imunizados por via nasal, $12 \mathrm{~h}$ após o desafio com a linhagem de $S$. pneumoniae ATCC6303.

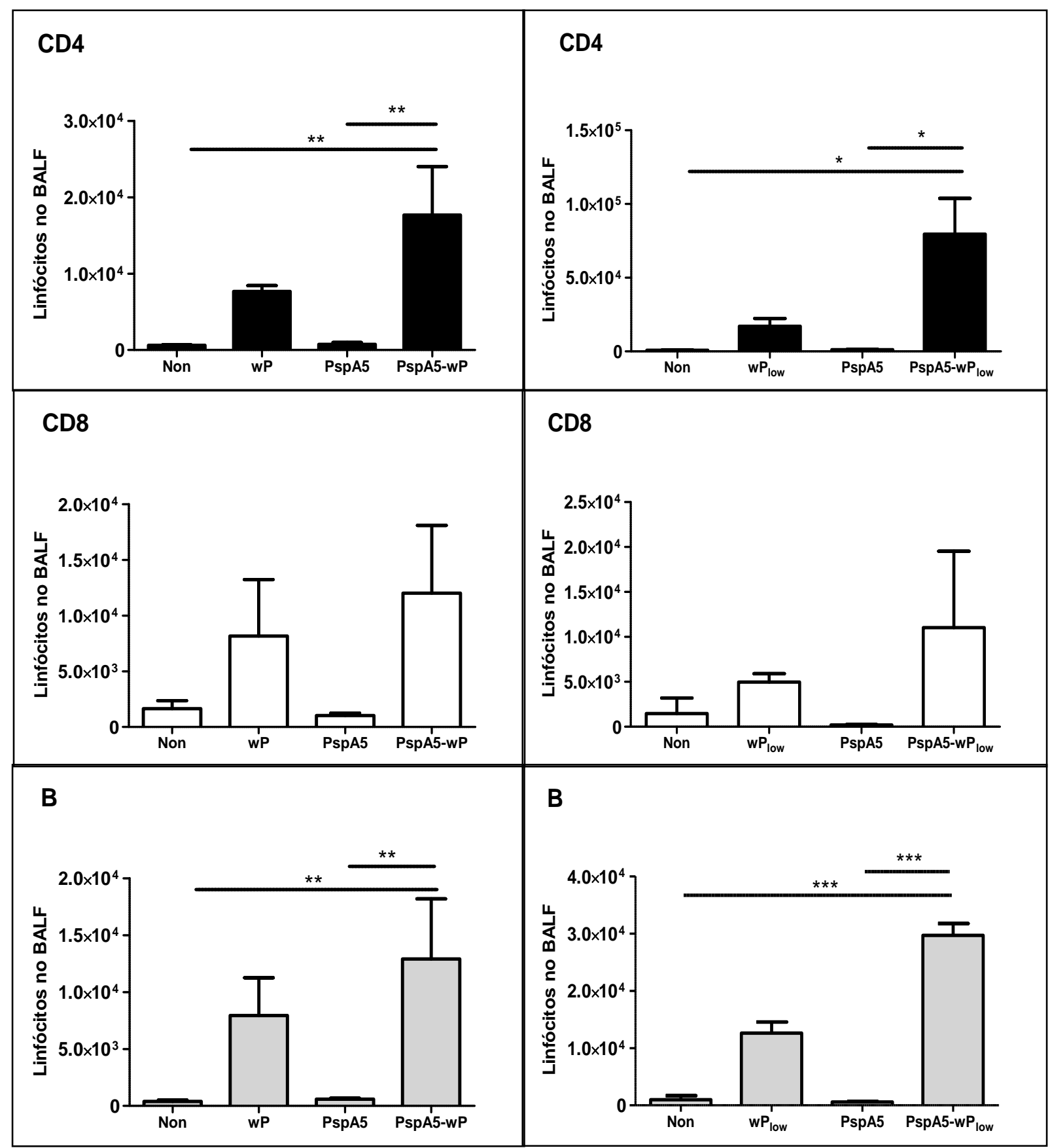

As barras representam as médias de 3 animais por grupo com os desvios padrão. Os asteriscos apontam para os valores estatisticamente diferentes $(* \mathrm{P}<0,05, * * \mathrm{P}<0,01$ e $* * * \mathrm{P}<0,001$, teste de Tukey). Non $=$ BALFs provenientes de camundongos não imunizados. Linfócitos $\mathrm{T} \mathrm{CD} 4^{+}$(painéis superiores), linfócitos $\mathrm{T} \mathrm{CD}^{+}$(painéis do meio) e linfócitos $\mathrm{B}$ (painéis inferiores). Nos painéis à esquerda a vacina wP foi usada como adjuvante e nos painéis à direita foi utilizada a vacina $\mathrm{wP}_{\text {low }}$.

Fonte: Lima (2012) 
Todos os tipos de linfócitos avaliados apresentaram-se aumentados nos camundongos imunizados com as combinações PspA5-wP ou PspA5-wP low $_{12}$ h após o desafio (Figura 19). Entretanto, apenas os linfócitos $\mathrm{T} \mathrm{CD}^{+}$e $\mathrm{B}$ apresentaram níveis significativamente mais altos quando comparados ao observado nos grupos não imunizados ou imunizados com PspA5 (Figuras 20A, B, E e F). A inoculação dos adjuvantes apenas (wP ou $\mathrm{wP}_{\text {low }}$ ) já produz um aumento, no influxo destes linfócitos, $12 \mathrm{~h}$ após o desafio, apesar de não ser estatisticamente significativo (Figura 19).

\subsubsection{ANÁLISE DOS ANTICORPOS ANTI-PSPA5 E DOS LINFÓCITOS PRESENTES NOS BALFS DOS CAMUNDONGOS IMUNIZADOS, 10 DIAS APÓS O DESAFIO}

A presença de anticorpos anti-PspA5 nos BALFs dos camundongos imunizados 10 dias após o desafio foi avaliada por ELISA, e está representada na Figura 18. Neste período, somente os grupos PspA5, PspA-wP e PspA5-wP $P_{\text {low }}$ contém camundongos sobreviventes (Tabelas 1 e 2).

Figura 20 - Concentrações de anticorpos IgG e IgA anti-PspA5 nos BALFs de camundongos BALB/c imunizados por via nasal, 10 dias após o desafio com a linhagem de $S$. pneumoniae ATCC6303

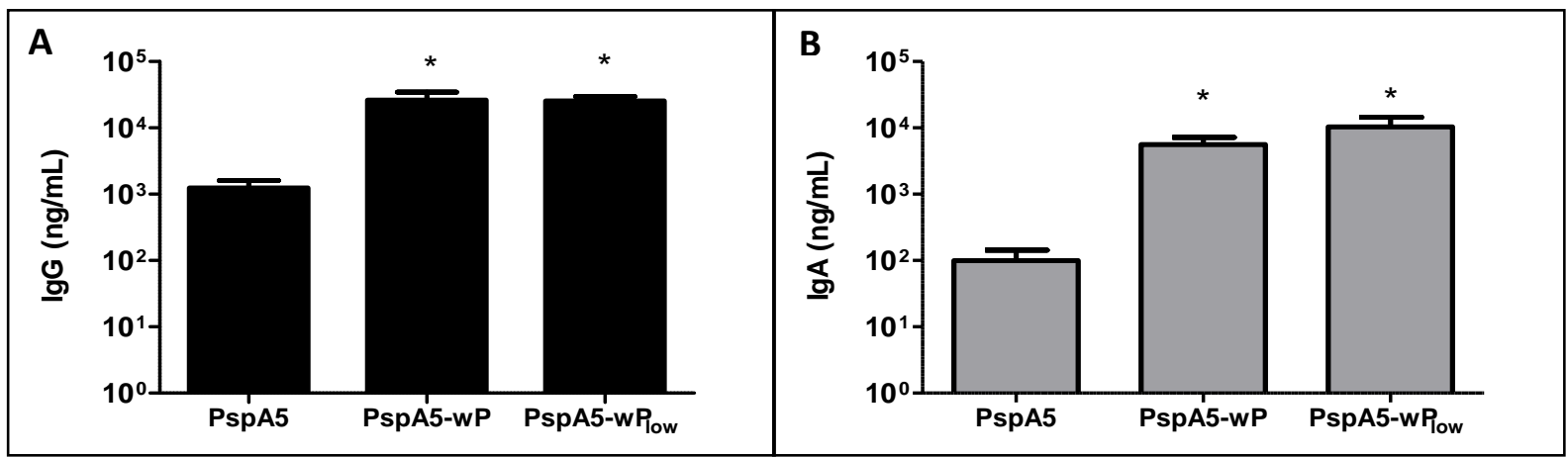

IgG (A) e IgA (B) As barras representam as médias de 3 animais por grupos com os desvios padrão. Os asteriscos apontam para os valores estatisticamente diferentes $(* \mathrm{P}=0,04$ em relação ao grupo PspA5; Teste de Mann Whitney).

Fonte: Lima (2012)

As concentrações de IgG e IgA anti-PspA5 nos BALFs dos camundongos sobreviventes, 10 dias após o desafio, foram significativamente maiores para aqueles que 
receberam PspA5-wP ou PspA5-wP $\mathrm{P}_{\text {low }}$ em relação ao àqueles imunizados com PspA5 (Figura $20 \mathrm{~A}$ e B).

A análise de linfócitos presentes nos BALFs de camundongos 10 dias após o desafio está apresentada na Figura 21.

Figura 21 - Contagem de células no BALF de camundongos BALB/c imunizados por via nasal, 10 dias após o desafio com a linhagem de S. pneumoniae ATCC6303.

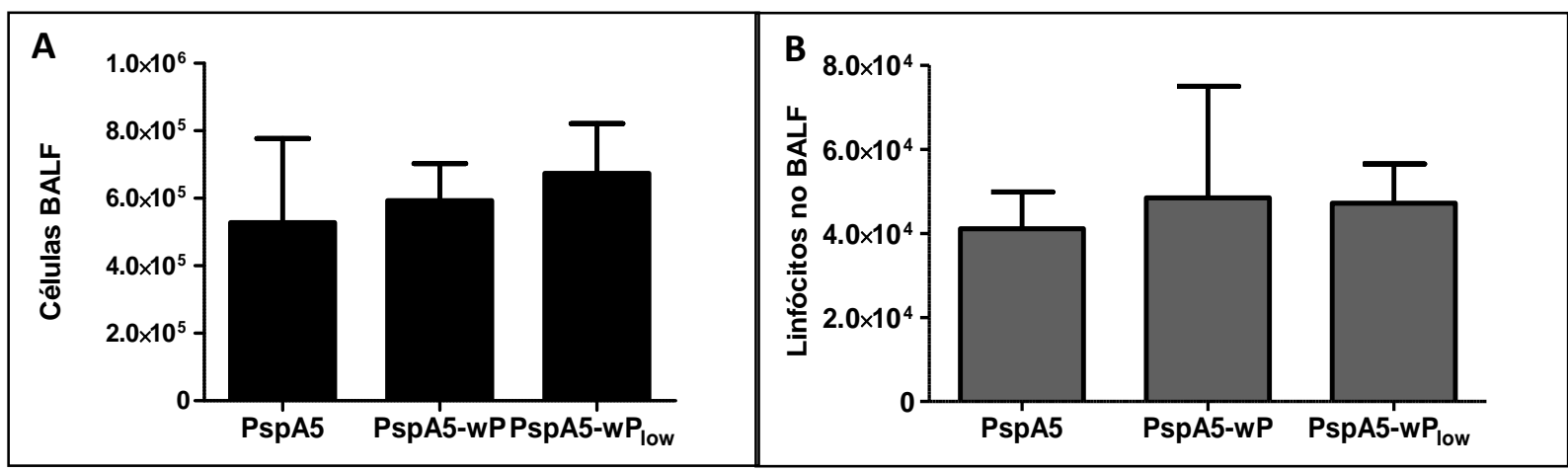

As barras representam as médias de 3 animais por grupo com os desvios padrão. (A) total de células no BALF e (B) total de linfócitos.

Fonte: Lima (2012)

Foi possível verificar uma redução do total de células (Figura 21A) e de linfócitos, neste ponto, (Figura 21B) nos camundongos que receberam as combinações PspA5-wP e PspA5-wP $P_{\text {low }}$, em relação ao ponto de 12 h após o desafio (Figura 20). Não houve diferença entre as quantidades de células totais ou de linfócitos observadas entre os três grupos. 
Figura 22 - Caracterização de linfócitos nos BALFs de camundongos BALB/c imunizados por via nasal, 10 dias após o desafio com a linhagem de $S$. pneumoniae ATCC6303.

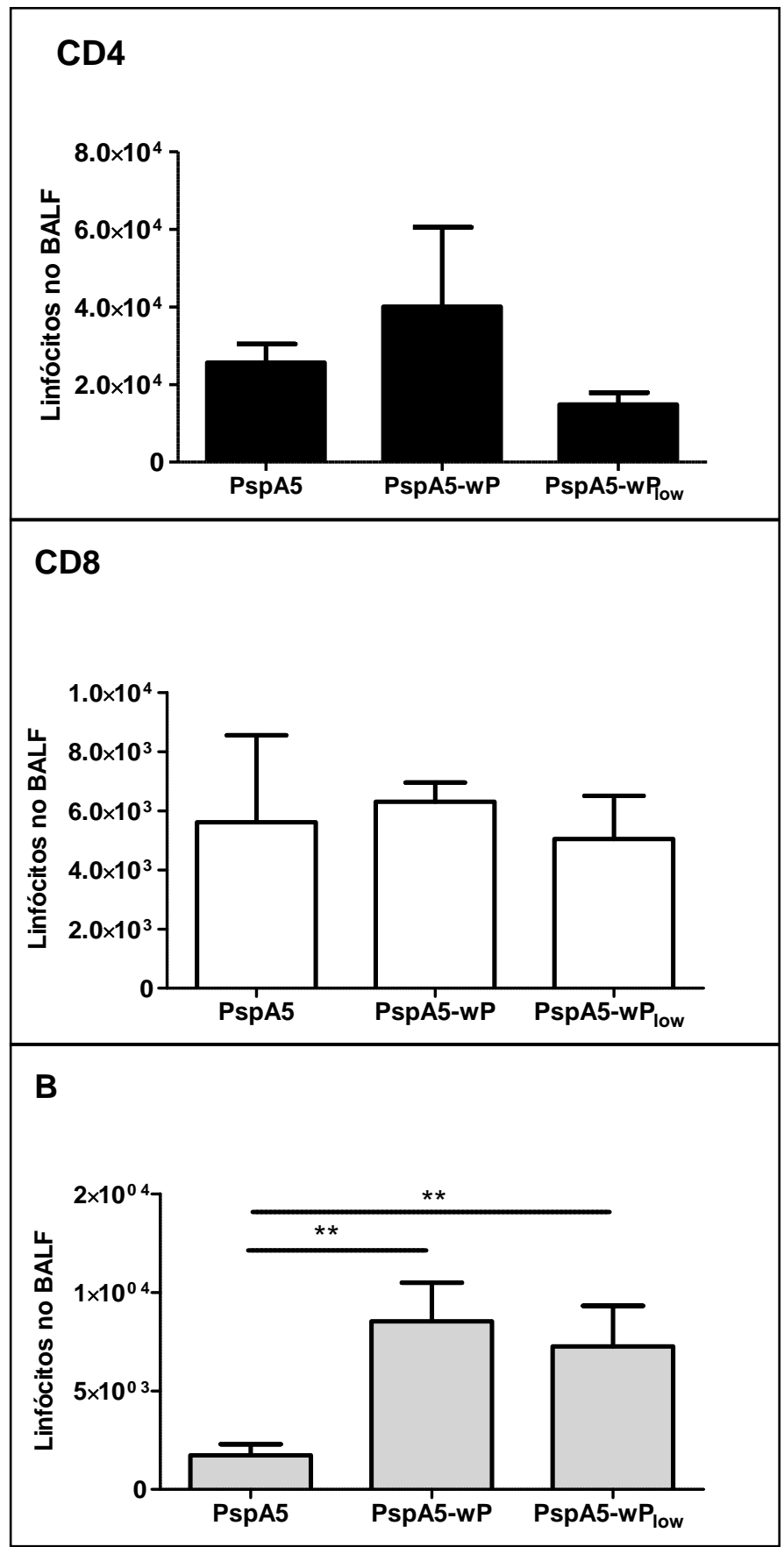

As barras representam, as médias de 3 animais por grupo com os desvios padrão. Os asteriscos apontam para os valores estatisticamente diferentes $(* * \mathrm{P}<0,02$, teste de Tukey,). Linfócitos $\mathrm{T} \mathrm{CD} 4^{+}$(painel superior), linfócitos $\mathrm{T} \mathrm{CD}^{+}$(painel do meio) e linfócitos B (painel inferior).

Fonte: Lima (2012) 
A caracterização dos linfócitos presentes nos BALFs, 10 dias após o desafio (Figura 22) mostrou que não houve diferenças significativas nos níveis de linfócitos $\mathrm{T} \mathrm{CD}^{+}$ou $\mathrm{T}$ $\mathrm{CD}^{+}$nos grupos avaliados. Entretanto, níveis significativamente mais altos de linfócitos $\mathrm{B}$ foram observados nos animais imunizados com PspA5-wP ou com PspA5-wP $\mathrm{P}_{\text {low }}$ em relação aos níveis observados nos camundongos imunizados apenas com PspA5 (valores de P anotados na legenda da Figura 22).

4.2.7 Avaliação da reatividade dos soros anti-PspA5 provenientes das imunizações nasais contra PspAs expressos por diferentes linhagens de S. pneumoniae

O antígeno PspA5 é capaz de induzir anticorpos que apresentam reatividade cruzada com PspAs de diferentes clados (Moreno et al., 2010). Para determinar a reatividade do soro dos camundongos imunizados com PspA5 ou PspA5-wP contra PspAs de diferentes clados, foram realizados Western Blots utilizando lisados proteicos de diferentes linhagens de pneumococo e os soros reunidos em pools dos grupos (Figura 23). 
Figura 23 - Reatividade dos soros dos camundongos BALB/c imunizados por via nasal com PspA5 ou com a combinação PspA5-wP contra lisados de S. pneumoniae

A

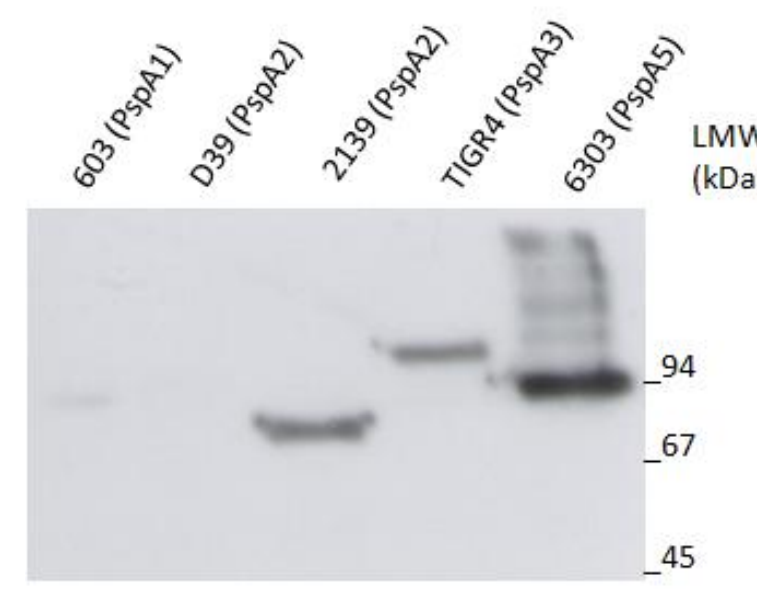

$\underline{\alpha-P s p A 5}$
B

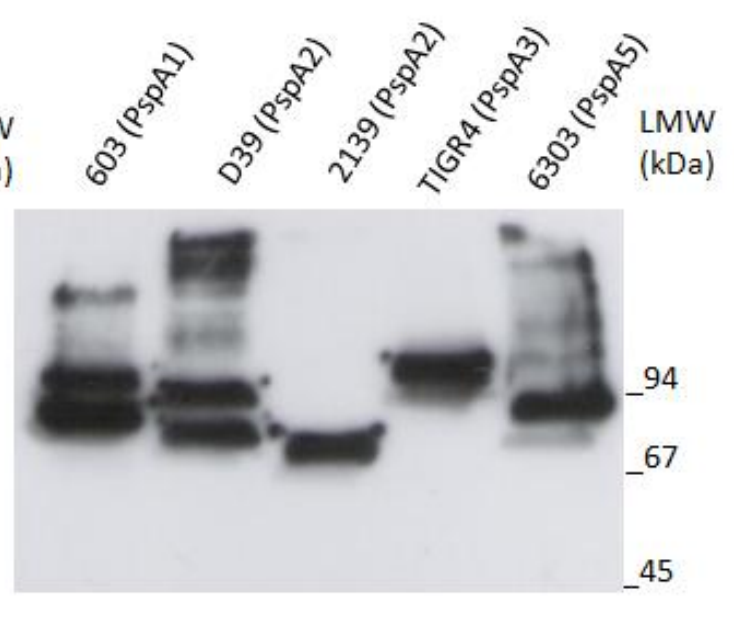

$\underline{\alpha-P s p A 5-w P}$

Camundongos BALB/c imunizados por via nasal com PspA5 (A) camundongos imunizados com a combinação PspA5-wP (B). Lisados de S. pneumoniae 603 (PspA1), D39 (PspA2), 2139 (PspA2), TIGR4 (PspA3) e ATCC6303 (PspA5). LMW, padrão de massa molecular (GE Healthcare). Ambos os soros foram utilizados na diluição 1:500.

Fonte: Lima (2012)

A Figura 23 mostra que o pool dos soros dos animais imunizados com PspA5 foi capaz de reconhecer PspAs de diferentes clados, como descrito anteriormente (Darrieux et al., 2008). Entretanto, algumas bandas foram reconhecidas fracamente, como a da linhagem 603 ou não apresentaram sinal positivo nestas condições, como a da linhagem D39. Por outro lado, observa-se maior intensidade nas bandas reconhecidas quando o pool dos soros de camundongos que receberam PspA5-wP foi utilizado.

\section{$\underline{4.2 .8 \text { Avaliação da proteção contra desafio de colonização em camundongos C57B1/6 }}$}

A seguir foi avaliada a capacidade protetora da combinação PspA5-wP, quando administrada por via nasal, contra a linhagem de S. pneumoniae 0603, que expressa PspA1, em modelo de desafio de colonização em camundongos C57Bl/6 (Figura 24). Neste desafio, a 
linhagem de pneumococo é inoculada por via nasal e a colonização é avaliada através do plaqueamento em ágar sangue de amostras de lavados nasais, coletados 5 dias após a inoculação.

Figura 24 - Contagem de unidades formadoras de colônia -UFC- presentes nos lavados nasais de camundongos não imunizados ou imunizados com wP, PspA5 ou PspA5-wP.

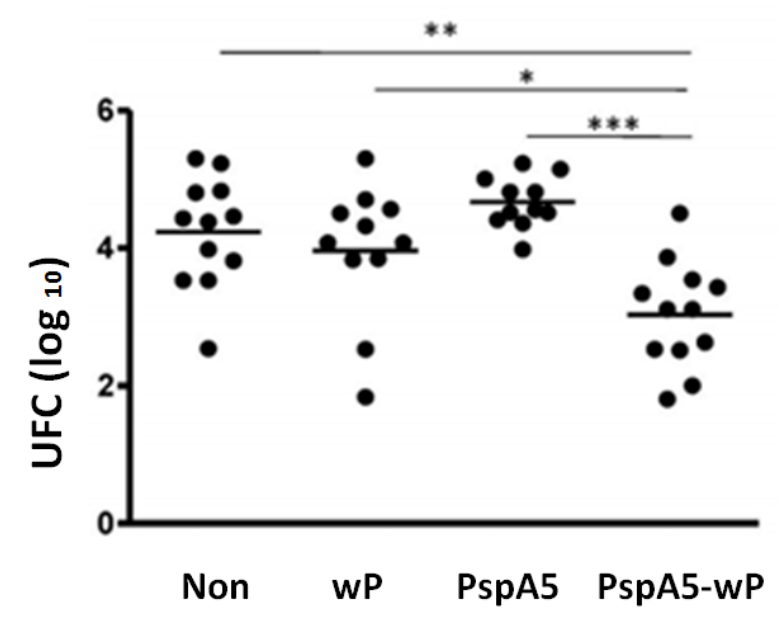

As médias das UFCs é representada pela barra e a contagem individual é representada pelos circulos. Non = lavados nasais provenientes de camundongos não imunizados. Os asteriscos apontam para os valores estatisticamente diferentes $(* \mathrm{P}=0,01 ; * * \mathrm{P}=0,003$; ***P $=0,001$, teste de Mann Whitney). Gráfico composto por resultados de dois experimentos independentes.

Fonte: Lima (2012)

A imunização dos camundongos com PspA5 não exerceu efeito na colonização nasal dos animais por pneumococo (Figura 24). Por outro lado, os animais que receberam a combinação PspA5-wP apresentaram redução significativa na recuperação de bactérias nos lavados nasais, em comparação com os animais que não foram imunizados ou que receberam apenas wP (Figura 24). Mais importante, a imunização dos camundongos com a combinação PspA5-wP reduziu significativamente a colonização por pneumococo quando comparada a imunização com PspA5 sozinho (valores de P anotados na legenda da Figura 24). 


\subsection{Avaliação do potencial protetor dos anticorpos induzidos pela vacina PspA5-wP através de imunização passiva}

Os experimentos de imunização nasal, demonstraram a indução de altos níveis de anticorpos, principalmente nos soros dos camundongos, e proteção contra o desafio letal pelas

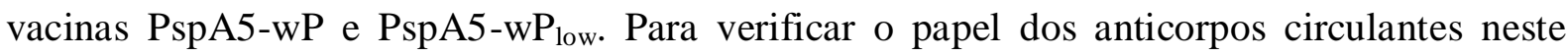
modelo, foi realizado um ensaio de imunização passiva, apresentado na Figura 26. Neste ensaio, soros obtidos em diferentes imunizações foram reunidos e inoculados em camundongos não imunizados $2 \mathrm{~h}$ antes do desafio letal com a linhagem de pneumococo ATCC6303.

Figura 25 - Sobrevivência dos animais que receberam os soros de camundongos imunizados por via nasal.

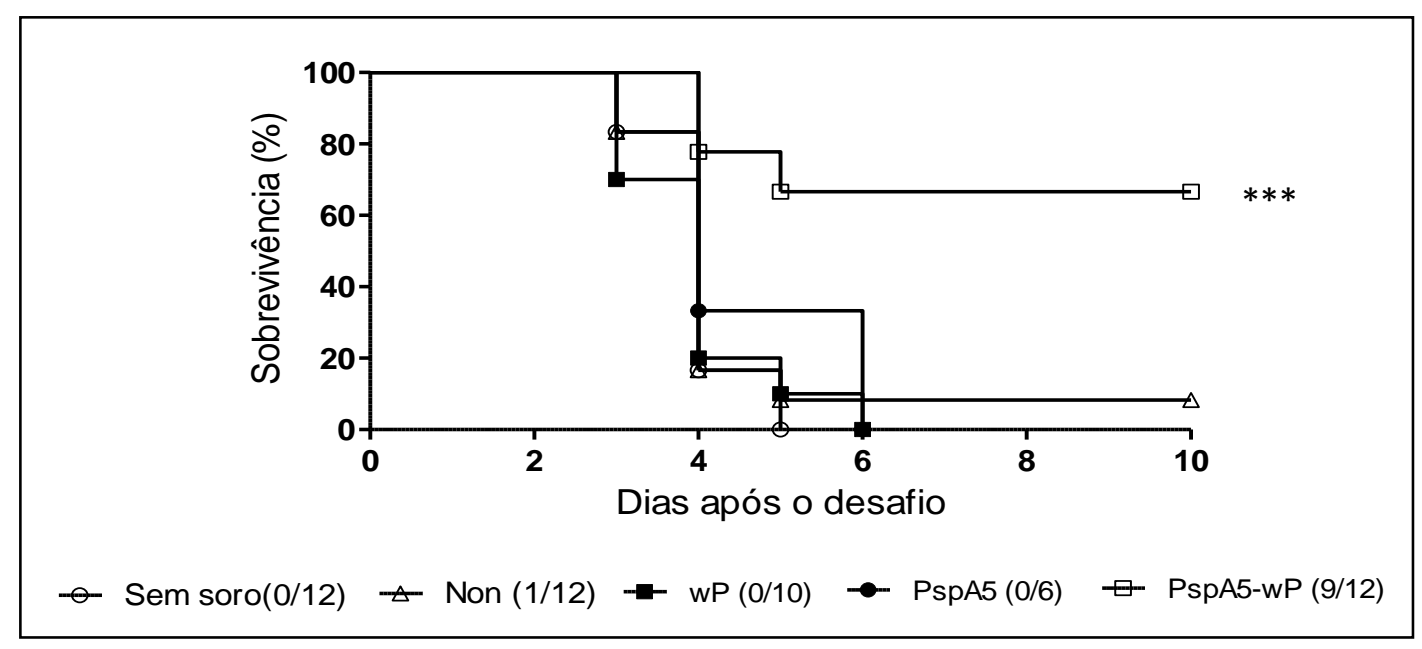

Os camundongos desafiados foram observados por 10 dias. Cada simbolo representa um animal. Non $=$ soros provenientes de camundongos não imunizados. Os asteriscos apontam para os valores estatisticamente diferentes $(* * * \mathrm{P}<0,001$ em relação ao grupo sem soro, teste exato de Fisher).

Fonte: Lima (2012)

Os animais que foram apenas desafiados com a linhagem ATCC6303 (grupo sem soro) começaram a morrer após o $3^{\circ}$ dia de desafio, e até o $5^{\circ}$ dia, nenhum sobrevivente restou neste grupo (Figura 25). A inoculação de soros provenientes de animais não imunizados (Non), imunizados com wP ou com PspA5, duas horas antes do desafio, não alterou significativamente a curva de sobrevivência, sendo que quase a totalidade dos animais 
morreram até o sexto dia após o desafio. Por outro lado, a inoculação dos soros provenientes dos animais imunizados com PspA5-wP levou a sobrevivência de 75\% dos animais (9 em 12).

\subsection{Avaliação das formulações vacinais inoculadas em camundongos por via subcutânea}

\subsubsection{Imunização de camundongos BALB/c e desafio letal com S. pneumoniae}

A proteção observada no ensaio de imunização passiva nos levou a testar formulações combinadas pela via subcutânea, utilizando a vacina $\mathrm{DTP}_{\text {low }}$ como adjuvante. A vacina DT foi também combinada a PspA5 neste experimento, para um controle da propriedade adjuvante da vacina pertussis, já que os outros componentes presentes na $\mathrm{DTP}_{\text {low }}$ podem exercer atividade adjuvante. Os camundongos receberam apenas uma dose de cada formulação. As concentrações de IgG anti-PspA5 presentes no soro dos animais imunizados por via subcutânea, foram determinadas por ELISA (Figura 26).

Figura 26 - Concentrações de IgG anti-PspA5 nos soros de camundongos BALB/c imunizados por via subcutânea.

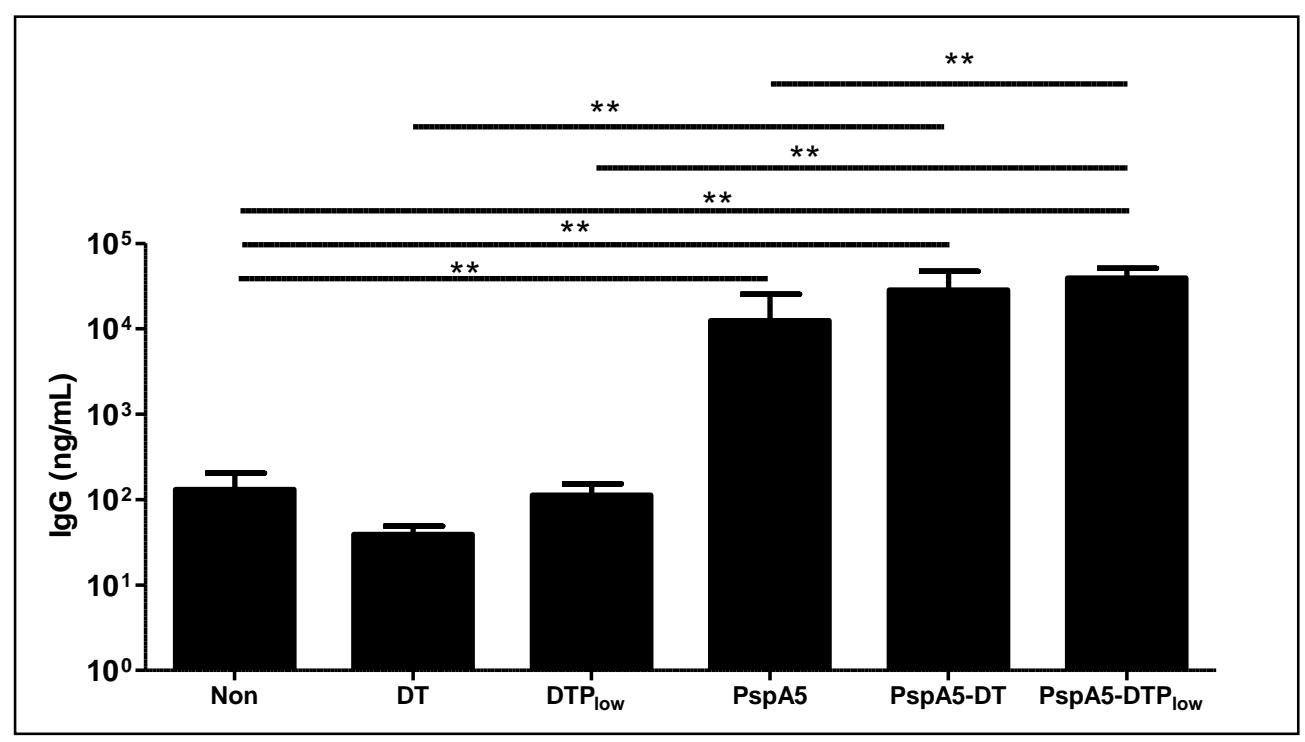

As barras representam as médias de 6 animais por grupo com os desvios padrão. Non $=$ soros provenientes de camundongos não imunizados. Os asteriscos apontam para os valores estatisticamente diferentes ( $* * \mathrm{P}<0,01$; teste de Mann Whitney).

Fonte: Lima (2012) 
Apesar de significativamente mais altas do que as observadas nos grupos controle, as concentrações de IgG anti-PspA5 nos animais imunizados apenas com PspA5 atingiram níveis próximos a $10.000 \mathrm{ng} / \mathrm{mL}$. No entanto, as concentrações de a IgG anti-PspA5 foram significativamente mais elevadas $(\mathrm{P}=0,002)$ nos animais imunizados com PspA5-DTP ${ }_{\text {low }}$ atingindo nível médio próximo a $100.000 \mathrm{ng} / \mathrm{mL}$ (Figura 26). Não houve diferença significativa entre os animais imunizados com PspA5 ou imunizados com PspA5-DT. Além disso, também não foram observadas diferenças significativas nas concentrações de IgG antiPspA5 entre o grupo que recebeu PspA5-DT e o grupo que recebeu PspA5-DTP low $_{\text {(Figura }}$ 26).

As concentrações dos subtipos IgG1 e IgG2a anti-PspA5 presentes no soro dos camundongos positivos para IgG anti-PspA5, foram também avaliadas (Figura 27).

Figura 27 - Concentrações dos subtipos IgG1 e IgG2a anti-PspA5 nos soros de camundongos BALB/c imunizados por via subcutânea.

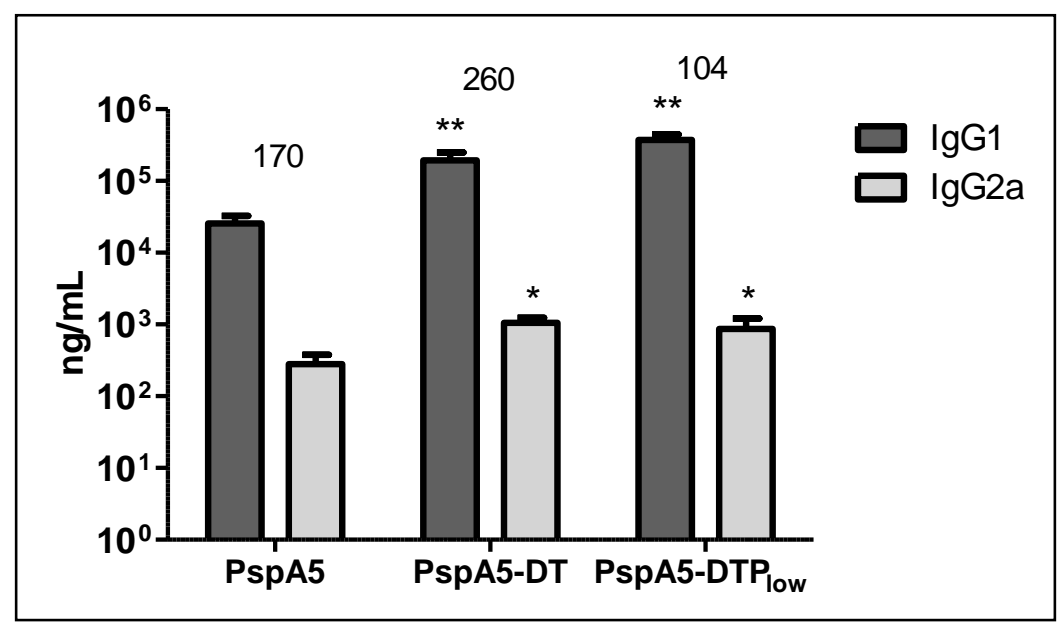

IgG1 (cinza escuro) e IgG2a (cinza claro). As barras representam as médias de 6 animais por grupo com os desvios padrão. O número acima das barras é o valor da razão $\operatorname{IgG} 1 / \operatorname{IgG} 2 \mathrm{a}(* \mathrm{P}=0,04 \mathrm{e} * * \mathrm{P}=0,002$ em relação ao grupo $\mathrm{PspA} 5$, teste de Mann Whitney).

Fonte: Lima (2012)

Como pode ser observado na Figura 27, todas as formulações induziram preferencialmente a produção de IgG1 anti-PspA5. Por outro lado, as concentrações de IgG2a nos animais vacinados foram significativamente mais altas nos animais vacinados com 


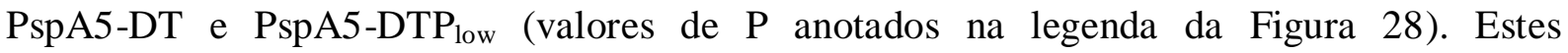
camundongos foram avaliados em desafio com a linhagem de S. pneumoniae ATCC6303 e a sobrevivência está apresentada na tabela 5.

Tabela 5 - Sobrevivência de animais imunizados por via subcutânea após o desafio letal com a linhagem ATCC6303 (sorotipo 3, PspA5).

\begin{tabular}{lccc}
\hline & Vivos/total & Sobrevivência & $\boldsymbol{P}^{*}$ \\
\hline Non & $0 / 6$ & -- & -- \\
DT & $0 / 6$ & -- & -- \\
DTP $_{\text {low }}$ & $0 / 6$ & -- & -- \\
PspA5 & $2 / 6$ & $33 \%$ & 0,14 \\
PspA5-DT & $4 / 6$ & $66,6 \%$ & 0,03 \\
PspA5-DTP & $6 / 6$ & $100 \%$ & 0,001 \\
\hline
\end{tabular}

* Valores em relação ao grupo não imunizado (Non), pelo teste exato de Fisher Fonte: Lima (2012)

A tabela 5 mostra que não houve animais sobreviventes nos grupos não imunizados,

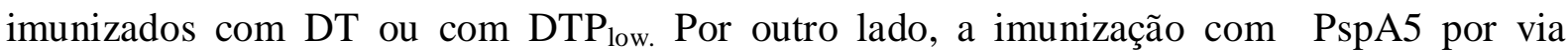
subcutânea, levou a sobrevivência de $33 \%$ dos animais. Um aumento na sobrevivência dos animais foi observado no grupo imunizado com PspA5-DT (66,6\% de sobreviventes). Entretanto, o resultado mais significativo foi observado no grupo imunizado com PspA5DTP $_{\text {low }}$, com $100 \%$ de sobreviventes.

Como foi observada proteção de $100 \%$ camundongos quando desafiados com o isolado de S. pneumoniae ATCC6303, que expressa PspA5, decidiu-se repetir o experimento e desafiar os camundongos com um isolado que expressa PspA de outro clado (Tabela 6). 
Tabela 6 - Sobrevivência de animais imunizados por via subcutânea após o desafio letal com a linhagem A66.1 (sorotipo 3, PspA2)

\begin{tabular}{lccc}
\hline & Vivos/total & Sobrevivência & $\boldsymbol{P}^{*}$ \\
\hline Non & $0 / 5$ & -- & -- \\
DT & $0 / 6$ & -- & -- \\
DTP $_{\text {low }}$ & $0 / 6$ & -- & -- \\
PspA5 & $0 / 6$ & -- & - \\
PspA5-DT & $3 / 6$ & $50 \%$ & 0,09 \\
PspA5-DTP & $4 / 6$ & $66,6 \%$ & 0,03 \\
\hline
\end{tabular}

* Valores em relação ao grupo não imunizado (Non), pelo teste exato de Fisher

Fonte: Lima (2012)

Nenhum camundongos dos grupos controle (Non, DT ou $\mathrm{DTP}_{\text {low }}$ ) ou do grupo imunizado com PspA5 sobreviveu após o desafio com o isolado A66.1 (que expressa PspA2). Por outro lado, 66,6\% dos camundongos imunizados com PspA5-DTP low $_{\text {sobreviveram ao }}$ desafio, sendo este o único grupo que apresentou resultado significativamente diferente dos grupos controle. A imunização com PspA5-DT, por sua vez, conferiu proteção a 50\% dos camundongos (Tabela 6).

4.4.2 Análise dos anticorpos anti-PspA5 e do influxo de linfócitos presentes nos BALFs dos camundongos imunizados por via subcutânea

Os resultados apresentados anteriormente demonstraram que a formulação PspA5$\mathrm{DTP}_{\text {low }}$ foi protetora para os camundongos em desafio letal com S.pneumoniae, induzindo uma elevada concentração de anticorpos sistêmicos. Para avaliar a indução de resposta imune pulmonar induzida pela imunização com a vacina aqui proposta, foi realizada análise dos BALFs de camundongos imunizados. Anticorpos IgG anti-PspA5 foram avaliados por ELISA 
nas amostras coletadas dos camundongos imunizados antes do desafio e $12 \mathrm{~h}$ após o desafio (Figura 28A e B).

Figura 28 - Concentrações de anticorpos IgG anti-PspA5 nos BALFs de camundongos BALB/c imunizados por via subcutânea.

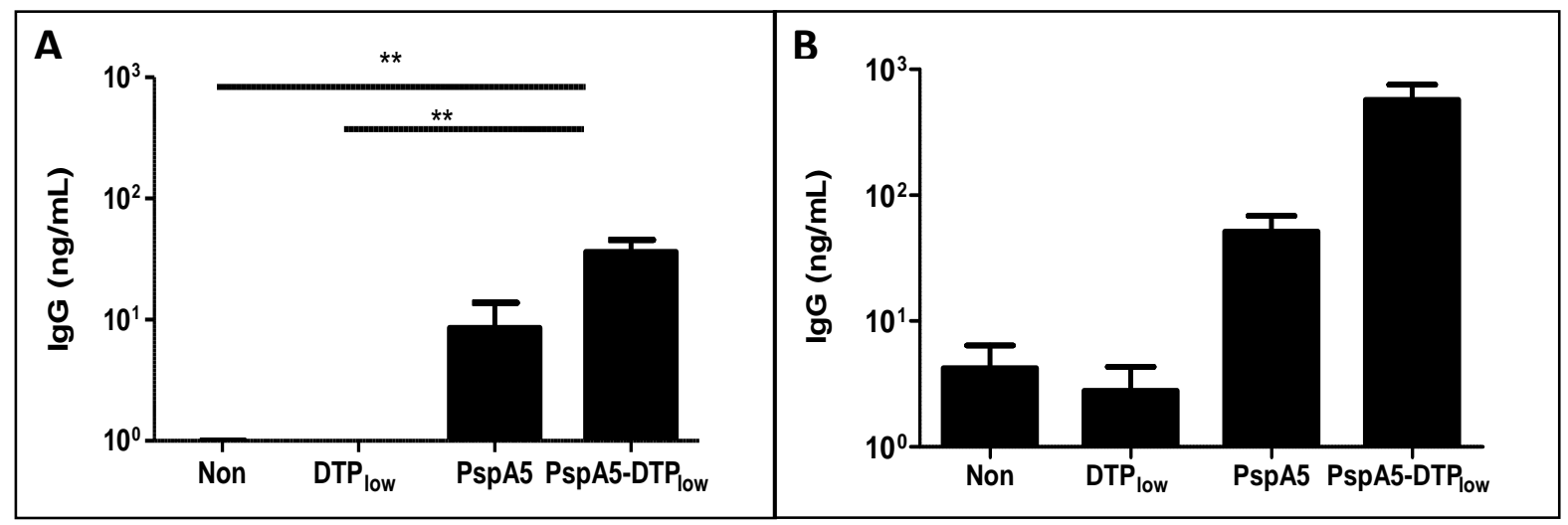

As barras representam as médias de 5 animais (A) e 3 animais (B) por grupo com os desvios padrão. (A) antes do desafio e (B) 12h após o desafio. Non = BALFs de camundongos não imunizados. Os asteriscos apontam para os valores estatisticamente diferentes (Em A, ${ }^{*} \mathrm{P}=0,009 \mathrm{Em} \mathrm{B},{ }^{*} * \mathrm{P}=0,01$ e $* \mathrm{P}=0,05$; Teste de Mann Whitney). Fonte: Lima (2012)

Antes do desafio, níveis significativamente mais altos de $\operatorname{IgG}$ nos BALFs de

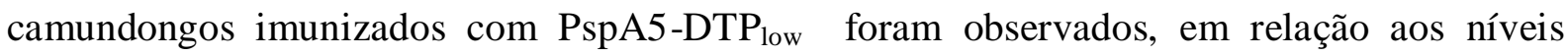
apresentados pelos animais não imunizados (Non) ou imunizados com $\mathrm{DTP}_{\text {low }}$ (valores de $\mathrm{P}$ anotados na legenda da Figura 28). Os animais imunizados com PspA5 também apresentaram aumento de IgG anti-PspA5 nos BALFs, embora estatisticamente não significativo. (Figura 28A). Em doze horas após o desafio, também foi possível observar níveis mais altos de IgG

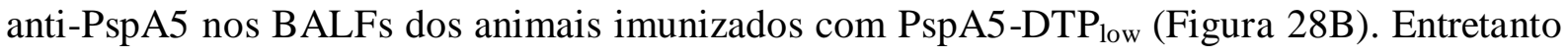
não foi observada diferença significativa pela análise estatística utilizada, provavelmente por este experimento ter sido feito com apenas 3 animais por grupo. É importante ressaltar que a concentração de anticorpos foi mais alta $12 \mathrm{~h}$ após o desafio, em relação aos níveis observados em camundongos não desafiados (Figuras 28A e B).

Foi realizada a análise dos BALFs, afim de investigar a presença de linfócitos nos pulmões dos camundongos imunizados por via subcutânea (Figura 29). 
Figura 29 - Contagem de células nos BALFs dos camundongos BALB/c imunizados por via subcutânea.

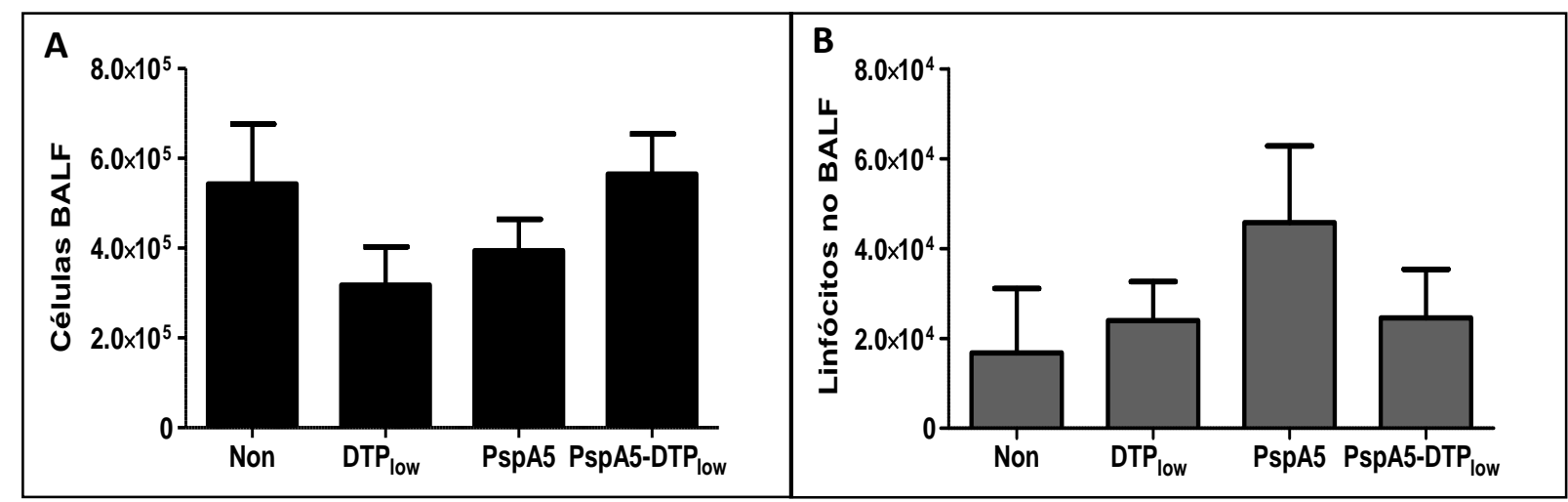

As barras representam as médias de 5 animais por grupos com os desvios padrão. (A) total de células e (B) total de linfócitos. Non= BALFs de camundongos não imunizados. Fonte: Lima (2012)

A contagem de células nos BALFs de camundongos imunizados por via subcutânea demonstrou que não houve diferença no total de células e de linfócitos nos camundongos imunizados com as diferentes formulações em relação aos animais não imunizados (Figura 29A e B). A caracterização dos diferentes linfócitos presentes nos BALFs destes animais é mostrada a seguir. 
Figura 30 - Caracterização dos linfócitos presentes nos BALFs de camundongos BALB/c imunizados por via subcutânea.

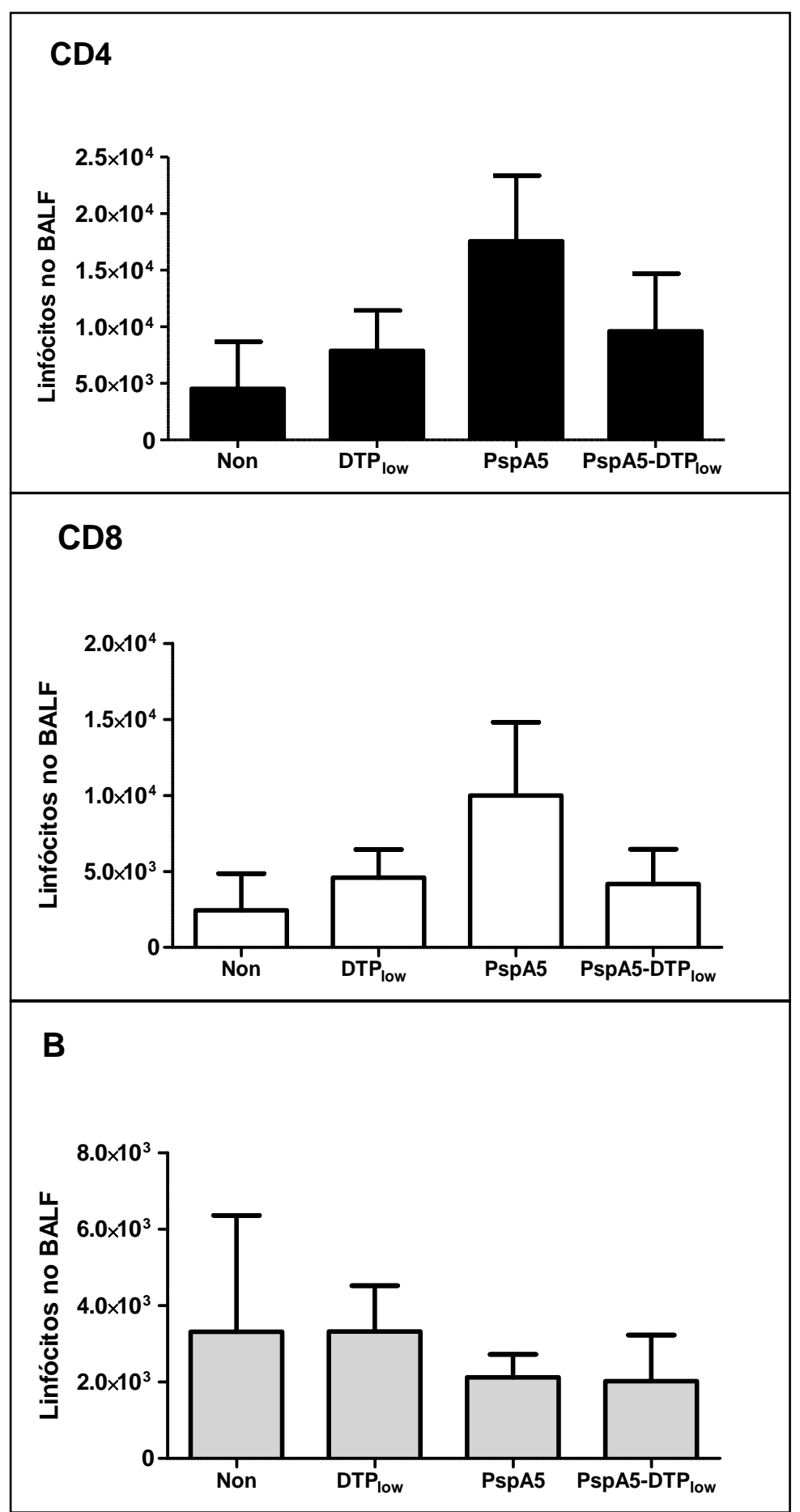

As barras representam as médias de 5 animais por grupo com os desvios padrão. Linfócitos $\mathrm{T} \mathrm{CD}^{+}$(painel superior), linfócitos $\mathrm{T} \mathrm{CD}^{+}$(painel do meio) e linfócitos $\mathrm{B}$ (painel inferior). Non= BALFs de camundongos não imunizados. Fonte: Lima (2012) 
Não foi possível detectar diferenças nas contagens de linfócitos $\mathrm{T} \mathrm{CD}^{+}, \mathrm{T} \mathrm{CD}^{+}$e $\mathrm{B}$ nos animais que receberam as diferentes formulações (Figura 30).

\subsection{Análise da resposta imune contra os outros componentes das diferentes formulações vacinais}

\section{$\underline{\text { 4.5.1 Análise da reatividade dos diferentes soros contra antígenos de B. pertussis }}$}

Para uma proposta de combinação de vacinas é necessário que se faça a avaliação do efeito da inclusão do antígeno PspA5 na resposta imune induzida por wP contra antígenos de pertussis. Para tanto, a reatividade dos soros produzidos nos experimentos de imunização nasal contra de antígenos de $B$. pertussis foi avaliada utilizando sobrenadantes do cultivo da bactéria (Figura 32). Este sobrenadante é comumente usado como base para a produção de formulações acelulares da vacina pertussis em diferentes países, já que contêm diversos antígenos secretados pela bactéria durante o cultivo. O Instituto Butantan não produz a vacina acelular, mas para facilitar a descrição dos resultados, este nome foi adotado no presente trabalho.

Figura 31 - Western blot utilizando extratos proteicos da linhagem de S. pneumoniae ATCC6303 e o sobrenadante do cultivo de B. pertussis (acelular).

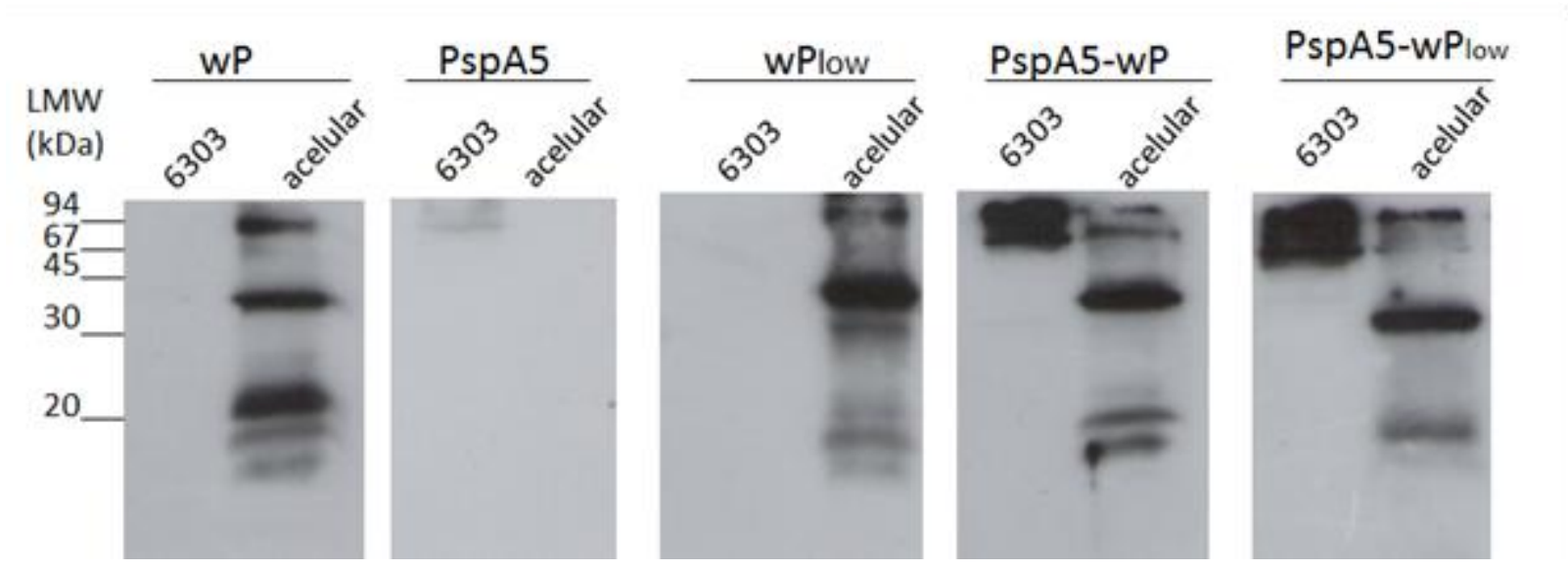

Os diferentes soros estão indicados acima de cada membrana. LMW, padrão de massa molecular (GE Healthcare).

Fonte: Lima (2012) 
Foi possível verificar a reatividade dos soros dos animais imunizados com wP, ou ${ } \mathrm{P}_{\text {low }}$ contra a vacina acelular na primeira e terceira membranas. Observou-se pouca reatividade do soro de camundongos imunizados com PspA5 contra o extrato da linhagem de pneumococo ATCC6303 (segunda membrana). Por outro lado, os soros de camundongos que receberam as combinações PspA5-wP ou PspA5-wP $\mathrm{P}_{\text {low }}$ apresentaram alta reatividade contra o extrato de pneumococo e contra a vacina acelular. Além disso, os soros de animais imunizados com as combinações PspA5-wP ou PspA5-wP $\mathrm{P}_{\text {low }}$ apresentaram um padrão parecido de reconhecimento de bandas quando comparados aos soros de animais imunizados com wP ou wP $\mathrm{P}_{\text {low }}$ (Figura 31).

O efeito da combinação com PspA5 na indução de anticorpos contra antígenos presentes na vacina acelular também foi avaliado por ELISA (Figura 33).

Figura 32 - Concentrações de anticorpos IgG anti-pertussis nos soros de camundongos $\mathrm{BALB} / \mathrm{c}$ imunizados por via nasal.

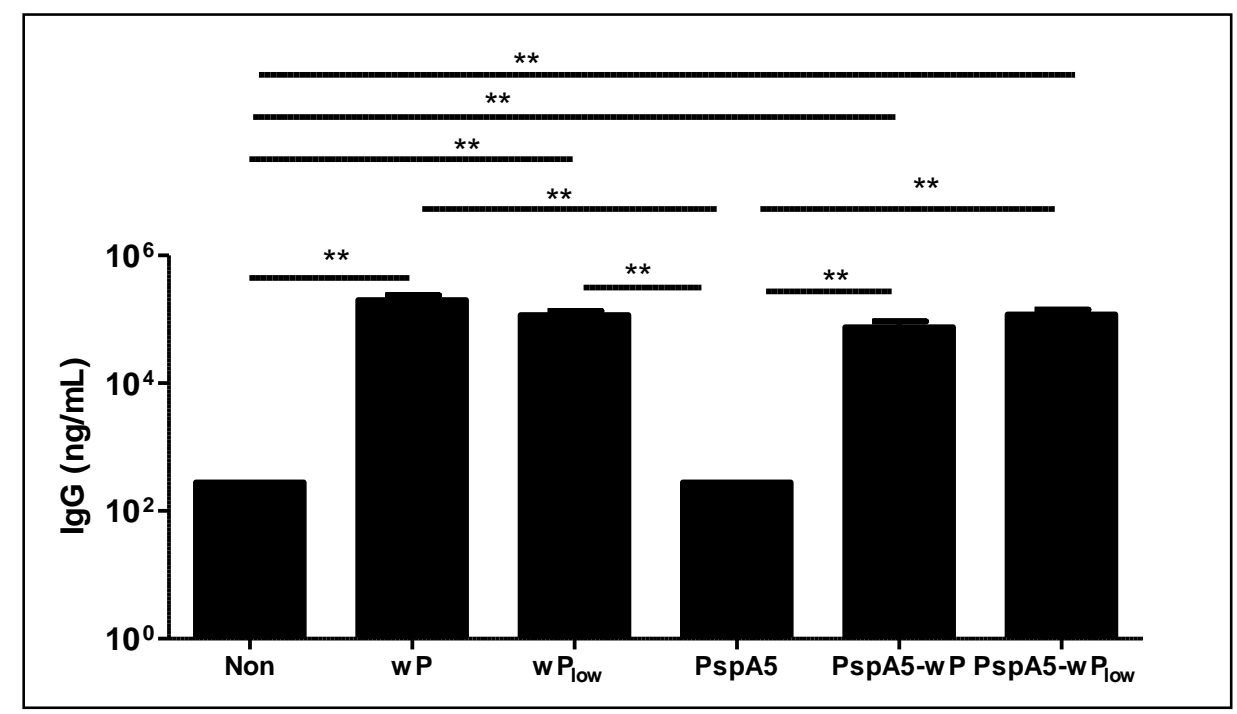

As barras representam as médias de 6 animais por grupo com os desvios padrão. Non $=$ soros de camundongos não imunizados. Os asteriscos apontam para os valores estatisticamente diferentes ( $* * \mathrm{P}<0,005$, teste de Mann Whitney).

Fonte: Lima (2012)

O gráfico mostra que os animais que receberam somente $\mathrm{wP}, \mathrm{wP}_{\text {low }}$ ou as combinações PspA5-wP e Pspa5-wP $\mathrm{P}_{\text {low }}$ apresentaram níveis semelhantes de anticorpos anti-pertussis no soro, com diferença estatística apenas em relação aos animais não imunizados ou imunizados com PspA5, conforme anotado na legenda da Figura 32. A resposta imune contra antígenos de pertussis também foi avaliada em camundongos imunizados por via subcutânea (Figura 33). 
Figura 33 - Concentrações de $\operatorname{IgG}$ anti-pertussis presente nos soros de camundongos imunizados por via subcutânea.

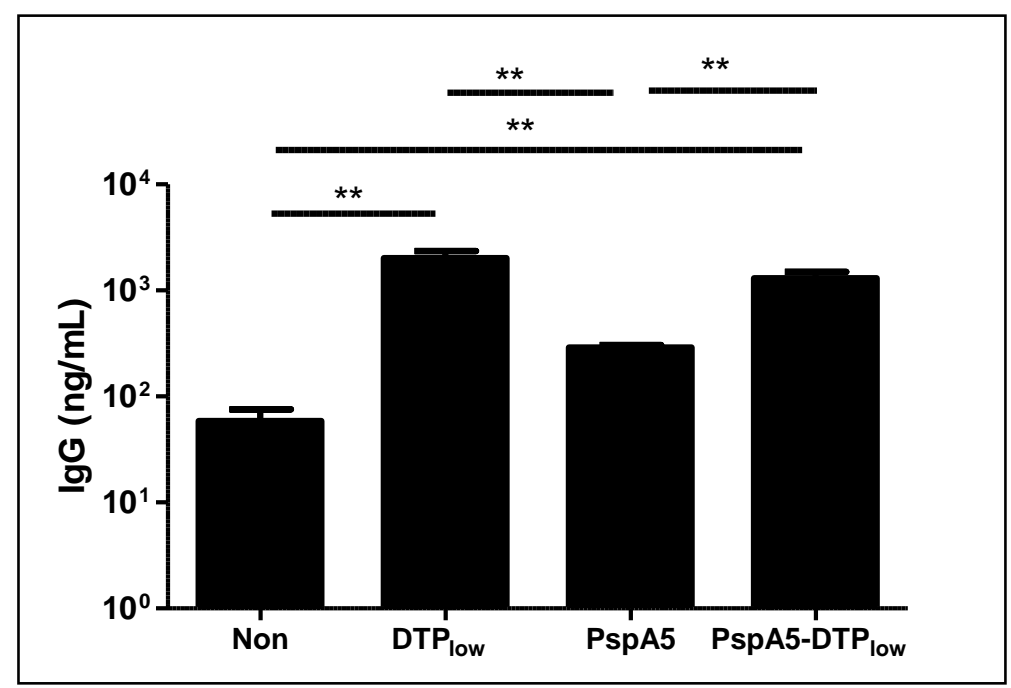

As barras representam as médias de 6 animais por grupo com os desvios padrão. Non $=$ soros de camundongos não imunizados. Os asteriscos apontam para os valores estatisticamente diferentes $(* * \mathrm{P}=0,005$ para todas as comparações, teste de Mann Whitney).

Fonte: Lima (2012)

Os camundongos que receberam $\mathrm{DTP}_{\text {low }}$ ou PspA5-DTP $\mathrm{P}_{\text {low }}$ apresentaram uma maior concentração de IgG anti-pertussis no soro, com diferença significativa em relação ao grupo não imunizado ou ao grupo imunizado com PspA5 (conforme valores de $\mathrm{P}$ mostrados na legenda da Figura 33). Não foi observada diferença estatística na produção de IgG antiantígenos de pertussis quando comparados os animais imunizados com $\mathrm{DTP}_{\text {low }}$ em relação aos animais imunizados com PspA5-DTP low $_{\text {. }}$ 


\subsubsection{Avaliação da proteção contra desafio com B. pertussis}

Como os resultados sugerem que não há prejuízo da resposta imune humoral contra antígenos de pertussis na presença de PspA5, decidiu-se avaliar a proteção induzida pela

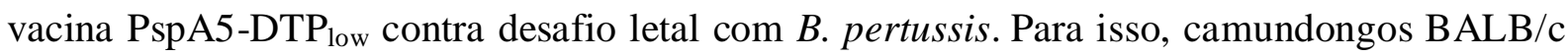
imunizados por via subcutânea, foram desafiados com a linhagem 18323 de B. pertussis.

Tabela 7 - Sobrevivência dos camundongos BALB/c imunizados por via subcutânea, após desafio com a linhagem 18323 de B. pertussis.

\begin{tabular}{lccc}
\hline & Vivos/total & Sobrevivência & $\boldsymbol{P}^{*}$ \\
\hline Non & $1 / 12$ & $8,3 \%$ & -- \\
DTP $_{\text {low }}$ & $7 / 12$ & $58,3 \%$ & 0,01 \\
PspA5 & $1 / 12$ & $8,3 \%$ & -- \\
PspA5-DTP & & $58,3 \%$ & 0,01 \\
\hline
\end{tabular}

* Valores em relação ao grupo não imunizado (Non), pelo teste exato de Fisher Fonte: Lima (2012)

O modelo de desafio utilizado foi o intracerebral, que apesar de bastante agressivo, é o desafio padrão, adotado pela Divisão de Desenvolvimento Tecnológico do Instituto Butantan para os testes dos lotes de vacina produzidos. A tabela 7 mostra que camundongos não imunizados ou que receberam PspA5 apresentaram uma sobrevivência baixa, de 8,3\%. Por outro lado, ambas as formulações DTP low $_{\text {PspA5-DTP }}$ low induziram 58,3\% de sobrevivência. 
4.5.3 Análise da reatividade dos soros dos camundongos imunizados por via subcutânea contra o toxoide tetânico

Além da resposta imune contra antígenos de pertussis, foi avaliada a presença de anticorpos IgG anti-toxoide tetânico nos soros dos camundongos imunizados por via subcutânea com as diferentes formulações (Figura 34).

Figura 34 - Concentrações de IgG anti-toxoide tetânico nos soros de camundongos imunizados por via subcutânea.

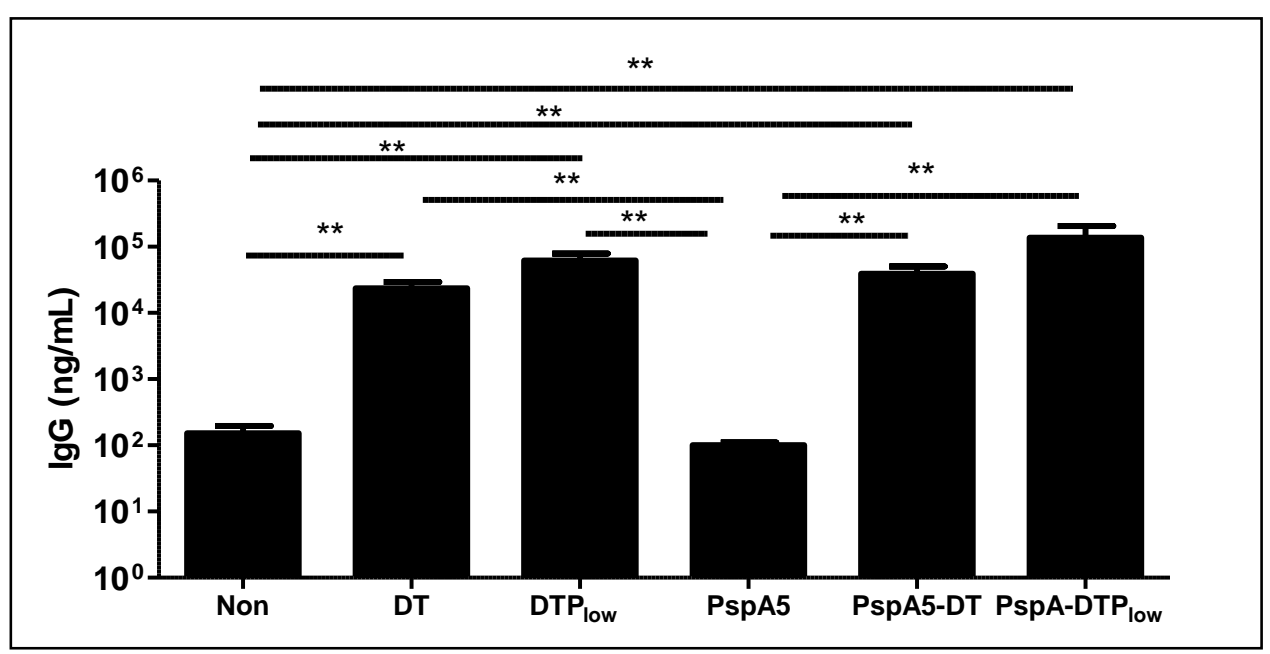

As barras representam as médias de 6 animais por grupo com os desvios padrão. Non $=$ soros de camundongos não imunizados. Os asteriscos apontam para os valores estatisticamente diferentes ( $* * \mathrm{P}<0,005$, teste de Mann Whitney).

Fonte: Lima (2012)

Camundongos que receberam DT, DTP ${ }_{\text {low }}$, PspA5-DT e PspA5-DTP low $_{\text {apresentaram }}$ altas concentrações de IgG anti-toxoide tetânico, com diferença significativa em relação aos camundongos não imunizados ou imunizados com PspA5 (valores de $\mathrm{P}$ anotados na legenda da Figura 34). 


\section{$\underline{\text { 4.5.4 Proteção contra desafio com toxina tetânica }}$}

Os camundongos imunizados com as diferentes formulações, foram submetidos à desafio com a toxina tetânica (Tabela 8).

Tabela 8 - Sobrevivência dos camundongos BALB/c imunizados por via subcutânea, após desafio com toxina tetânica.

\begin{tabular}{lccc}
\hline & Vivos/total & sobrevivência & $\boldsymbol{P}^{*}$ \\
\hline Non & $1 / 6$ & $16,6 \%$ & -- \\
DTP $_{\text {low }}$ & $6 / 6$ & $100 \%$ & 0,01 \\
PspA5 & $0 / 6$ & -- & -- \\
PspA5-DTP & & $100 \%$ & 0,01 \\
\hline
\end{tabular}

* Valores em relação ao grupo não imunizado (Non), pelo teste Teste exato de Fisher Fonte: Lima (2012)

Na dose utilizada, a toxina tetânica levou à morte de quase todos os camundongos não imunizados (Non) ou imunizados com PspA5. Por outro lado, os camundongos que receberam

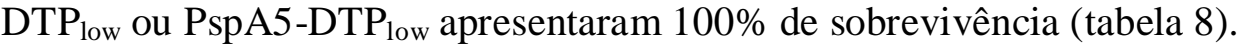


4.5.5 Análise da reatividade dos soros dos camundongos imunizados por via subcutânea $\underline{\text { contra toxoide diftérico }}$

A análise da reatividade dos soros contra o toxoide diftérico também foi realizada por ELISA (Figura 35).

Figura 35 - Concentrações de IgG anti-toxoide diftérico nos soros de camundongos imunizados por via subcutânea.

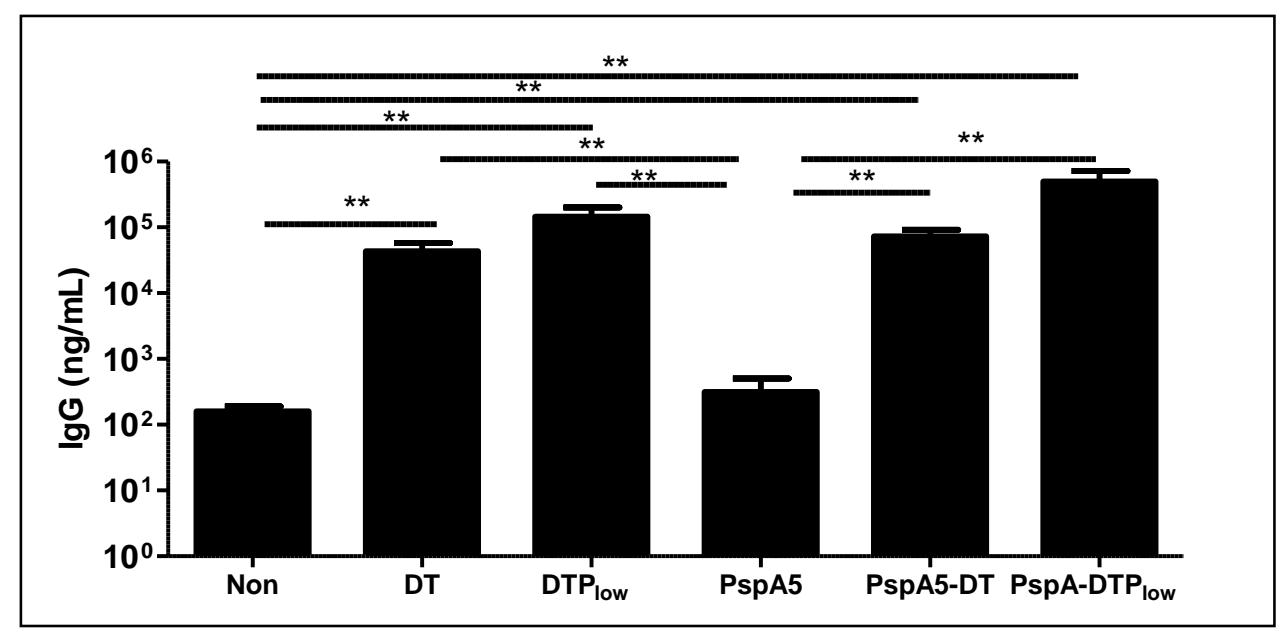

As barras representam as médias de 6 animais por grupo com os desvios padrão. Non $=$ soros de camundongos não imunizados. Os asteriscos apontam para os valores estatisticamente diferentes ( $* * \mathrm{P}<0,005$, teste de Mann Whitney).

Fonte: Lima (2012)

Camundongos imunizados com DT, DTP ${ }_{\text {low }}$, PspA5-DT e PspA-DTP low $_{\text {apresentaram }}$ concentrações elevadas de anticorpos anti-toxoide diftérico, que foram significativamente mais altas em relação às observadas nos animais não vacinados (Non) ou imunizados com PspA5 (valor de P na legenda da Figura 35). 
4.5.5 Análise da neutralização da toxina diftérica induzida pelo soro dos camundongos imunizados por via subcutânea

Os soros dos camundongos imunizados por via subcutânea foram utilizados para verificar a capacidade de neutralizar a ação citotóxica da toxina diftérica sobre as células Vero. Para isto, os soros de animais imunizados com as diferentes formulações foram incubados com com 2X a DL50 da toxina diftérica e, após 1h, a mistura foi incubada na presença de células Vero. O cultivo foi mantido por 4 dias. As células sobreviventes são capazes de se dividir e podem ser fixadas e coradas ao final do período de incubação. Os resultados estão demonstrados na Figura 36. 
Figura 36 - Ensaio de neutralização da toxina diftérica com os diferentes soros experimentais.

A

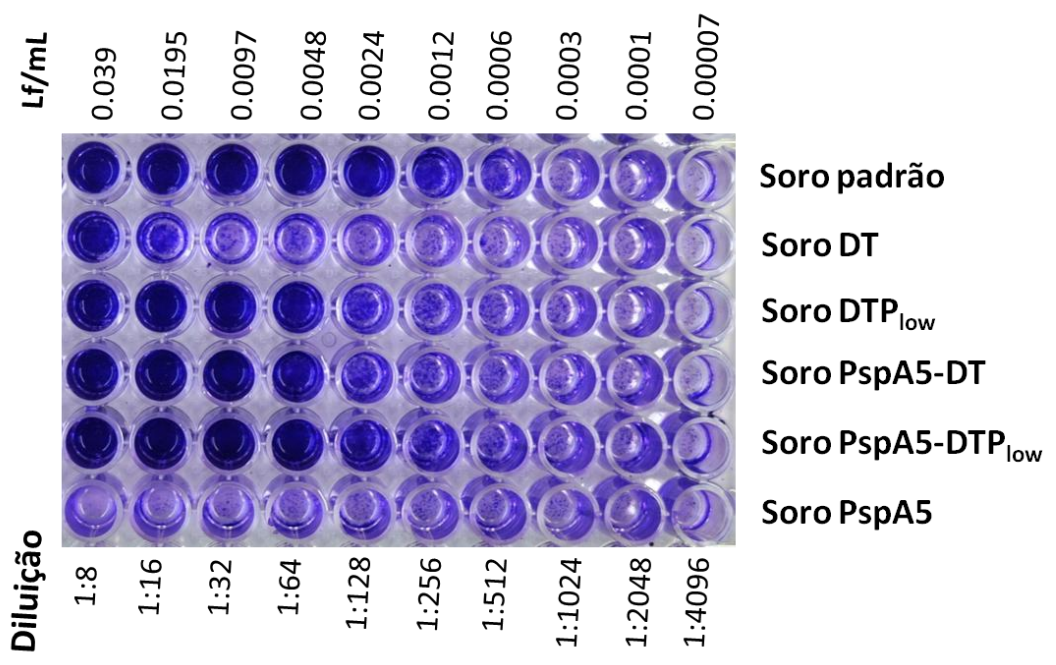

B

C

soro anti-diftérico
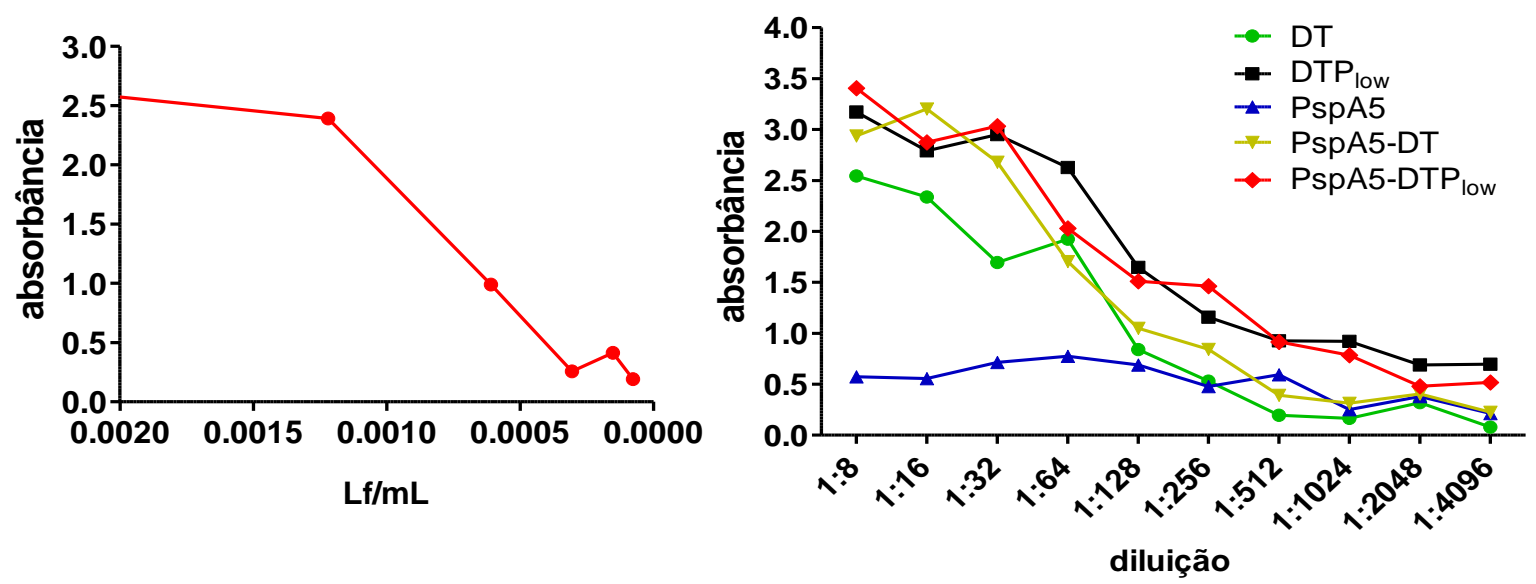

Foram adicionadas diluições seriadas (1 para 2) soro anti diftérico e do soro de

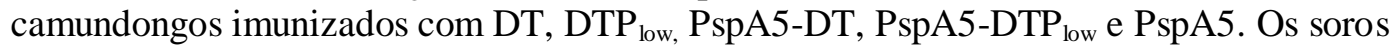
dos camundongos imunizados foram reunidos em pools de cada grupo. Após o perído de incubação das células Vero com as misturas da toxina com os diferentes soros, as células sobreviventes ao ensaio foram fixadas em formaldeído contendo cristal violeta (A) Placa com representativa de um experimento, (B) curva obtida pela neutralização da toxina diftérica induzida pelo soro anti-diftérico padrão (C) curvas obtidas com os soros de camundongos imunizados com DT, DTP low, PspA5, PspA5-DT e PspA5-DTP low. Os valores de absorbância foram obtidos pela leitura do corante após eluição com etanol $100 \%$. Os gráficos foram compostos pelos dados obtidos de experimentos realizados com soros de 2 experimentos de imunização independentes.

Fonte: Lima (2012) 
A neutralização toxina diftérica induzida pelos soros dos camundongos imunizados demonstrou que aproximadamente $50 \%$ de células vivas são observadas nas diluições de 1:64,

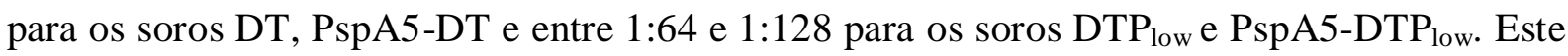
mesmo resultado foi observado para $0,0010 \mathrm{Lf} / \mathrm{mL}$ do soro anti-diftérico padrão (Figura $36 \mathrm{~B}$ e C). 


\section{DISCUSSÃO}

Mais de dez anos passaram-se desde o licenciamento da primeira vacina pneumocócica conjugada e as doenças pneumocócicas ainda causam a morte de quase 1 milhão de crianças no mundo todos os anos (O'Brien et al., 2009). As vacinas conjugadas conferem proteção sorotipo específica, podendo causar a substituição dos sorotipos prevalentes numa determinada população por sorotipos não cobertos por elas, conforme foi observado após a introdução da vacina PCV7 em alguns países (Weinberger et al., 2011). Por isso, torna-se imprescindível o desenvolvimento de novas vacinas que sejam eficientes e de baixo custo. Neste trabalho a proposta foi utilizar o antígeno proteico PspA5 para a formulação de uma vacina contra pneumococo, em combinação com a vacina celular pertussis como adjuvante.

Trabalhos anteriores demonstraram que PspA é um antígeno vacinal eficiente em diferentes modelos animais (Briles et al., 2003; Ferreira et al., 2010; Oma et al., 2009). A região N-terminal de PspA está exposta ao sistema imune e contém epítopos protetores. Provavelmente por este motivo, PspAs de diferentes isolados de pneumococo apresentam variabilidade de sequência de aminoácidos nesta região, sendo classificados em 6 diferentes clados. Apesar disso, a imunização de camundongos com os PspAs dos clados 4 e 5 confere proteção cruzada contra linhagens que expressam PspAs de diferentes clados em modelos de desafio em camundongos BALB/c (Moreno et al., 2010). Neste trabalho, o antígeno PspA5 foi escolhido para avaliar o potencial adjuvante da vacina pertussis.

O uso da vacina celular pertussis como adjuvante têm sido investigado em diferentes modelos. A imunização nasal com uma vacina composta pelo vírus influenza inativado em combinação com a vacina celular pertussis conferiu aumento de IgG e IgA anti-influenza no soro e de IgA anti-influenza na saliva dos camundongos imunizados (Berstad et al., 2000a). Entre as estratégias realizadas em humanos, destaca-se a administração da vacina wDTP combinada com a vacina contra Hepatite B (HBV) em crianças. Esta combinação induziu o aumento de anticorpos anti-hepatite B quando comparada à vacina HBV sozinha (Prikazsky e Bock, 2001). Outro estudo demonstrou que a imunização de crianças com uma vacina acelular pertussis juntamente com a vacina conjugada contra pneumococo 11 valente (PncD/T11, Aventis Pasteur) reduziu a concentração de anticorpos contra os diferentes sorotipos de 
pneumococo cobertos pela vacina. Por outro lado, quando a vacina PncD/T11 foi combinada com uma vacina celular pertussis, este efeito não foi observado (Dagan et al., 2004).

Apesar de a vacina pertussis ser administrada em crianças pela via intramuscular, alguns grupos propõem o uso de vacinas inativadas ou atenuadas por via nasal (Berstad et al., 2000a; Locht, 2008; Mielcarek et al., 2006). Em voluntários humanos, a inoculação da bactéria inativada por via nasal induziu anticorpos séricos e de mucosa, além de resposta de células T específicas para antígenos de pertussis (Berstad et al., 2000b; Berstad et al., 2000c). Esta via também é comumente proposta para o desenvolvimento de novas vacinas contra Streptococcus pneumoniae (Arulanandam et al., 2001; Briles et al., 2000b; Fukuyama et al., 2010; Oma et al., 2009).

No modelo de desafio com a linhagem de pneumococo ATCC6303 estabelecido no nosso laboratório observa-se que camundongos não imunizados começam a demonstrar os primeiros sinais da doença $24 \mathrm{~h}$ após o desafio intranasal. Neste período a quantidade de bactérias recuperadas no pulmão dos camundongos começa a aumentar gradativamente até 60 h após o desafio, período em que os animais apresentam ereção dos pêlos, perda de peso e de atividade. Em aproximadamente $30 \mathrm{~h}$, as bactérias começam a invadir a corrente sanguínea e os animais morrem entre 72 h e 5 dias após o desafio (Ferreira et al., 2009b). Por outro lado, em estudo recente, nosso grupo demonstrou que camundongos imunizados com PspA5-wP ou PspA5-wP $\mathrm{P}_{\text {low }}$ não apresentam níveis detectáveis de bactéria no sangue em diferentes períodos após o desafio (Oliveira et al. 2010).

Os resultados obtidos no presente trabalho demonstraram que a imunização nasal de camundongos com PspA5 induziu aumento de anticorpos específicos no sangue dos camundongos. Entretanto, quando combinado a wP ou wP $\mathrm{P}_{\text {low }}$, concentrações ainda mais altas de anticorpos anti-PspA5 nos soros dos camundongos foram observadas. Além do aumento de anticorpos no soro, também se observou que as vacinas PspA5-wP ou PspA5-wP $\mathrm{P}_{\text {low }}$ induziram aumento de anticorpos dos tipos IgA e IgG, bem como dos subtipos IgG1 e IgG2a antiPspA5 nos pulmões dos camundongos imunizados. Realizando ensaios in vitro com o BALF destes camundongos, detectou-se maior capacidade de ligação destes anticorpos à superfície de S. pneumoniae. Através do uso de mutantes da linhagem ATCC6303 que não expressam os antígenos PspA e/ou PspC, observamos que estes anticorpos reagem especificamente com a proteína PspA. A ligação de IgA na superfície das bactérias que não expressam PspA foi abolida, enquanto que uma reatividade mais baixa foi observada para a ligação de IgG no 
mutante $6303^{\text {PspA- }}$. A ausência desta ligação no mutante $6303^{\text {PspA-/PspC }}$ indica que a reatividade cruzada da IgG nos BALFs dos animais imunizados com PspA5-wP ou PspA5-wP low $_{\text {é contra }}$ o antígeno PspC, e pode ser explicada pela presença de epítopos comuns aos dois antígenos (Brooks-Walter et al., 1999). Os altos níveis de anticorpos anti-PspA5 presentes no soro e nas mucosas podem ser responsáveis por impedir a passagem das bactérias para o sangue ou pela sua eliminação assim que atingem a corrente sanguínea. O papel dos anticorpos neste modelo é reforçado pela proteção observada no ensaio de imunização passiva, onde o soro dos animais imunizados com PspA5-wP foi capaz de conferir sobrevivência a $75 \%$ dos camundongos.

A capacidade de inibir a fixação do componente C3 do sistema complemento à superfície da bactéria é um papel já descrito para PspA, que possibilita a evasão do sistema imune (Ren et al., 2004; Tu et al., 1999). Anticorpos anti-PspA apresentam a capacidade de reverter esta inibição in vitro (Ren et al., 2004). A indução de diferentes subtipos de IgG caracteriza o tipo de resposta imune induzida, sendo que a presença de mais IgG1 em camundongos caracteriza uma resposta Th (T-helper) 2 (Th2), enquanto que a presença de mais IgG2a caracteriza uma resposta Th1. Em publicações anteriores, anticorpos IgG2a antiPspA foram associados à maior indução de deposição de complemento na superfície de pneumococos. Vacinas capazes de induzir este tipo de resposta foram mais eficazes em conferir proteção contra pneumococo em modelos animais (Arulanandam et al., 2001; Ferreira et al., 2008). No presente trabalho, demonstrou-se que as amostras de BALF dos camundongos imunizados com PspA5-wP ou PspA5-wP $\mathrm{P}_{\text {low }}$ induziram maior deposição do componente $\mathrm{C} 3$ do complemento à superfície do pneumococo, in vitro. Estas também foram as duas formulações que induziram maiores níveis de IgG2a capazes de se ligar à superfície da bactéria in vitro.

Não foi observada diferença significativa em relação ao uso das diferentes vacinas celulares (wP e $\mathrm{wP}_{\text {low }}$ ) como adjuvantes para a indução de anticorpos e proteção dos camundongos contra o desafio letal com pneumococo, demonstrando que a menor quantidade de LPS presente na vacina ${ } \mathrm{P}_{\text {low }}$ não prejudicou sua atividade adjuvante. Além disso, a imunização nasal de camundongos da linhagem $\mathrm{C} 3 \mathrm{H} / \mathrm{HeJ}$, que apresentam mutação pontual no receptor TLR4, tornando-o não responsivo a LPS, com PspA5-wP, induziu altos níveis de anticorpos anti-PspA5 e proteção contra o desafio letal com pneumococo. Estes resultados foram similares aos observados nas linhagens de camundongos $\mathrm{C} 3 \mathrm{H} / \mathrm{HePas}$ (parental) e BALB/c. Assim, a atividade adjuvante observada não é dependente da sinalização por TLR4. 
Para determinar se o LPS presente na vacina celular pertussis não estava exercendo atividade adjuvante pela ativação de outro receptor diferente de TLR4, camundongos $\mathrm{C} 3 \mathrm{H} / \mathrm{HeJ}$ foram imunizados com PspA5 em combinação com LPS de B. pertussis. Porém, a indução de anticorpos sistêmicos e a sobrevivência observada em desafio letal foram semelhantes às observadas em camundongos imunizados somente com PspA5. Esses resultados demonstram que o LPS não é determinante para a atividade adjuvante conferida pela vacina celular pertussis neste modelo. A ação adjuvante exercida pela vacina pertussis pode ser dada por outros componentes da bactéria como a toxina pertussis, a adenilato ciclase ou a adesina FHA e deve ser investigada neste modelo (McGuirk et al., 2000; Poulain-Godefroy et al., 2008; Ryan et al., 1998)

Apesar das bactérias não serem detectadas na corrente sanguínea de camundongos imunizados com PspA5-wP ou PspA5-wP $\mathrm{P}_{\text {low }}$, a quantidade de bactérias nos pulmões é relativamente constante algumas horas após o desafio e começa a reduzir gradativamente após 72h. Níveis baixos de pneumococo ainda são detectados em 10 e 21 dias após o desafio (Oliveira et al., 2010). Apesar desta redução gradativa, um pico de resposta inflamatória nos pulmões, com indução de citocinas e influxo de células imunes ocorre $12 \mathrm{~h}$ após o desafio. Este pico é rapidamente controlado nos animais imunizados com PspA5-wP ou PspA5-wP low (dados não publicados). Estes dados indicam que há um controle forte da resposta imu ne pulmonar nos animais vacinados neste ponto, que pode estar relacionado à sobrevivência. Por este motivo, neste trabalho escolheu-se o ponto de $12 \mathrm{~h}$ para a análise mais detalhada da resposta imune humoral e celular nos pulmões. Inicialmente, em animais não desafiados, observou-se aumento significativo de linfócitos no pulmão dos camundongos imunizados com PspA5-wP ou PspA5-wP $\mathrm{P}_{\text {low }}$, que foram caracterizados como linfócitos $\mathrm{T} \mathrm{CD}^{+}, \mathrm{T} \mathrm{CD}^{+}$e B. Em análise efetuada no pico da resposta inflamatória (12 h após o desafio) observou-se aumento apenas dos linfócitos $\mathrm{T} \mathrm{CD}^{+}$e $\mathrm{B}$ nos camundongos imunizados com PspA5-wP low. Os dados também mostraram que neste ponto, ainda se observam altos níveis de IgG e IgA anti-PspA5 nestes animais. Por outro lado, as análises realizadas em camundongos sobreviventes, dez dias após o desafio, mostraram que apenas os linfócitos B no pulmão de camundongos imunizados com PspA5-wP e PspA5-wP $\mathrm{P}_{\text {low }}$ ainda se apresentavam elevados. Neste ponto foram observados também níveis significativamente mais altos de IgG e IgA antiPspA5 na mucosa respiratória. Em comparação com os pontos anteriores as concentrações foram aparentemente mais baixas, possivelmente por um esgotamento dos anticorpos pela ligação às bactérias presentes no pulmão. 
Um estudo realizado recentemente demonstrou que uma vacina composta por PspA combinada a uma vacina de DNA expressando Flt3, um importante adjuvante de mucosa, quando inoculada por via nasal em camundongos, induziu altos níveis de IgA anti-PspA e conferiu proteção contra colonização por pneumococo. A importância destes anticorpos para a proteção foi demonstrada em camundongos deficientes para a produção de $\operatorname{IgA}$, que não foram protegidos pela formulação, mesmo apresentando elevadas concentrações de IgG antiPspA na mucosa respiratória e na saliva (Fukuyama et al., 2010). Nossos resultados sugerem um papel importante dos anticorpos pulmonares para a proteção no modelo de desafio invasivo. No entanto, mais estudos são necessários para a determinação da necessidade destes anticorpos, tanto IgA como IgG anti-PspA, para a proteção.

A proteção contra colonização por pneumococo em modelos animais, induzida por uma vacina celular inativada ou por uma formulação proteica, contendo os antígenos PspC, PsaA e pneumolisina é dependente de células T $\mathrm{CD}^{+}{ }^{+}$circulantes secretoras da citocina IL-17 (Basset et al., 2007; Lu et al., 2008; Malley et al., 2005). Por outro lado, em um estudo realizado recentemente demonstrou-se que linfócitos $\mathrm{T} C \mathrm{CD} 8^{+}$são importantes na proteção contra infecção pneumocócica invasiva, já que camundongos deficientes em linfócitos $\mathrm{T}$ $\mathrm{CD}^{+}$apresentaram menor sobrevivência a um desafio respiratório letal. A depleção destas células em camundongos C57Bl/6 através da inoculação de anticorpos anti-CD8, produziu o mesmo efeito. Este mesmo estudo indica que os linfócitos T CD4 ${ }^{+}$não são determinantes para a proteção dos camundongos neste modelo, pois camundongos deficientes em linfócitos $\mathrm{T}$ $\mathrm{CD}^{+}$apresentaram sobrevivência semelhante à observada em camundongos selvagens após o desafio (Weber et al., 2011). Apesar de observarmos infiltração de linfócitos T CD4 ${ }^{+}, \mathrm{T}_{\mathrm{CD}}{ }^{+}$ e B nos animais vacinados com as formulações PspA5-wP ou PspA5-wP $\mathrm{P}_{\text {low }}$, apenas os linfócitos B permaneceram altos em todos os pontos analisados. Entretanto, para determinar a importância destes tipos celulares para a proteção induzida pelas vacinas, seria necessária a realização de outros ensaios, como, por exemplo, a depleção dos linfócitos T CD4 ${ }^{+}, \mathrm{T}_{\mathrm{CD}}{ }^{+}$ ou B, no momento do desafio, em animais imunizados.

Em ensaios de Western Blot observou-se que os soros de camundongos imunizados com PspA5-wP e PspA5-w $\mathrm{P}_{\text {low }}$ apresentaram reatividade aumentada contra PspAs de diferentes clados expressos por diferentes linhagens de $S$. pneumoniae. Este resultado pode ocorrer devido à maior concentração de anticorpos anti-PspA5 presentes no soro dos camundongos imunizados com as combinações ou à indução de anticorpos que reconhecem melhor domínios comuns aos diferentes clados de PspA. A proteção cruzada conferida pela vacina PspA5-wP foi avaliada por um desafio de colonização com a linhagem 603, que 
expressa PspA do clado 1. Os resultados demonstraram que a vacina PspA5-wP reduziu significativamente a colonização dos camundongos imunizados, sendo mais eficiente que a proteína sozinha. Estes resultados comprovam que a melhora na reatividade cruzada tem efeito benéfico na proteção contra uma linhagem que expressa um PspA heterólogo, neste modelo animal. A imunização intramuscular de uma vacina de DNA expressando PspA5 também promoveu proteção cruzada, reduzindo a colonização de camundongos C57B1/6 pela linhagem de S. pneumoniae 603, corroborando nossos resultados. Além disso, a imunização passiva de camundongos com o soro de camundongos imunizados com esta vacina de DNA também foi capaz de reduzir a colonização por pneumococo, indicando que os anticorpos sistêmicos também possuem papel importante na proteção contra colonização. A vacina de DNA expressando PspA5 induziu elevadas concentrações de IgG no soro dos camundongos, com balanço de IgG1 e IgG2a (Ferreira et al., 2010), semelhante ao que se observa na

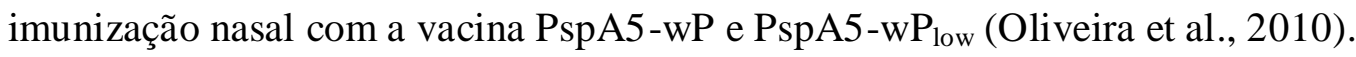

O resultado de proteção obtido no ensaio de imunização passiva nos incentivou a testar formulações vacinais por outras vias. A partir daí, foi realizada a imunização de camundongos por via subcutânea, utilizando a vacina DTP $_{\text {low }}$ como adjuvante. Somente uma

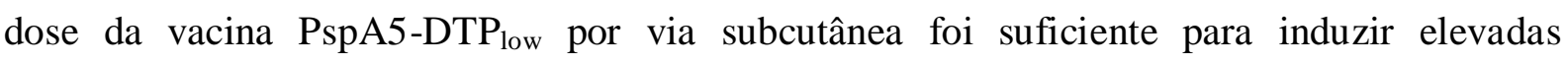
concentrações de anticorpos anti-PspA5 no soro e proteger $100 \%$ dos camundongos contra o desafio letal com a linhagem ATCC6303 (que expressa PspA5) e proteger parcialmente $(66,6 \%)$ contra o desafio com a linhagem A66.1 (que expressa PspA2). Animais imunizados com PspA5-DT também foram desafiados com ATCC6303 e A66.1. No entanto observamos que esta combinação promoveu uma proteção menor (66,6 e 50\%, respectivamente). Isto indica que o componente pertussis tem capacidade de modular a resposta, promovendo melhor proteção. No entanto, até o momento, não foi possível definir os elementos determinantes para as diferenças observadas com as duas formulações, pois ambas induziram elevadas concentrações de anticorpos do tipo IgG anti-PspA5 no soro e balanço de

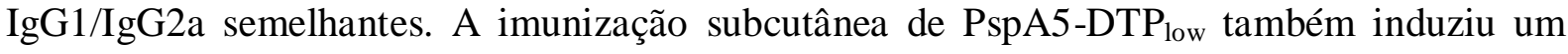
aumento da concentração de anticorpos anti-PspA5 do tipo IgG no pulmão dos camundongos antes e 12 h após o desafio com a linhagem ATCC6303. Seria interessante avaliar se a formulação PspA5-DT também é capaz de induzir estes anticorpos. Por outro lado, não foi observado aumento das concentrações de IgA anti-PspA5 nos BALFs dos camundongos imunizados com PspA5-DTP ${ }_{\text {low }}$ (dados não mostrados). Além disso, a análise do BALF demonstrou que não houve alteração em relação ao total de células e de linfócitos nos pulmões dos camundongos imunizados antes ou após o desafio (dados observados 12h após o 
desafio, não mostrados). Juntos, esses resultados sugerem que o mecanismo de proteção induzido por PspA5-DTP ${ }_{\text {low }}$ é independente da infiltração de linfócitos e da presença de IgA nos pulmões dos camundongos.

Após a avaliação da resposta imune contra pneumococo induzida pela combinação de PspA5 com as vacinas celulares pertussis ( $\mathrm{wP}$ e $\mathrm{wP}_{\text {low }}$ ) e com a vacina $\mathrm{DTP}_{\text {low }}$, foram realizadas avaliações sobre a o efeito de PspA5 nas respostas imunes induzidas contra pertussis, tétano e difteria. Em ensaios de Western Blot e ELISA, demonstrou-se que os soros de camundongos imunizados com PspA5-wP, PspA5-wP $P_{\text {low }}$ ou com PspA5-DTP low $_{\text {low }}$ apresentaram reatividade anti-pertussis semelhante à observada com os soros de camundongos imunizados com $\mathrm{wP}, \mathrm{wP}_{\text {low }}$ ou $\mathrm{DTP}_{\text {low. }}$. Além disso, a proteção conferida pela formulação PspA5-DTP ${ }_{\text {low }}$ foi equivalente àquela conferida pela vacina $\mathrm{DTP}_{\text {low }}$ contra $\mathrm{o}$ desafio intracerebral com $B$. pertussis. Esses resultados comprovam que a resposta contra pertussis não foi afetada quando incluímos PspA5 à vacina $\mathrm{DTP}_{\text {low. }}$ A avaliação da resposta contra tétano foi realizada por meio de ELISA utilizando o toxoide tetânico. Este ensaio demonstrou que concentrações equivalentes de anticorpos anti-toxoide tetânico foram detectadas nos soros de camundongos imunizados com PspA5-DTP low $_{\text {e }}$ DTP $_{\text {low }}$ Ambas as formulações conferiram $100 \%$ de proteção contra o desafio com a toxina tetânica, comprovando que também para este componente, não há prejuízo pela adição de PspA5. A avaliação da resposta contra difteria também foi realizada por ELISA e também demonstrou que animais imunizados com PspA5-DTP low $_{\text {e }}$ DTP $_{\text {low }}$ apresentaram concentrações semelhantes de anticorpos anti-toxoide diftérico. O ensaio biológico para certificação e liberação de lotes da vacina contra difteria é realizado pela neutralização da toxina in vivo, em cobaios, expressa em unidades internacionais (UI) por mL. Entretanto, o soro anti-diftérico padrão utilizado neste trabalho foi quantificado pelo ensaio de floculação em tubo de ensaio quando em contato com a toxina diftérica, sendo expresso em $\mathrm{Lf} / \mathrm{mL}$. Esta medida não tem relação direta com a UI apresentada pelo soro (Lyng et al., 1990). O ensaio de neutralização da atividade citotóxica da toxina diftérica em células Vero foi proposto como alternativa ao ensaio biológico (Gupta e Siber, 1996; Mazzantini et al., 2004). Este ensaio foi escolhido neste trabalho para a comparação dos diferentes soros provenientes dos camundongos imunizados. Os resultados mostraram que os soros de animais imunizados com DT, DTP ${ }_{\text {low }}$, PspA5-DT e PspA5-DTP ${ }_{\text {low }}$ apresentaram capacidade semelhante de neutralizar a atividade citotóxica da toxina diftérica em células Vero. Estes dados indicam que a combinação de 
PspA5 com vacina $\mathrm{DTP}_{\text {low }}$ também não prejudica a resposta imune induzida em camundongos contra a toxina diftérica.

A vacina DTP é administrada em crianças brasileiras há muitos anos, sem relatos de efeitos adversos graves. A inclusão do antígeno PspA5 na vacina DTP, apresenta algumas vantagens, como por exemplo a aplicação de doses únicas, formando uma vacina tetravalente. Esta estratégia seria válida para a redução de visitas às Unidades de Saúde, um fator importante em lugares onde há dificuldades de acesso aos postos de vacinação e para a redução de custos das vacinações em massa. 


\section{CONCLUSÕES}

A combinação de PspA5 com as vacinas $w \mathrm{P}$ ou $\mathrm{wP}_{\text {low }}$ por via nasal protegeu camundongos contra desafio letal ou de colonização com pneumococo. A resposta imune foi caracterizada por uma produção elevada de anticorpos sistêmicos e de mucosa e um influxo de linfócitos no pulmão, caracterizados como T CD4 ${ }^{+}, \mathrm{T} \mathrm{CD}^{+}$e B.

O LPS de B. pertussis não é essencial para a atividade adjuvante da vacina wP neste modelo.

A combinação de PspA5 com a vacina DTP $_{\text {low }}$ administrada por via subcutânea protegeu os camundongos em desafios letais com pneumococo, e induziu elevadas concentrações de anticorpos do tipo IgG no soro e no BALF dos camundongos imunizados. Os resultados também sugerem que a proteção, neste caso, não é dependente do influxo de linfócitos no pulmão.

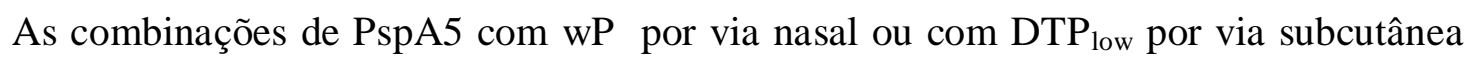
foram mais eficazes que a proteína sozinha em conferir proteção cruzada contra linhagens de pneumococo que expressam PspAs heterólogos

Não há prejuízo na resposta de anticorpos contra toxoide diftérico, toxoide tetânico ou antígenos de pertussis quando o antígeno PspA5 é incluído na vacina $\mathrm{DTP}_{\text {low. }}$ A combinação PspA5-DTP $_{\text {low }}$ foi tão efetiva quanto a vacina DTP $_{\text {low }}$ em proteger os camundongos em desafio com $B$. pertussis e com a toxina tetânica ou em neutralizar a toxina diftérica em ensaio in vitro. 


\section{REFERÊNCIAS}

Abreu PA, Miyasato PA, Vilar MM, Dias WO, Ho PL, Tendler M, Nascimento AL. Sm14 of Schistosoma mansoni in fusion with tetanus toxin fragment $\mathrm{C}$ induces immunoprotection against tetanus and schistosomiasis in mice. Infect Immun 2004 72(10): 5931-5937.

Aida Y, Pabst MJ. Removal of endotoxin from protein solutions by phase separation using Triton X114. J Immunol Methods, 1990 132(2): 191-195.

Areas AP, Oliveira ML, Miyaji EN, Leite LC, Ho PL. Intradermal immunization of mice with cholera toxin B-pneumococcal surface protein A fusion protein is protective against intraperitoneal challenge with Streptococcus pneumoniae. Infect Immun 2005 73(6): 3810-3813.

Arulanandam BP, Lynch JM, Briles DE, Hollingshead S, Metzger DW. Intranasal vaccination with pneumococcal surface protein A and interleukin-12 augments antibody-mediated opsonization and protective immunity against Streptococcus pneumoniae infection. Infect Immun 2001 69(11): 67186724.

Basset A, Thompson CM, Hollingshead SK, Briles DE, Ades EW, Lipsitch M, Malley R. Antibodyindependent, CD4+ T-cell-dependent protection against pneumococcal colonization elicited by intranasal immunization with purified pneumococcal proteins. Infect Immun 2007 75(11): 5460-5464.

Berstad AK, Andersen SR, Dalseg R, Dromtorp S, Holst J, Namork E, Wedege E, Haneberg B. Inactivated meningococci and pertussis bacteria are immunogenic and act as mucosal adjuvants for a nasal inactivated influenza virus vaccine. Vaccine 2000a 18(18): 1910-1919.

Berstad AK, Holst J, Froholm LO, Haugen IL, Wedege E, Oftung F, Haneberg B. A nasal whole-cell pertussis vaccine induces specific systemic and cross-reactive mucosal antibody responses in human volunteers. J Med Microbiol 2000b 49(2): 157-163.

Berstad AK, Oftung F, Korsvold GE, Haugen IL, Froholm LO, Holst J, Haneberg B. Induction of antigen-specific $\mathrm{T}$ cell responses in human volunteers after intranasal immunization with a whole-cell pertussis vaccine. Vaccine 2000c 18(22): 2323-2330.

Bettinger JA, Scheifele DW, Kellner JD, Halperin SA, Vaudry W, Law B, Tyrrell G. The effect of routine vaccination on invasive pneumococcal infections in Canadian children, Immunization Monitoring Program, Active 2000-2007. Vaccine 2010 28(9): 2130-2136.

Brandileone MC, Andrade AL, Teles EM, Zanella RC, Yara TI, Di Fabio JL, Hollingshead SK. Typing of pneumococcal surface protein A (PspA) in Streptococcus pneumoniae isolated during epidemiological surveillance in Brazil: towards novel pneumococcal protein vaccines. Vaccine 2004 22(29-30): 3890-3896.

\footnotetext{
*De acordo com:

International Committee of Medical Journal Editors. Uniform requirements for manuscripts submitted to Biomedical Journal: sample references. Available from: http://www.icmje.org [2007 May 22]
} 
Briles DE, Ades E, Paton JC, Sampson JS, Carlone GM, Huebner RC, Virolainen A, Swiatlo E, Hollingshead SK. Intranasal immunization of mice with a mixture of the pneumococcal proteins PsaA and PspA is highly protective against nasopharyngeal carriage of Streptococcus pneumoniae. Infect Immun 2000a 68(2): 796-800.

Briles DE, Hollingshead S, Brooks-Walter A, Nabors GS, Ferguson L, Schilling M, Gravenstein S, Braun P, King J, Swift A. The potential to use PspA and other pneumococcal proteins to elicit protection against pneumococcal infection. Vaccine 2000b 18(16): 1707-1711.

Briles DE, Hollingshead SK, Paton JC, Ades EW, Novak L, van Ginkel FW, Benjamin WH, Jr. Immunizations with pneumococcal surface protein A and pneumolysin are protective against pneumonia in a murine model of pulmonary infection with Streptococcus pneumoniae. J Infect Dis 2003 188(3): 339-348.

Brooks-Walter A, Briles DE, Hollingshead SK. The pspC gene of Streptococcus pneumoniae encodes a polymorphic protein, $\mathrm{PspC}$, which elicits cross-reactive antibodies to PspA and provides immunity to pneumococcal bacteremia. Infect Immun 1999 67(12): 6533-6542.

Calix JJ, Nahm MH. A new pneumococcal serotype, 11E, has a variably inactivated wcjE gene. J Infect Dis 2010 202(1): 29-38.

Campos IB, Darrieux M, Ferreira DM, Miyaji EN, Silva DA, Areas AP, Aires KA, Leite LC, Ho PL, Oliveira ML. Nasal immunization of mice with Lactobacillus casei expressing the Pneumococcal Surface Protein A: induction of antibodies, complement deposition and partial protection against Streptococcus pneumoniae challenge. Microbes Infect 2008 10(5): 481-488.

Constenla DO. Economic impact of pneumococcal conjugate vaccination in Brazil, Chile, and Uruguay. Rev Panam Salud Publica, 2008 24(2): 101-112.

Dagan R, Goldblatt D, Maleckar JR, Yaich M, Eskola J. Reduction of antibody response to an 11 valent pneumococcal vaccine coadministered with a vaccine containing acellular pertussis components. Infect Immun 2004 72(9): 5383-5391.

Darrieux M, Moreno AT, Ferreira DM, Pimenta FC, de Andrade AL, Lopes AP, Leite LC, Miyaji EN. Recognition of pneumococcal isolates by antisera raised against PspA fragments from different clades. J Med Microbiol 2008 57(Pt 3): 273-278.

De Carvalho AP, Pereira EM. Acellular pertussis vaccine for adolescents. J Pediatr (Rio J) 2006; 82 Supl 1: S15-24.

Ferreira DM, Darrieux M, Oliveira ML, Leite LC, Miyaji EN. Optimized immune response elicited by a DNA vaccine expressing pneumococcal surface protein a is characterized by a balanced immunoglobulin G1 (IgG1)/IgG2a ratio and proinflammatory cytokine production. Clin Vaccine Immunol 2008 15(3): 499-505.

Ferreira DM, Darrieux M, Silva DA, Leite LC, Ferreira JM, Jr., Ho PL, Miyaji EN, Oliveira ML. Characterization of protective mucosal and systemic immune responses elicited by pneumococcal surface protein PspA and PspC nasal vaccines against a respiratory pneumococcal challenge in mice. Clin Vaccine Immunol 2009a 16(5): 636-645.

Ferreira DM, Moreno AT, Cianciarullo AM, Ho PL, Oliveira ML, Miyaji EN. Comparison of the pulmonary response against lethal and non-lethal intranasal challenges with two different pneumococcal strains. Microb Pathog 2009b 47(3): 157-163. 
Ferreira DM, Oliveira ML, Moreno AT, Ho PL, Briles DE, Miyaji EN. Protection against nasal colonization with Streptococcus pneumoniae by parenteral immunization with a DNA vaccine encoding PspA (Pneumococcal surface protein A). Microb Pathog 2010 48(6): 205-213.

Fukuyama Y, King JD, Kataoka K, Kobayashi R, Gilbert RS, Oishi K, Hollingshead SK, Briles DE, Fujihashi K. Secretory-IgA antibodies play an important role in the immunity to Streptococcus pneumoniae. J Immunol 2010 185(3): 1755-1762.

Gupta RK, Siber GR. Use of in vitro Vero cell assay and ELISA in the United States potency test of vaccines containing adsorbed diphtheria and tetanus toxoids. Dev Biol Stand 1996 86: 207-215.

Harandi AM, Davies G, Olesen OF. Vaccine adjuvants: scientific challenges and strategic initiatives. Expert Rev Vaccines 2009 8(3): 293-298.

Hollingshead SK, Baril L, Ferro S, King J, Coan P, Briles DE. Pneumococcal surface protein A (PspA) family distribution among clinical isolates from adults over 50 years of age collected in seven countries. J Med Microbiol 2006 55(Pt 2): 215-221.

Hollingshead SK, Becker R, Briles DE. Diversity of PspA: mosaic genes and evidence for past recombination in Streptococcus pneumoniae. Infect Immun 2000 68(10): 5889-5900.

Hsu KK, Shea KM, Stevenson AE, Pelton SI. Changing serotypes causing childhood invasive pneumococcal disease: Massachusetts, 2001-2007. Pediatr Infect Dis J 2010 29(4): 289-293.

Kadioglu A, Weiser JN, Paton JC, Andrew PW. The role of Streptococcus pneumoniae virulence factors in host respiratory colonization and disease. Nat Rev Microbiol 2008 6(4): 288-301.

Klein JO. The epidemiology of pneumococcal disease in infants and children. Rev Infect Dis 1981 3(2): 246-253.

Langermann S, Palaszynski S, Sadziene A, Stover CK, Koenig S. Systemic and mucosal immunity induced by BCG vector expressing outer-surface protein A of Borrelia burgdorferi. Nature 1994 372(6506): 552-555.

Locht C. A common vaccination strategy to solve unsolved problems of tuberculosis and pertussis? Microbes Infect 2008 10(9): 1051-1056.

Lu YJ, Gross J, Bogaert D, Finn A, Bagrade L, Zhang Q, Kolls JK, Srivastava A, Lundgren A, Forte S, Thompson CM, Harney KF, Anderson PW, Lipsitch M, Malley R. Interleukin-17A mediates acquired immunity to pneumococcal colonization. PLoS Pathog 2008 4(9): e1000159.

Lyng J, Heron I, Ljungqvist L. Quantitative estimation of diphtheria and tetanus toxoids. 3. Comparative assays in mice and in guinea-pigs of two tetanus toxoid preparations. Biologicals 1990 18(1): 3-9.

Malley R, Trzcinski K, Srivastava A, Thompson CM, Anderson PW, Lipsitch M. CD4+ T cells mediate antibody-independent acquired immunity to pneumococcal colonization. Proc Natl Acad Sci U S A 2005 102(13): 4848-4853.

Mazzantini RP, Miyaji EN, Dias WO, Sakauchi D, Nascimento AL, Raw I, Winter N, Gicquel B, Rappuoli R, Leite LC. Adjuvant activity of Mycobacterium bovis BCG expressing CRM197 on the immune response induced by BCG expressing tetanus toxin fragment C. Vaccine 2004 22(5-6): 740746. 
McCool TL, Cate TR, Moy G, Weiser JN. The immune response to pneumococcal proteins during experimental human carriage. J Exp Med 2002 195(3): 359-365.

McGuirk P, Johnson PA, Ryan EJ, Mills KH. Filamentous hemagglutinin and pertussis toxin from Bordetella pertussis modulate immune responses to unrelated antigens. J Infect Dis 2000 182(4): 1286-1289.

Mielcarek N, Cornette J, Schacht AM, Pierce RJ, Locht C, Capron A, Riveau G. Intranasal priming with recombinant Bordetella pertussis for the induction of a systemic immune response against a heterologous antigen. Infect Immun 1997 65(2): 544-550.

Mielcarek N, Debrie AS, Raze D, Bertout J, Rouanet C, Younes AB, Creusy C, Engle J, Goldman WE, Locht C. Live attenuated B. pertussis as a single-dose nasal vaccine against whooping cough. PLoS Pathog 2006 2(7): e65.

Miyaji EN, Dias WO, Tanizaki MM, Leite LC. Protective efficacy of PspA (pneumococcal surface protein A)-based DNA vaccines: contribution of both humoral and cellular immune responses. FEMS Immunol Med Microbiol 2003 37(1): 53-57.

Moreno AT, Oliveira ML, Ferreira DM, Ho PL, Darrieux M, Leite LC, Ferreira JM, Jr., Pimenta FC, Andrade AL, Miyaji EN. Immunization of mice with single PspA fragments induces antibodies capable of mediating complement deposition on different pneumococcal strains and cross-protection. Clin Vaccine Immunol 2010 17(3): 439-446.

Nascimento IP, Dias WO, Quintilio W, Christ AP, Moraes JF, Vancetto MD, Ribeiro-Dos-Santos G, Raw I, Leite LC. Neonatal immunization with a single dose of recombinant BCG expressing subunit S1 from pertussis toxin induces complete protection against Bordetella pertussis intracerebral challenge. Microbes Infect 2008 10(2): 198-202.

Nguyen CT, Kim SY, Kim MS, Lee SE, Rhee JH. Intranasal immunization with recombinant PspA fused with a flagellin enhances cross-protective immunity against Streptococcus pneumoniae infection in mice. Vaccine 2011 29(34): 5731-5739.

Nuorti JP, Whitney CG. Prevention of pneumococcal disease among infants and children - use of 13valent pneumococcal conjugate vaccine and 23 -valent pneumococcal polysaccharide vaccine recommendations of the Advisory Committee on Immunization Practices (ACIP). MMWR Recomm Rep 2010 59(RR-11): 1-18.

O'Brien KL, Wolfson LJ, Watt JP, Henkle E, Deloria-Knoll M, McCall N, Lee E, Mulholland K, Levine OS, Cherian T. Burden of disease caused by Streptococcus pneumoniae in children younger than 5 years: global estimates. Lancet 2009 374(9693): 893-902.

Oliveira ML, Areas AP, Campos IB, Monedero V, Perez-Martinez G, Miyaji EN, Leite LC, Aires KA, Lee Ho P. Induction of systemic and mucosal immune response and decrease in Streptococcus pneumoniae colonization by nasal inoculation of mice with recombinant lactic acid bacteria expressing pneumococcal surface antigen A. Microbes Infect 2006 8(4): 1016-1024.

Oliveira ML, Miyaji EN, Ferreira DM, Moreno AT, Ferreira PC, Lima FA, Santos FL, Sakauchi MA, Takata CS, Higashi HG, Raw I, Kubrusly FS, Ho PL. Combination of pneumococcal surface protein A (PspA) with whole cell pertussis vaccine increases protection against pneumococcal challenge in mice. PLoS One 2010 5(5): e10863.

Oliveira ML, Monedero V, Miyaji EN, Leite LC, Lee Ho P, Perez-Martinez G. Expression of Streptococcus pneumoniae antigens, PsaA (pneumococcal surface antigen A) and PspA (pneumococcal surface protein A) by Lactobacillus casei. FEMS Microbiol Lett 2003 227(1): 25-31. 
Oma K, Zhao J, Ezoe H, Akeda Y, Koyama S, Ishii KJ, Kataoka K, Oishi K. Intranasal immunization with a mixture of PspA and a Toll-like receptor agonist induces specific antibodies and enhances bacterial clearance in the airways of mice. Vaccine 2009 27(24): 3181-3188.

Pimenta FC, Ribeiro-Dias F, Brandileone MC, Miyaji EN, Leite LC, Sgambatti de Andrade AL. Genetic diversity of PspA types among nasopharyngeal isolates collected during an ongoing surveillance study of children in Brazil. J Clin Microbiol 2006 44(8): 2838-2843.

Poulain-Godefroy O, Vendeville C, Locht C, Riveau G. Bordetella pertussis filamentous hemagglutinin delivered by mucosal routes enhances immunoglobulin levels in serum and mucosal fluids. FEMS Immunol Med Microbiol 2008 54(1): 129-136.

Prikazsky V, Bock HL. Higher anti-hepatitis B response with combined DTPw-HBV vaccine compared with separate administration in healthy infants at 3, 4 and 5 months of age in Slovakia. Int J Clin Pract 2001 55(3): 156-161.

Ramos CR, Abreu PA, Nascimento AL, Ho PL. A high-copy T7 Escherichia coli expression vector for the production of recombinant proteins with a minimal N-terminal His-tagged fusion peptide. Braz $\mathbf{J}$ Med Biol Res 2004 37(8): 1103-1109.

Reed SG, Bertholet S, Coler RN, Friede M. New horizons in adjuvants for vaccine development. Trends Immunol 2009 30(1): 23-32.

Ren B, Szalai AJ, Hollingshead SK, Briles DE. Effects of PspA and antibodies to PspA on activation and deposition of complement on the pneumococcal surface. Infect Immun 2004 72(1): 114-122.

Ryan M, McCarthy L, Rappuoli R, Mahon BP, Mills KH. Pertussis toxin potentiates Th1 and Th2 responses to co-injected antigen: adjuvant action is associated with enhanced regulatory cytokine production and expression of the co-stimulatory molecules B7-1, B7-2 and CD28. Int Immunol 1998 10(5): 651-662.

Shaper M, Hollingshead SK, Benjamin WH, Jr., Briles DE. PspA protects Streptococcus pneumoniae from killing by apolactoferrin, and antibody to PspA enhances killing of pneumococci by apolactoferrin [corrected]. Infect Immun 2004 72(9): 5031-5040.

Tai SS. Streptococcus pneumoniae protein vaccine candidates: properties, activities and animal studies. Crit Rev Microbiol 2006 32(3): 139-153.

Techasaensiri C, Messina AF, Katz K, Ahmad N, Huang R, McCracken GH, Jr. Epidemiology and evolution of invasive pneumococcal disease caused by multidrug resistant serotypes of 19A in the 8 years after implementation of pneumococcal conjugate vaccine immunization in Dallas, Texas. Pediatr Infect Dis J 2010 29(4): 294-300.

Tu AH, Fulgham RL, McCrory MA, Briles DE, Szalai AJ. Pneumococcal surface protein A inhibits complement activation by Streptococcus pneumoniae. Infect Immun 1999 67(9): 4720-4724.

Waltman WD, McDaniel LS, Gray BM, Briles DE. Variation in the molecular weight of PspA (pneumococcal surface protein A) among Streptococcus pneumoniae. Microb Pathog 1990 8(1): 6169.

Weber SE, Tian H, Pirofski LA. CD8+ cells enhance resistance to pulmonary serotype 3 Streptococcus pneumoniae infection in mice. J Immunol 2011 186(1): 432-442. 
Weinberger DM, Malley R, Lipsitch M. Serotype replacement in disease after pneumococcal vaccination. Lancet 2011 378(9807): 1962-1973.

WHO. Pneumococcal conjugate vaccine for childhood immunization - WHO position paper. Weekly Epidemiol Record 2007 82(12): 93-104.

Wysocki J, Tejedor JC, Grunert D, Konior R, Garcia-Sicilia J, Knuf M, Bernard L, Dieussaert I, Schuerman L. Immunogenicity of the 10-valent pneumococcal non-typeable Haemophilus influenzae protein D conjugate vaccine (PHiD-CV) when coadministered with different neisseria meningitidis serogroup C conjugate vaccines. Pediatr Infect Dis J 2009 28(4 Suppl): S77-88.

Yother J, Briles DE. Structural properties and evolutionary relationships of PspA, a surface protein of Streptococcus pneumoniae, as revealed by sequence analysis. J Bacteriol 1992 174(2): 601-609.

Zorzeto TQ, Higashi HG, da Silva MT, Carniel Ede F, Dias WO, Ramalho VD, Mazzola TN, Lima SC, Morcillo AM, Stephano MA, Antonio MA, Zanolli Mde L, Raw I, Vilela MM. Immunogenicity of a whole-cell pertussis vaccine with low lipopolysaccharide content in infants. Clin Vaccine Immunol 2009 16(4): 544-550. 


\section{ANEXO A - SOLUÇÕES E MEIOS DE CULTURA}

\section{ANEXO A.1 Soluções:}

a) Solução de lise para $S$. pneumoniae: $0,01 \%$ dodecil sulfato de sódio, $0,1 \%$ deoxicolato de sódio e $0,15 \mathrm{M}$ de citrato de sódio

b) Solução tampão de equilíbrio: Tris-HCl 50 mM, pH8, NaCl 150mM, Imidazol 5mM

c) Soluções tampão de lavagem: Tris-HCl 50mM, pH8, $\mathrm{NaCl} 150 \mathrm{mM}$ e imidazol nas concentrações $5 \mathrm{mM}, 20 \mathrm{mM}, 40 \mathrm{mM}$ ou $60 \mathrm{mM}$.

d) Solução tampão de diálise: Tris- $\mathrm{HCl} 10 \mathrm{mM}$ pH8,0, $\mathrm{NaCl} 20 \mathrm{mM}$ e glicina $0,1 \%(\mathrm{p} / \mathrm{v})$

e) Solução tampão Tris-glicina: Tris base $0,3 \%(\mathrm{p} / \mathrm{v})$, glicina 1,88\% (p/v) e SDS 0,1\% (p/v) ajustado para $\mathrm{pH} 8,3$

f) Solução tampão de amostra para SDS-PAGE: Tris-HCl 1M pH 6,8, SDS 1\%, Azul de Bromofenol 0,05\% (p/v), glicerol 5\% (v/v) e $\beta$-mercaptoetanol 1,43 M

g) Solução corante de SDS-PAGE: “Comassie Blue Brillant” 0,25\% (p/v), etanol 40\% (v/v) e ácido acético $10 \%(\mathrm{v} / \mathrm{v})$

h) Solução descorante de SDS-PAGE: Etanol 30\% (v/v) e ácido acético $10 \%$ (v/v).

g) PBS (Solução tampão salina fosfato): $\mathrm{NaCl} 1,37 \mathrm{M}, \mathrm{KCl} 27 \mathrm{M}, \mathrm{Na}_{2} \mathrm{HPO}_{4} 100 \mathrm{mM}, \mathrm{KH}_{2} \mathrm{PO}_{4}$ $14 \mathrm{mM}$ ajustado para $\mathrm{pH} 7,4$.

h) PBS-T: PBS e Tween ${ }^{\circledR} 200,1 \%(\mathrm{v} / \mathrm{v})$

i) Solução tampão carbonato-bicarbonato: $\mathrm{Na}_{2} \mathrm{CO}_{3} 50 \mathrm{mM}$ e $\mathrm{NaHCO}_{3} 50 \mathrm{mM}$, ajustado para pH 9,6.

j) Solução tampão citrato-fosfato: Citrato de sódio $100 \mathrm{mM}$ e fosfato de sódio monobásico $\left(\mathrm{NaH}_{2} \mathrm{PO}_{4}\right) 300 \mathrm{mM}$ pH5,0.

k) Solução tampão Tris-glicina 5x: Tris base 1,5\% (p/v), glicina 9,4\% (p/v) e SDS 0,5\% (p/v) ajustado para $\mathrm{pH} 8,3$. 
1) Solução tampão de transferência de Western Blot: Tris-glicina 5x 20\% (p/v), etanol 20\% $(\mathrm{p} / \mathrm{v})$.

m) Solução tampão de lise de eritrócitos: $\mathrm{NH}_{4} \mathrm{Cl}$ 0,15M, $\mathrm{KHCO}_{3} 1 \mathrm{mM}$, EDTA 0,1 mM, pH 7,2 ANEXO A.2 Meios de Cultura:

a) Meio líquido 2YT: Triptona 1,6\% (p/v), extrato de levedura $1 \%(\mathrm{p} / \mathrm{v})$ e $\mathrm{NaCl}$ 0,5 (p/v)

b) Meio líquido 2YT-amp: meio 2 YT contendo $100 \mu \mathrm{g} / \mathrm{mL}$ de ampicilina.

c) Meio líquido 2YT/ON: Triptona 1,6\% (p/v) e extrato de levedura $1 \%(\mathrm{p} / \mathrm{v})$

d) Meio líquido 2YT/ON-amp: Meio 2YT/ON contendo $100 \mu \mathrm{g} / \mathrm{mL}$ de ampicilina

e) Meio sólido 2YT/ON-amp: meio 2YT/ON-amp contendo 1,6\% (p/v) de Agar.

f) Meio líquido THY: Meio Todd-Hewitt (Difco) contendo 0,5\% de extrato de levedura.

g) Meio ágar sangue sólido: Meio Triptic Soy ágar com 5\% de sangue de carneiro (v/v) (Laborclin, Pinhais, PR, Brasil). 